\title{
Radio wavelength molecular observations of comets C/1999 T1 (McNaught-Hartley), C/2001 A2 (LINEAR), $\mathrm{C} / 2000 \mathrm{WM}_{1}$ (LINEAR) and 153P/lkeya-Zhang ${ }^{\star}$
}

\author{
N. Biver ${ }^{1}$, D. Bockelée-Morvan ${ }^{1}$, J. Crovisier ${ }^{1}$, D. C. Lis ${ }^{2}$, R. Moreno ${ }^{1,3}$, P. Colom ${ }^{1}$, F. Henry ${ }^{1}$, F. Herpin ${ }^{4}$, \\ G. Paubert ${ }^{5}$, and M. Womack ${ }^{6}$
}

\author{
1 LESIA, CNRS UMR 8109, Observatoire de Paris, 5 pl. J. Janssen, 92195 Meudon, France \\ e-mail: Nicolas.Biver@obspm. fr \\ 2 California Institute of Technology, MS 320-47, Pasadena, CA 91125, USA \\ 3 IRAM, 300 rue de la Piscine, 38406 Saint-Martin-d'Hères, France \\ 4 Observatoire de Bordeaux, BP 89, 33270 Floirac, France \\ 5 IRAM, Avd. Divina Pastora, 7, 18012 Granada, Spain \\ ${ }^{6}$ St. Cloud State University, MS 324, St. Cloud, MN 56301-4498, USA
}

Received 18 July 2005 / Accepted 7 December 2005

\section{ABSTRACT}

We present a comparative study of the relative abundances of $\mathrm{CO}, \mathrm{CH}_{3} \mathrm{OH}, \mathrm{H}_{2} \mathrm{CO}, \mathrm{HCN}, \mathrm{HNC}, \mathrm{CS}, \mathrm{H}_{2} \mathrm{~S}, \mathrm{CH}_{3} \mathrm{CN}$, SO and $\mathrm{HNCO}$ in comets C/1999 T1 (McNaught-Hartley), C/2001 A2 (LINEAR), C/2000 WM (LINEAR) and 153P/Ikeya-Zhang, four of the brightest comets seen in 2001-2002. This investigation is based on millimetre/submillimetre observations made with the IRAM 30-m, SEST, CSO and Kitt Peak $12-\mathrm{m}$ telescopes. Although these four comets are expected to originate from the Oort cloud, they present significant differences in molecular abundances, especially as regards to the most volatile species: $\mathrm{CO}$ and $\mathrm{H}_{2} \mathrm{~S}$. In particular comet $\mathrm{C} / 2000 \mathrm{WM}_{1}$ looks quite depleted in these volatiles, suggesting it may have a different origin than the others. Heliocentric variations of molecular relative abundance in the coma are also investigated. Significant increases in the $\mathrm{CS} / \mathrm{HCN}$ and $\mathrm{HNC} / \mathrm{HCN}$ production rate ratios with decreasing heliocentric distances are observed.

Key words. comets: general - radio lines: solar system - submilimetre

\section{Introduction}

The composition of cometary nuclei is of great importance for understanding their origin. For example, it is presumed that Oort-cloud comets were formed in the giant planet region (Jupiter-Neptune), before being expelled to the outer part of the Solar System. On the other hand, short period "Jupiterfamily" comets may have accreted directly in the Kuiper Belt beyond Neptune (Duncan et al. 2004). Having spent most of their time in a very cold environment, these objects should not have evolved very much since their formation. Thus, their composition provides clues to the composition in the regions of the Solar Nebula where they formed. The last decade has proven the efficiency of microwave observations in investigating the chemical composition of cometary atmospheres. About 20 different cometary molecules have now been identified at radio wavelengths (Bockelée-Morvan et al. 2004). Biver et al. (2002) presented a brief overview of the chemical diversity among 24 comets observed prior to 2002 .

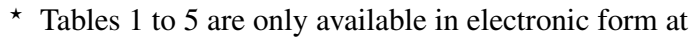
http://www . edpsciences.org
In the present paper, we extend this investigation to four of the brightest comets seen in 2001-2002. Comets C/1999 T1 (McNaught-Hartley), C/2001 A2 (LINEAR), C/2000 WM (LINEAR) and 153P/Ikeya-Zhang are all thought to originate from the Oort cloud but with likely different historical orbit evolutions. With orbital periods (before planetary perturbations) of $27000,81000,26000$ and 360 years, respectively, all four comets are not new in the Oort sense (aphelia are well closer to the Sun than the mean distance to the Oort cloud), and have already experienced some alteration at previous perihelia. Comet 153P/Ikeya-Zhang is officially numbered as a short-period comet. It was previously observed by Johannes Hevelius in 1661 and likely also seen in 1273 and 877 (Hasegawa \& Nakano 2003). C/2001 A2 and 153P have low inclination orbits $\left(36^{\circ}\right.$ and $28^{\circ}$ respectively) which cannot fully exclude an origin from the low inclination reservoir formed by the Kuiper Belt and Scattered Disk.

Section 2 presents the spectroscopic millimetre to submillimetre data obtained on these four comets. Section 3 discusses the various parameters and observational constraints used to derive the production rates. The comparison between 
the molecular abundances and the heliocentric evolution of the production rates is presented in Sect. 4.

\section{Observations}

$\mathrm{C} / 1999 \mathrm{~T} 1$ and $\mathrm{C} / 2000 \mathrm{WM}_{1}$ were discovered more than a year before perihelion so that coordinated radio observations could be scheduled in advance through regular allocations of telescope time. In contrast $\mathrm{C} / 2001 \mathrm{~A} 2$ and $153 \mathrm{P}$ were observed on a target-of-opportunity time-line. These four comets were bright enough so that several other observing campaigns at infrared (e.g., Mumma et al. 2002) to UV (e.g., Feldman et al. 2002) wavelengths were conducted, providing complementary information to those presented here.

\subsection{C/1999 T1 (McNaught-Hartley)}

Comet C/1999 T1 (McNaught-Hartley) was discovered well ahead of perihelion, on 7 Oct. 1999 (McNaught \& Hartley 1999) at 5.3 AU from the Sun. Being initially a southern object it moved northwards as it came to perihelion at $1.17 \mathrm{AU}$ on 13 Dec. 2000. It reached perigee at $1.29 \mathrm{AU}$ on $3 \mathrm{Feb}$. 2001. Although being an intrinsically active comet with a water production rate at perihelion reaching $Q_{\mathrm{H}_{2} \mathrm{O}}=10^{29}$ molec s$^{-1}$ (Crovisier et al. 2002), it did not become brighter than visual magnitude $m_{1}=7.7$, due to its relative large distance to the Earth and the Sun. The comet was first detected with the Swedish-ESO Submillimetre Telescope (SEST) 15-m radio telescope in Chile through its HCN J(3-2) line in September 2000. It was then observed at the Caltech Submillimeter Observatory (CSO) 10.4-m telescope on Mauna Kea on 5-7 Jan. 30, and 4-8 Feb. 2001 and at the Institut de Radio Astronomie Millimétrique (IRAM) 30-m facility in Spain, during the 24 Jan. -2 Feb. time interval. These latter observations suffered from bad weather on 24-30 January. The $\mathrm{OH} 18-\mathrm{cm}$ lines were also daily observed with the Nançay radio telescope during the 16 Nov.-7 Dec. 2000 and 5-30 Jan. 2001 time intervals (Colom et al. 2004). Inferred $\mathrm{OH}$ production rates provide information on the water outgassing rate, which was also measured by the Submillimeter Wave Astronomy Satellite (SWAS) in Feb. 2001 (Bensch et al. 2004).

\subsection{C/2001 A2 (LINEAR)}

Comet C/2001 A2 was discovered on 15 Jan. 2001 by the Lincoln Near Earth Asteroid Research (LINEAR) project telescope of the Lincoln Laboratory (Massachusetts, USA). It was then only a non-promising faint 17 th magnitude object at 2.3 AU from the Sun. But around 28 March it experienced a steep increase in brightness of 5 magnitudes followed by additional 1 to 1.5 magnitude short-lived outbursts around 11 May, 12 June and 12 July (Sekanina et al. 2002). These outbursts are likely connected to the release of fragments observed at the European Southern Observatory and elsewhere (Jehin et al. 2002, Sekanina et al. 2002). Comet C/2001 A2 reached naked eye visibility during two months with a peak brightness at $m_{1}=3.3$ in June. This was shortly after its perihelion on 24 May 2001 at $r_{\mathrm{h}}=0.78 \mathrm{AU}$ and before perigee on 30 June at $0.24 \mathrm{AU}$. The initial surge in brightness made it a potentially interesting comet and target-of-opportunity observations were scheduled at IRAM on 8-10 July. It was also observed during short time intervals before sunrise at CSO on 16-19 June. Observations with the Kitt Peak National Observatory (KPNO) 12-m radio telescope on Kitt Peak (USA) were conducted on 5, 6, 11 and 12 June. The comet evolution was followed at Nançay between 2 April and 12 July, except during times of unfavourable $\mathrm{OH}-\mathrm{maser}$ inversion. The peak outgassing rate occasionally exceeded $2 \times 10^{29}$ molec s$^{-1}$ (Crovisier et al. 2002). The water line at $556.9 \mathrm{GHz}$ was also observed and mapped with the Odin satellite on 27 April, and between 20 June and 7 July (Lecacheux et al. 2003).

\section{3. $C / 2000 W M_{1}$ (LINEAR)}

$\mathrm{C} / 2000 \mathrm{WM}_{1}$ (LINEAR) was originally catalogued as a 18th magnitude asteroid when discovered on the 16th of November 2000 still at 5.8 AU from the Sun (Green 2000). This is the 46th comet discovery by LINEAR. With a perigee at $0.32 \mathrm{AU}$ on 2 Dec. 2001 and a perihelion at only 0.55 AU on 22 Jan. 2002, it was a potentially interesting target. Around perigee it reached naked eye magnitude $m_{1} \approx 5.5$ with $Q_{\mathrm{H}_{2} \mathrm{O}}=4 \times 10^{28}$ molec s$^{-1}$ (Lecacheux et al. 2003). Observations were scheduled around that time at IRAM (23-27 Nov.) and at CSO (3-8 Dec.), with cooperative weather. The $557 \mathrm{GHz}$ water line was observed with Odin on 8 Dec. 2001 and 12 March 2002. Shortly after perihelion, on 30 Jan. 2002, the comet experienced a significant outburst of 3 magnitudes up to $m_{1}=2.8$. Nançay OH observations at $18 \mathrm{~cm}$ took place daily between 4 Oct. and 16 Dec. 2001 and resumed when the comet came back to higher declinations on 13 February till 20 April 2002 (Colom et al. 2004).

\section{4. $153 P / 2002$ C1 (Ikeya-Zhang)}

This comet was co-discovered on 1 Feb. 2002 by two amateurs, Kaoru Ikeya (Japan) and Daquing Zhang (China) (Nakano \& Zhu 2002) and was given the provisional designation $\mathrm{C} / 2002 \mathrm{C} 1$. It became quickly a bright object. It reached perihelion on $18 \mathrm{March}$ at $0.51 \mathrm{AU}$ and perigee on 29 April at $0.40 \mathrm{AU}$ and with a visual magnitude of 3.4 at its brightest with a total outgassing rate around $9 \times 10^{29}$ molec s$^{-1}$ (Dello Russo et al. 2004), it remained visible to the naked eye for nearly three months. It is a typical Halley-class comet. Soon after its discovery, its orbital period was determined to be close to 360 years and it was establish that this comet was likely the return of the historical comet observed in Europe in 1661 (Marsden \& Nakano 2002).

Given the high interest of this new target, several observing programs were scheduled. At IRAM, observations took place at 3 periods (18-19 March, 29-30 April and 8-12 May) complemented by CSO observations (25-27 April) to follow the heliocentric evolution of the chemical abundances, especially the $\mathrm{HNC} / \mathrm{HCN}$ ratio. The May run was hampered by bad weather which prevented an efficient deep search for molecular species only revealed in C/1995 O1 (Hale-Bopp) or C/1996 B2 (Hyakutake). The comet was also extensively observed with 


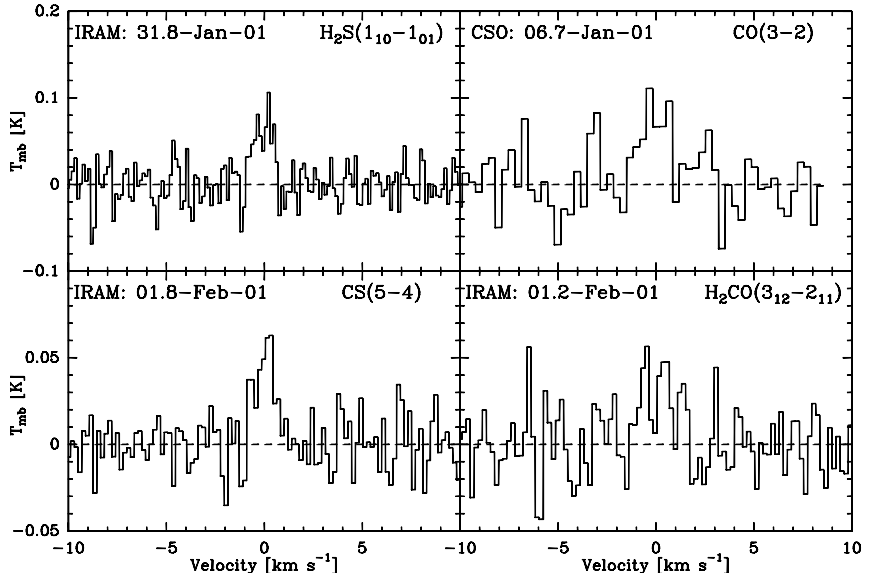

Fig. 1. Sample of molecular spectra obtained on comet C/1999 T1 (McNaught-Hartley).

Odin on 22-28 April: $\mathrm{H}_{2} \mathrm{O}$ emission was mapped and $\mathrm{H}_{2}^{18} \mathrm{O}$ detected (Lecacheux et al. 2003). HCN J(3-2) was detected with the Kitt Peak 12-m on 29 March. Nançay OH $18 \mathrm{~cm}$ observations took place regularly between 29 Feb. and 20 June, excepted during periods when maser inversion was too unfavourable, especially in March.

\subsection{Summary of observations}

Table 1 lists the molecules and transitions included in our survey, in order of increasing frequency. The average half power beam width (HPBW) of each telescope used to observe the given molecular line is provided. Precise line frequencies and corresponding parameters (energy levels and line strength) were taken from the Cologne Database for Molecular Spectroscopy (CDMS, http://www.ph1. uni-koeln.de/vorhersagen/; Müller et al. 2005) and the JPL molecular Spectroscopy database (http://spec.jpl . nasa.gov/; Pickett et al. 1998).

Of the molecules listed in Table 1, eight species (HCN, $\mathrm{CH}_{3} \mathrm{OH}, \mathrm{H}_{2} \mathrm{CO}, \mathrm{CS}, \mathrm{H}_{2} \mathrm{~S}, \mathrm{CH}_{3} \mathrm{CN}, \mathrm{HNC}$ and $\mathrm{CO}$ ) were searched for in all four comets. The five first species were detected in all comets: sample spectra of each comet are shown for $\mathrm{HCN}$ in Figs. 2, 4, 6 and 8, $\mathrm{H}_{2} \mathrm{CO}, \mathrm{CS}$ and $\mathrm{H}_{2} \mathrm{~S}$ in Figs. 1, 3,5 and 7, and $\mathrm{CH}_{3} \mathrm{OH}$ in Figs. 11, 12 and 13. In addition, $\mathrm{CH}_{3} \mathrm{CN}$ was detected in $\mathrm{C} / 2001 \mathrm{~A} 2$ and $153 \mathrm{P}$ (Fig. 10) and was marginal in $\mathrm{C} / 2000 \mathrm{WM}_{1}$. HNC was detected in $\mathrm{C} / 2001 \mathrm{~A} 2$ and 153P (Figs. 4 and 8) and $\mathrm{CO}$ was detected in C/1999 T1 and 153P (Figs. 1 and 7). Also, HNCO (Fig. 9) was detected in 153P and $\mathrm{SO}$ was marginally present in $\mathrm{C} / 2001 \mathrm{~A} 2$ (Fig. 3). Finally, $\mathrm{HC}_{3} \mathrm{~N}$, OCS and $\mathrm{HCOOH}$ were searched for in $\mathrm{C} / 2001 \mathrm{~A} 2$ and $153 \mathrm{P}$ but no emission was detected beyond the $3-\sigma$ detection limit. A significant upper limit on the intensity of the HDO $\left(1_{10}-1_{01}\right)$ line at $509 \mathrm{GHz}$ in $153 \mathrm{P}$ was also obtained at CSO.

Most lines observed or searched for in Table 1 were observed both at high resolution (20 to $100 \mathrm{kHz}$, in order to resolve the line with a resolution better than $0.1 \mathrm{~km} \mathrm{~s}^{-1}$ ) and with a low resolution $(1 \mathrm{MHz})$ wide band backend. Tables 2-5

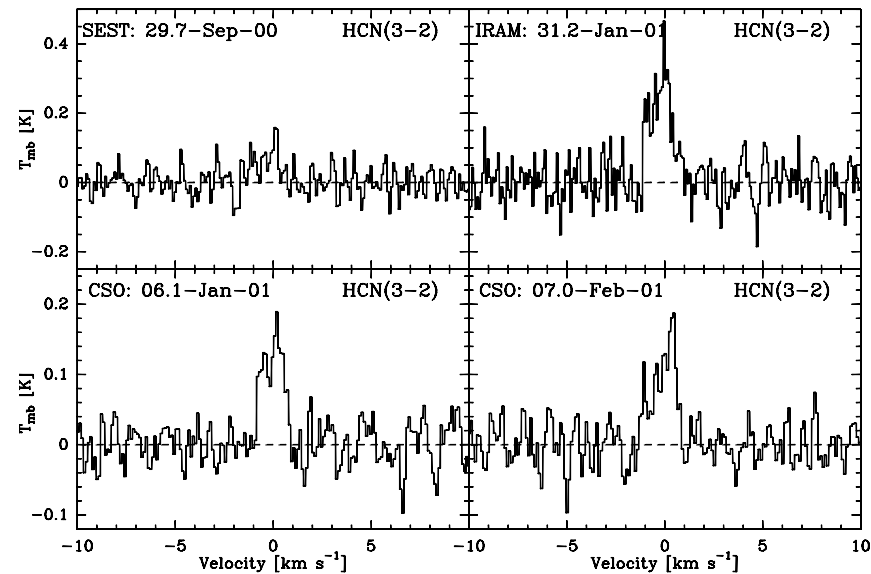

Fig. 2. HCN $J(3-2)$ line at $265.9 \mathrm{GHz}$ observed on comet C/1999 T1 (McNaught-Hartley).

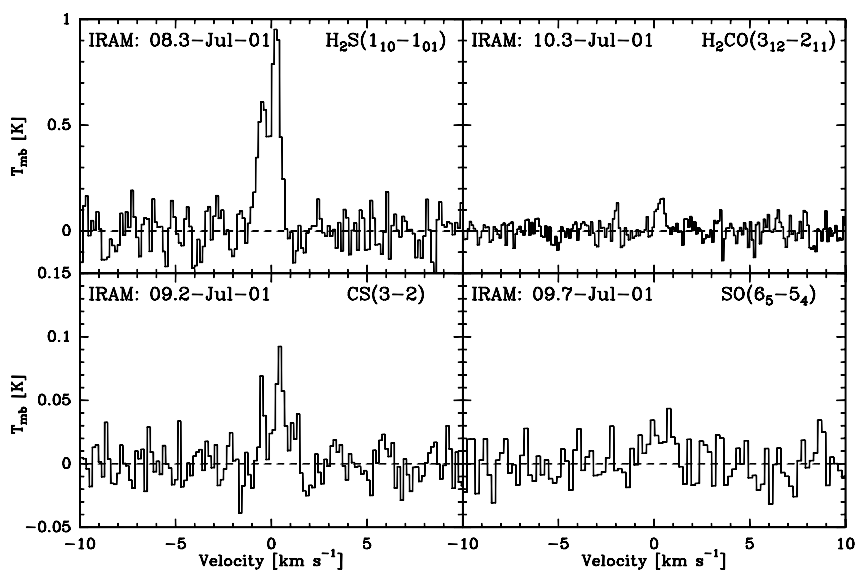

Fig. 3. Sample of molecular spectra obtained on comet C/2001 A2 (LINEAR).

provide the relevant information on the lines observed in these comets. For each observed line we provide the observing circumstances (date, heliocentric distance, geocentric distance and integration time: Cols. (1)-(4)) the molecule and transition, the integrated line intensity and rms or 3- $\sigma$ upper limit and the velocity offset of the line. In the last column we give the positional offset that was used in the computation of production rates.

Ephemeris offsets were computed afterwards by comparing the ephemeris (either from the JPL's HORIZONS system or from the Minor Planet Center) used during observations and the latest available ephemeris. For some observations of

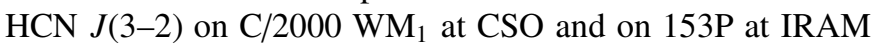
we obtained coarse maps which helped us to pinpoint the maximum of brightness.

\section{Data analysis}

In most cases the production rates were derived following the methodology and parameters described in Biver et al. (1999a). To model the gas density in the coma, an isotropic steady-state outflow described by a Haser density radial profile is assumed. 


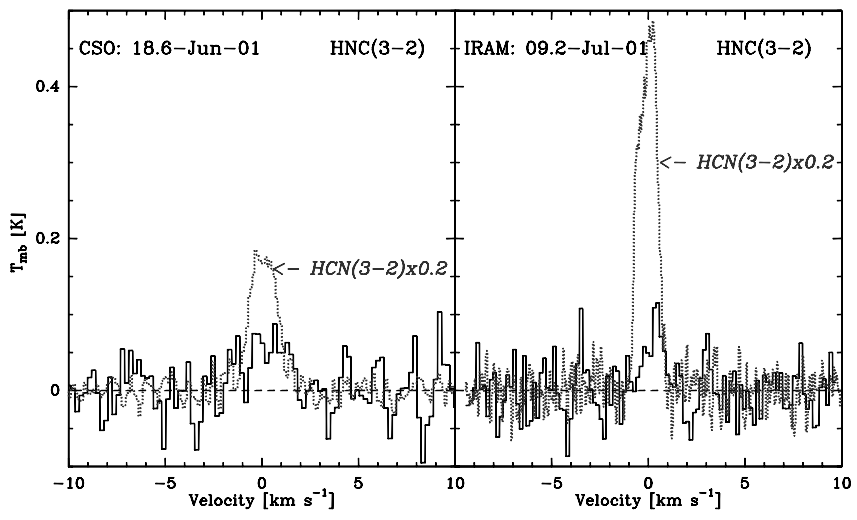

Fig. 4. Quasi-simultaneous observations of $\mathrm{HCN} J(3-2)$ and HNC $J(3-2)$ lines on comet C/2001 A2 (LINEAR). The HCN $J(3-2)$ line (dotted lines) intensity has been divided by 5 to fit with the vertical intensity scale in main beam brightness temperature.

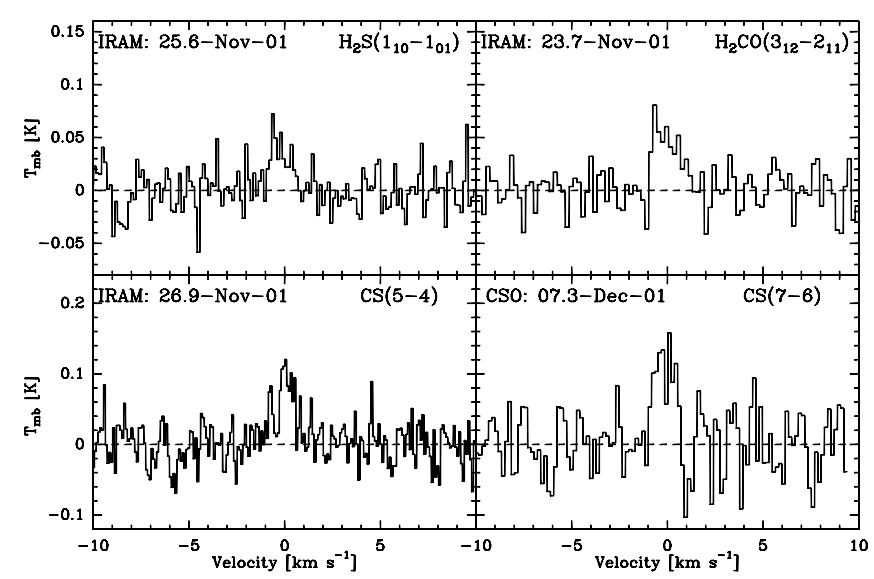

Fig. 5. Sample of molecular spectra obtained on comet $\mathrm{C} / 2000 \mathrm{WM}_{1}$ (LINEAR).

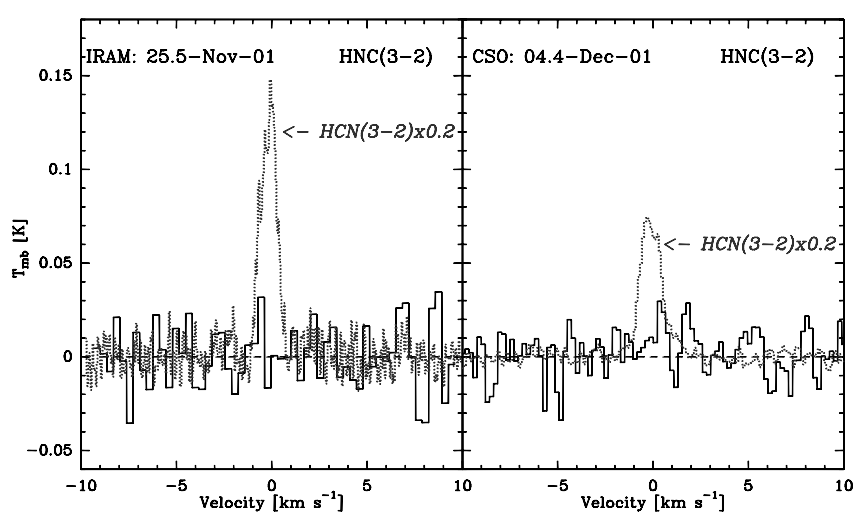

Fig. 6. Simultaneous observations of $\mathrm{HCN} J(3-2)$ and HNC $J(3-$ 2) (not detected) lines on comet $\mathrm{C} / 2000 \mathrm{WM}_{1}$ (LINEAR). The HCN $J(3-2)$ lines (dotted lines) intensities have been divided by 5 to fit with the vertical intensity scale.

The velocity is assumed to be constant throughout the coma and deduced from line shapes. The number of molecules in the coma is also decreasing with distance to the nucleus due to photodissociation by solar UV (which scales as $r_{\mathrm{h}}^{-2}$ ). The

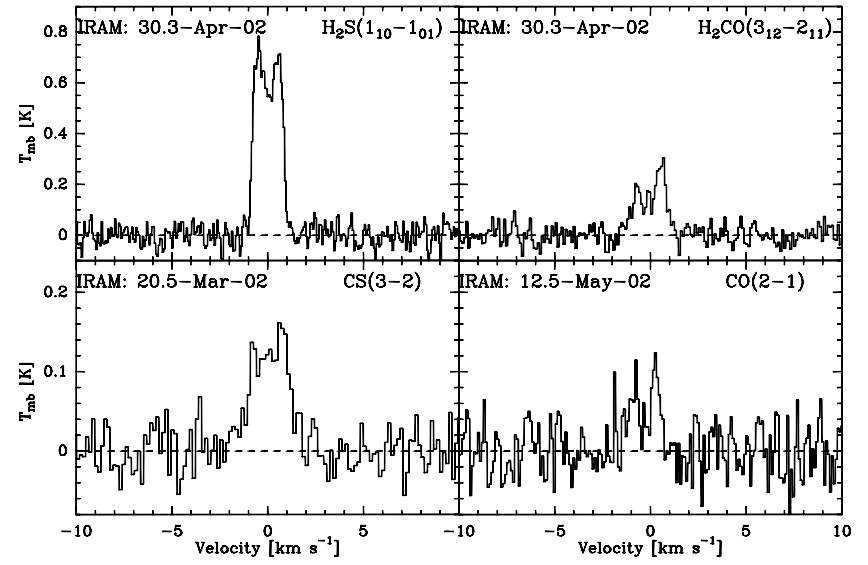

Fig. 7. Sample of molecular spectra obtained on comet 153P/Ikeya-Zhang.

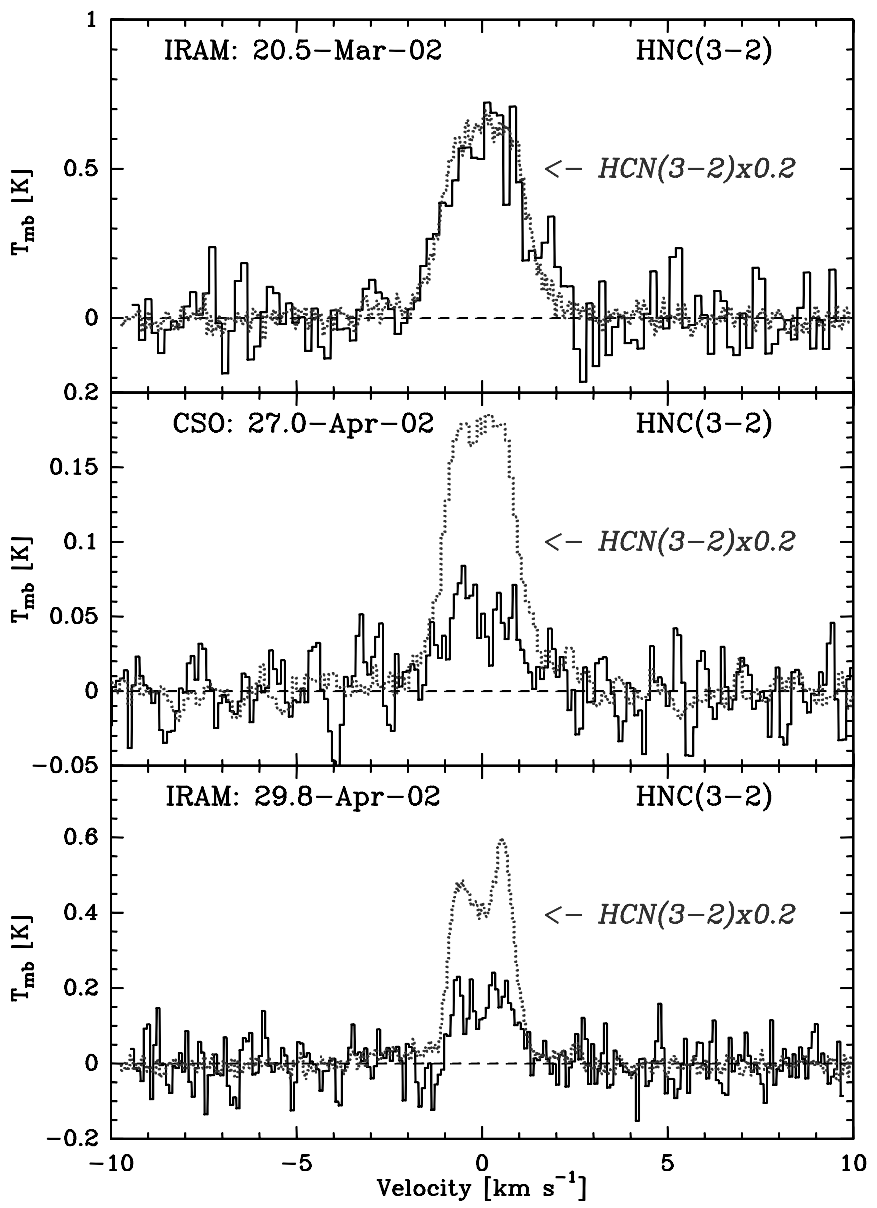

Fig. 8. Simultaneous observations of the HCN $J(3-2)$ line (dotted line, plotted with an intensity divided by 5) and HNC $J(3-2)$ line (plain line) on comet 153P/Ikeya-Zhang. One can readily see that the $\mathrm{HNC} / \mathrm{HCN}$ line ratio decreased from about 20\% in March to 5\% at the end of April.

populations of the molecular rotational levels are calculated from the model, taking into account collisional excitation with neutral gas at a constant temperature (see Biver et al. 1999a for assumed cross-sections), collisions with electrons (as 


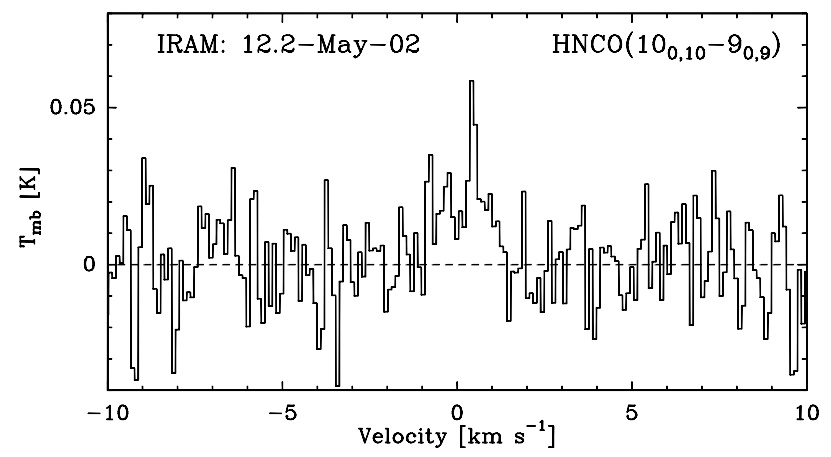

Fig. 9. Detection of the HNCO line at $219.8 \mathrm{GHz}$ on comet 153P/Ikeya-Zhang at IRAM.

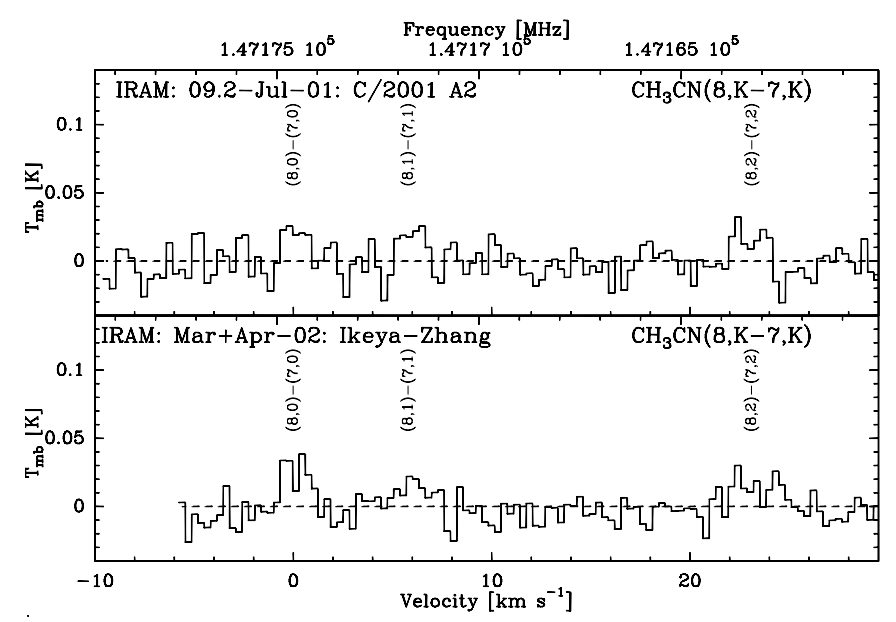

Fig. 10. Medium resolution spectra of three methyl-cyanide lines observed around $147 \mathrm{GHz}$ in comets $\mathrm{C} / 2001 \mathrm{~A} 2$ (LINEAR) and $153 \mathrm{P} /$ Ikeya-Zhang with IRAM. The velocity scale refers to the $(8,0)-(7,0)$ line.

described in the same reference), and infrared pumping of vibrational bands for radiative excitation. Line intensities are then computed from a radiative transfer code by integrating the flux over the beam size of the antenna.

\subsection{Photodissociation rates}

Table 7 specifies the adopted HCN photodissociation rates at $1 \mathrm{AU}$ from the Sun, based on the solar activity dependence as given in Crovisier (1994). The Lyman- $\alpha$ flux was estimated from the solar 10.7-cm flux monitored daily (www. sec. noaa.gov/ftpdir/indices/old_indices/), as suggested in Crovisier (1989). Solar activity was close to its maximum during the observations, so these lifetimes are smaller than in Biver et al. (1999a). The HNC lifetime is assumed to be the same as HCN. Other molecular lifetimes are not as sensitive to solar activity. The methanol photodissociation rate varied between 1.45 and $1.55 \times 10^{-5} \mathrm{~s}^{-1}$. Using the default $\mathrm{CH}_{3} \mathrm{OH}$ value given in Biver et al. (1999a) leads to almost similar production rates. For $\mathrm{H}_{2} \mathrm{CO}, \mathrm{CO}, \mathrm{H}_{2} \mathrm{~S}$ and $\mathrm{CH}_{3} \mathrm{CN}$, photodissociation rates are taken from Crovisier (1994), identical to those adopted in Biver et al. (1999a). In the case of CS we adopted a photodissociation rate $\beta_{0}(\mathrm{CS})=2.0 \times 10^{-5} \mathrm{~s}^{-1}$ at $1 \mathrm{AU}$ from the

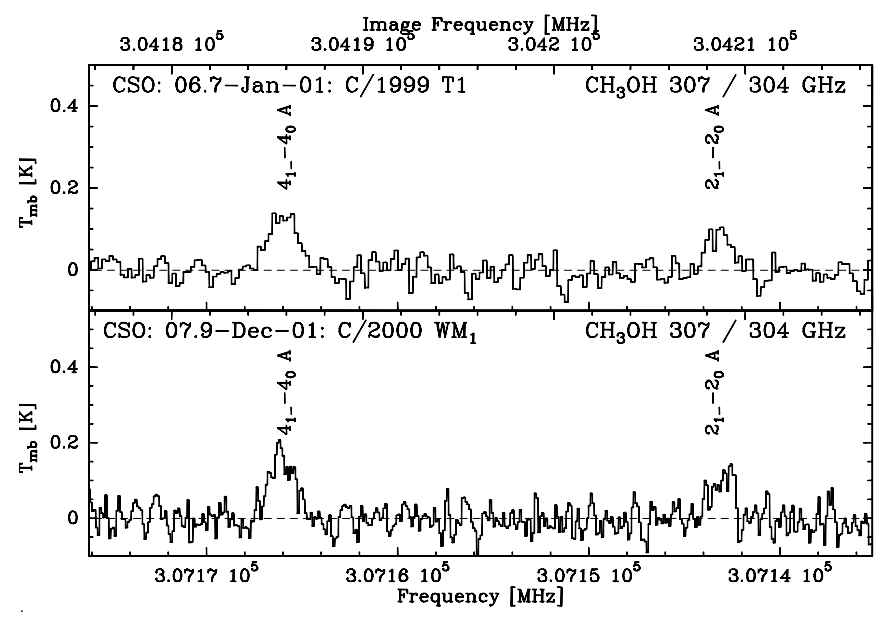

Fig. 11. Methanol lines simultaneously observed with the same tuning at $304 \mathrm{GHz}$ (lower sideband) and $307 \mathrm{GHz}$ (upper sideband) on comets C/1999 T1 (McNaught-Hartley) and C/2000 WM (LINEAR) $^{2}$ with the CSO. Frequency scale is upper sideband.

Sun, following recent constraints based on observations very close to the Sun presented in Biver et al. (2003). The effect of doubling $\beta_{0}(\mathrm{CS})$ (in comparison to Biver et al. 1999a) is investigated in Sect. 4.1. For SO we use $\beta_{0}(\mathrm{SO})=1.5 \times 10^{-4} \mathrm{~s}^{-1}$, from Bockelée-Morvan et al. (2000). Photodissociation rates for other molecules (OCS, $\mathrm{HC}_{3} \mathrm{~N}, \mathrm{HCOOH}$ and $\mathrm{HNCO}$ ) are also taken from Bockelée-Morvan et al. (2000).

\subsection{Outflow velocities}

The line shapes have been used to derive an estimate of the gas outflow velocity $\left(v_{\text {exp }}\right)$. Indeed, the line shapes are quite symmetric for most comets, suggesting isotropic outgassing. However, most lines observed in $\mathrm{C} / 2000 \mathrm{WM}_{1}$ (Figs. 5, 6) are blue-shifted with Doppler shifts of -0.10 to $-0.20 \mathrm{~km} \mathrm{~s}^{-1}$ (Table 4, Col. 7). This indicates preferential sunward outgassing (the phase angle varied between 12 and $60^{\circ}$ ) but this asymmetry is not strong enough to justify the use of a fully asymmetrical model to derive production rates (no strong jet has been reported in the visible). The mean half-width at half maximum (HWHM) of the cometary lines with the best signalto-noise ratio was used to derive the expansion velocity $\left(v_{\exp }\right)$. The adopted $v_{\text {exp }}$ is actually about $10 \%$ lower than the HWHM to take into account spectral resolution and thermal broadening. We found $v_{\exp } \approx 0.80,0.78,0.75$ and $0.86 \mathrm{~km} \mathrm{~s}^{-1}$ at $1 \mathrm{AU}$, with a $r_{\mathrm{h}}^{-0.5}$ heliocentric dependence, for C/1999 T1, $\mathrm{C} / 2001 \mathrm{~A} 2, \mathrm{C} / 2000 \mathrm{WM}_{1}$ and 153P, respectively. Values actually used are given in Table 7 . The errors on the production rates resulting from rounding off or from the uncertainty on $v_{\exp }$ are less than $10 \%$. The expansion velocity is actually expected to slightly increase throughout the coma (Combi et al. 2004), but in order to reproduce the observed line shape and given that molecules of very different lifetimes (e.g. $\mathrm{H}_{2} \mathrm{~S}$ and $\mathrm{CO}$ ) have very similar line widths, the variation of the expansion velocity in the region of the coma sampled by the observations must be relatively small. Using a velocity profile such as those 

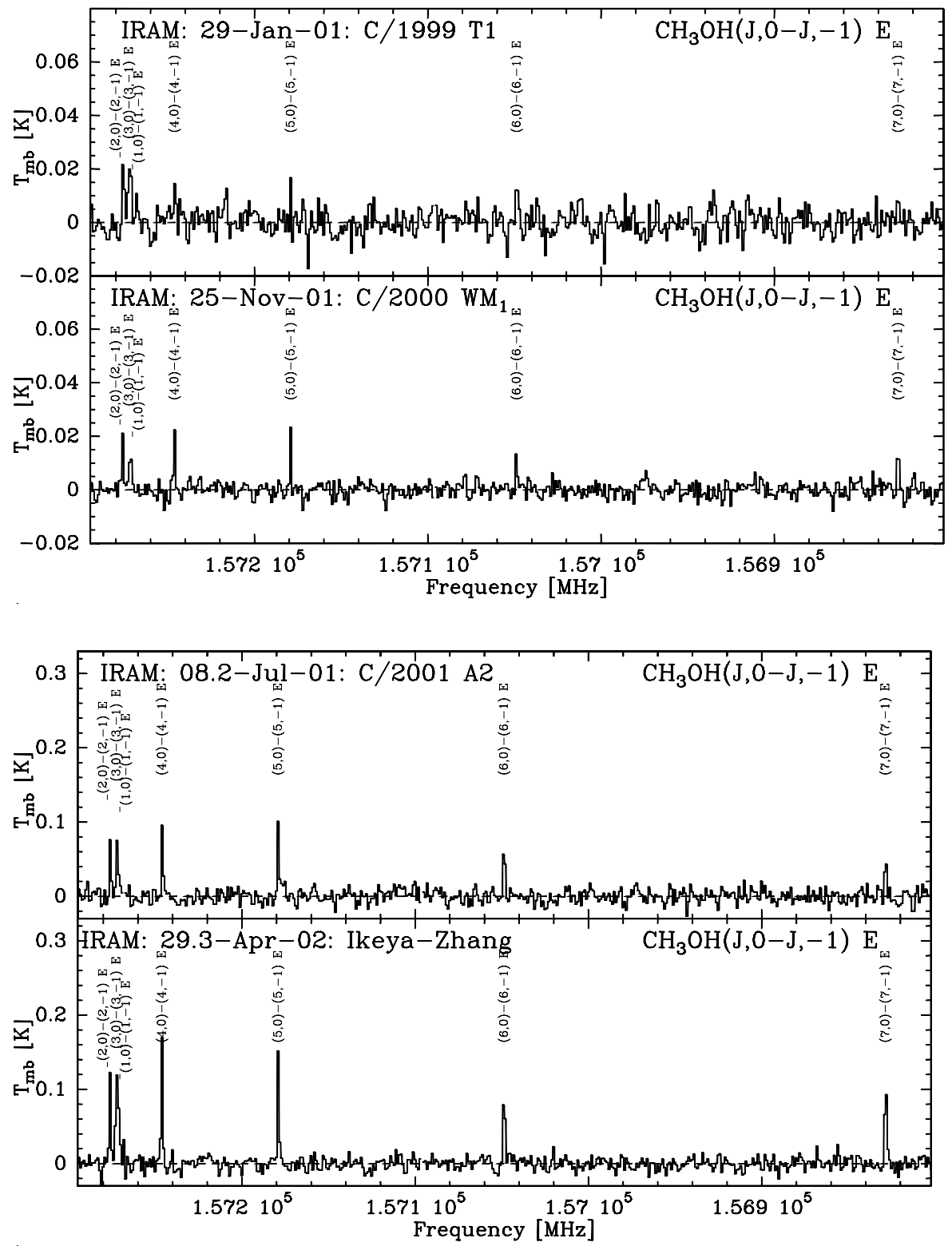

Fig. 12. Wide-band, low resolution spectra of methanol lines observed at $157 \mathrm{GHz}$ on comets C/1999 T1 (McNaught-Hartley) and $\mathrm{C} / 2000 \mathrm{WM}_{1}$ (LINEAR) with IRAM.
Fig. 13. Wide-band, low resolution spectra of methanol lines observed at $157 \mathrm{GHz}$ on comets $\mathrm{C} / 2001 \mathrm{~A} 2$ (LINEAR) and 153P/Ikeya-Zhang with IRAM. of Combi et al. (2004) does not affect production rates by more than $10 \%$.

\subsection{Gas temperatures}

When available, rotational temperatures $\left(T_{\text {rot }}\right)$ of methanol or other species were used to derive the gas temperature $T$. Actual values measured in the four comets are given in Table 6. Some groups of methanol lines are particularly well suited to measure the gas temperature $T: \mathrm{CH}_{3} \mathrm{OH}$ lines at $304 / 307 \mathrm{GHz}$ (for $T=10-50 \mathrm{~K}$ ) (Fig. 11), $157 \mathrm{GHz}$ (for $T=10-80 \mathrm{~K}$ ) (Figs. 12, 13) and $252 \mathrm{GHz}$ (for $T=40-140 \mathrm{~K}$ ) are the best. Other series of lines do not provide precise estimates of the gas temperature as they probe excitation conditions intermediate between thermal and fluorescence equilibrium. Inferred gas temperatures are given in Table 6, and the assumed values used to derive production rates are given in Table 7 . The values we used follow roughly $T[\mathrm{~K}]=60 r_{\mathrm{h}}^{-1}(153 \mathrm{P}$ and $\mathrm{C} / 2001 \mathrm{~A} 2)$ to $66 r_{\mathrm{h}}^{-1}\left(\mathrm{C} / 1999 \mathrm{~T} 1\right.$ and $\left.\mathrm{C} / 2000 \mathrm{WM}_{1}\right)$, which gives a good agreement to the measured values. A large uncertainty resides for the March observations of comet 153P at only 0.5 AU from the Sun. A steep increase (as $r_{\mathrm{h}}^{-1}$ or steeper) of the temperature of the coma when the comet approaches the Sun has been observed in a few comets (Biver et al. 1999a, 2000, 2002). However, below $r_{\mathrm{h}} \approx 0.6 \mathrm{AU}$ in comet Hyakutake, no significant further increase of $T$ could be measured (Biver et al. 1999a). A weighted fit on the measurements of $T$ in 153P (averaged by periods of 3 days) yields $T[\mathrm{~K}]=57 \pm 4 \times r_{\mathrm{h}}^{-0.9 \pm 0.6}$, which extrapolates to $105 \mathrm{~K}$ at $0.5 \mathrm{AU}$. A temperature of $140 \pm 10 \mathrm{~K}$ was actually measured in the infrared also at $r_{\mathrm{h}}=0.5 \mathrm{AU}$ (Dello Russo et al. 2004), but the infrared ro-vibrational temperatures tend to be higher than the gas temperature derived from radio measurements (see for example the values measured for C/2001 A2 around 9 July 2001 in Table 6 and in Dello Russo et al. (2005)). So we adopted $120 \mathrm{~K}$ as a compromise, which is consistent with the law $T[\mathrm{~K}]=60 r_{\mathrm{h}}^{-1}$. In any 
Table 6. Gas temperature measurements or collision rate constraints.

\begin{tabular}{|c|c|c|c|c|c|}
\hline \multirow{2}{*}{$\begin{array}{l}\text { UT date } \\
\text { [mm/dd.dd] }\end{array}$} & \multirow{2}{*}{$\begin{array}{c}\left\langle r_{\mathrm{h}}\right\rangle \\
{[\mathrm{AU}]}\end{array}$} & \multirow[t]{2}{*}{ Molecular lines } & \multicolumn{2}{|c|}{ Temperature [K] } & \multirow{2}{*}{$x_{\mathrm{ne}}^{1}$} \\
\hline & & & Rotational & Kinetic $^{1}$ & \\
\hline \multicolumn{6}{|c|}{ C/1999 T1 (McNaught-Hartley) (2001) } \\
\hline $01 / 06.67$ & 1.233 & $\mathrm{CH}_{3} \mathrm{OH} 304 / 307 \mathrm{GHz}$ & $52_{-16}^{+36}$ & $60_{-20}^{+40}$ & \\
\hline $01 / 30.6-31.2$ & 1.395 & $\mathrm{HCN}(3-2) /(1-0)$ & $21.1 \pm 2.6$ & & $1.2 \pm 0.4$ \\
\hline $01 / 31.2-31.2$ & 1.398 & $\mathrm{HCN}(3-2) /(1-0)$ & $19.4 \pm 2.0$ & & $0.55 \pm 0.2$ \\
\hline $01 / 30.5$ & 1.400 & $\mathrm{CH}_{3} \mathrm{OH} 157 \mathrm{GHz}$ & $39 \pm 6$ & $38 \pm 6$ & \\
\hline $02 / 05.7-06.1$ & 1.448 & $\mathrm{HCN}(4-3) /(3-2)$ & $32 \pm 7$ & & $1.4_{-0.8}^{+1.8}$ \\
\hline \multicolumn{6}{|c|}{ C/2001 A2 (LINEAR) (2001) } \\
\hline $06 / 11.7$ & 0.855 & $\mathrm{CH}_{3} \mathrm{OH} 157 \mathrm{GHz}$ & $>62$ & $>50$ & \\
\hline $06 / 12.8$ & 0.863 & $\mathrm{CH}_{3} \mathrm{OH} 145 \mathrm{GHz}$ & $37 \pm 26$ & & $<1.1$ \\
\hline $07 / 08.2$ & 1.143 & $\mathrm{HCN}(3-2) /(1-0)$ & $38 \pm 5$ & & $0.6_{-0.3}^{+0.4}$ \\
\hline $07 / 08.23$ & 1.144 & $\mathrm{CH}_{3} \mathrm{OH} 157 \mathrm{GHz}$ & $56 \pm 5$ & $51 \pm 5$ & \\
\hline $07 / 10.2$ & 1.169 & $\mathrm{HCN}(3-2) /(1-0)$ & $50 \pm 6$ & & $1.8_{-0.6}^{+0.9}$ \\
\hline \multicolumn{6}{|c|}{ C/2000 WM 1 (LINEAR) (2001) } \\
\hline $11 / 24.0$ & 1.343 & $\mathrm{HCN}(3-2) /(1-0)$ & $23.7 \pm 2.3$ & & $0.3 \pm 0.2$ \\
\hline $11 / 24.8$ & 1.329 & $\mathrm{HCN}(3-2) /(1-0)$ & $58_{-13}^{+21}$ & & $14_{-10}^{+18}$ \\
\hline $11 / 25.4$ & 1.320 & $\mathrm{CH}_{3} \mathrm{OH} 157 \mathrm{GHz}$ & $56 \pm 7$ & $50 \pm 6$ & \\
\hline $11 / 25.8$ & 1.313 & $\operatorname{HCN}(3-2) /(1-0)$ & $23.0 \pm 2.7$ & & $0.2_{-01}^{+0.15}$ \\
\hline $12 / 03.36$ & 1.191 & $\mathrm{CH}_{3} \mathrm{OH} 304 / 307 \mathrm{GHz}$ & $36_{-7}^{+9}$ & $35_{-7}^{+9}$ & \\
\hline $12 / 05.0$ & 1.165 & $\mathrm{CH}_{3} \mathrm{OH} 242 \mathrm{GHz}$ & $74 \pm 35$ & $150_{-80}^{+-}$ & \\
\hline $12 / 07.7$ & 1.121 & $\mathrm{HCN}(4-3) /(3-2)$ & $51_{-7}^{+9}$ & & $1.5_{-07}^{+1.3}$ \\
\hline $12 / 08.0$ & 1.116 & $\mathrm{CH}_{3} \mathrm{OH} 304 / 307 \mathrm{GHz}$ & $48_{-11}^{+18}$ & $46_{-10}^{+17}$ & \\
\hline \multicolumn{6}{|c|}{ 153P/Ikeya-Zhang (2002) } \\
\hline $03 / 20.52$ & 0.508 & $\mathrm{CH}_{3} \mathrm{OH} 157 \mathrm{GHz}$ & $99 \pm 43$ & $75 \pm 35$ & \\
\hline $03 / 20.6$ & 0.508 & $\mathrm{HCN}(3-2) /(1-0)$ & $67_{-11}^{+16}$ & & $1.4_{-0.9}^{+1.8}$ \\
\hline $04 / 25.59$ & 0.977 & $\mathrm{CH}_{3} \mathrm{OH} 251 \mathrm{GHz}$ & $59 \pm 5$ & $72 \pm 6$ & \\
\hline $04 / 27.64$ & 1.011 & $\mathrm{CH}_{3} \mathrm{OH} 251 \mathrm{GHz}$ & $87 \pm 13$ & $114 \pm 20$ & \\
\hline $04 / 29.30$ & 1.039 & $\mathrm{CH}_{3} \mathrm{OH} 157 \mathrm{GHz}$ & $62 \pm 4$ & $54 \pm 4$ & \\
\hline $04 / 30.2$ & 1.055 & $\mathrm{HCN}(3-2) /(1-0)$ & $40 \pm 3$ & & $0.9_{-0.2}^{+0.3}$ \\
\hline $05 / 09.85$ & 1.217 & $\mathrm{CH}_{3} \mathrm{OH} 157 \mathrm{GHz}$ & $40 \pm 7$ & $37 \pm 6$ & \\
\hline $05 / 11.34$ & 1.242 & $\mathrm{CH}_{3} \mathrm{OH} 157 \mathrm{GHz}$ & $35 \pm 7$ & $32 \pm 6$ & \\
\hline $05 / 12.0$ & 1.253 & $\mathrm{HCN}(3-2) /(1-0)$ & $31 \pm 2$ & & $0.9 \pm 0.2$ \\
\hline $05 / 12.08$ & 1.254 & $\mathrm{CH}_{3} \mathrm{OH} 220 / 254 \mathrm{GHz}$ & $57_{-8}^{+13}$ & $59 \pm 10$ & \\
\hline
\end{tabular}

${ }^{1}$ A constraint on $x_{\mathrm{ne}}$ (see text) is given for observations that do not constraint the kinetic temperature but rather the collision rate.

case, in Sect. 4 we will investigate the influence of this uncertainty on $T( \pm 20 \mathrm{~K}$ for that period) on the production rates.

\subsection{Collisional excitation}

Table 7 also provides water outgassing rates measured with different means at the time of our observations, notably those derived from observations of the $\mathrm{H}_{2} \mathrm{O}$ line at $556.9 \mathrm{GHz}$ with the Odin satellite (Lecacheux et al. 2003; Hjalmarson et al. 2005). The Odin observations of $\mathrm{H}_{2} \mathrm{O}$ are a good reference as the beam size (127") and type of lines (pure rotational) are more comparable to the observations analyzed in this paper than are the infrared, UV or decimetric observations used to derive the $\mathrm{H}_{2} \mathrm{O}$ production rates. The computation of water production rates has been done with a similar model, too. We use these production rates and total collision cross-sections from Biver et al. (1999a) to compute neutral-neutral collision rates. The collisions with electrons are modelled as presented in Biver (1997) and Biver et al. (2000). Electron density and temperature are scaled according to the water production rate and the formulae in Biver (1997). Electron density is globally multiplied by a scaling factor " $x_{\text {ne }}$ " independent of the distance to the nucleus in the coma. This factor is constrained by the rotational temperatures that are sensitive to the collision rate rather than to the gas temperature (Table 6). The weighted average value for $x_{\text {ne }}$ determined from the $\mathrm{HCN}$ observations is between $0.6 \pm 0.5$ and $1.1 \pm 0.3$ for the four comets with a mean value of $\approx 0.9$. On the other hand, a lower value (0.2) provides a good match to the spatial distribution of the intensity of the $\mathrm{H}_{2} \mathrm{O}\left(1_{10}-1_{01}\right)$ line observed in comets $\mathrm{C} / 2001 \mathrm{~A} 2$ and $153 \mathrm{P}$ with the Odin satellite (Lecacheux et al. 2003; Biver et al. 2006). Derived $x_{\mathrm{ne}}$ are significantly sensitive to the assumed neutral-neutral crosssections. This may explain the different $x_{\text {ne }}$ values found from $\mathrm{HCN}$ and $\mathrm{H}_{2} \mathrm{O}$ observations. We thus adopted $x_{\mathrm{ne}} \approx 0.5$ as a compromise for all comets.

\subsection{Collisional versus radiative excitation of SO}

We assume $\mathrm{SO}_{2}$ as the main parent source of $\mathrm{SO}$ (Bockelée-Morvan et al. 2000), implying a parent scale-length of $\approx 4500 \mathrm{~km}$ at $r_{\mathrm{h}}=1.2 \mathrm{AU}$. Infrared and UV pumping are likely marginally affecting the rotational populations due to relative weakness of the $g$-factors. Indeed, following Kim et al. (1999), the $g$-factor of the main $A-X$ band should be on the 
Table 7. Model parameters used.

\begin{tabular}{|c|c|c|c|c|c|c|}
\hline $\begin{array}{l}\text { UT date } \\
{[\mathrm{mm} / \mathrm{dd}-\mathrm{dd}]}\end{array}$ & $\begin{array}{l}\left\langle r_{\mathrm{h}}\right\rangle \\
{[\mathrm{AU}]}\end{array}$ & $\begin{array}{l}\text { Temperature } \\
\text { in the coma }\end{array}$ & $\begin{array}{c}v_{\exp } \\
{\left[\mathrm{km} \mathrm{s}^{-1}\right]}\end{array}$ & $\begin{array}{c}\beta_{0}(\mathrm{HCN}) \\
{\left[\mathrm{s}^{-1}\right]}\end{array}$ & $\begin{array}{r}Q_{\mathrm{H}_{2} \mathrm{C}} \\
{\left[\mathrm{molec} \mathrm{s}^{-1}\right]}\end{array}$ & (Ref.) \\
\hline \multicolumn{7}{|c|}{ C/1999 T1 (McNaught-Hartley) (2000/2001) } \\
\hline $09 / 28-30$ & 1.64 & $40 \mathrm{~K}$ & 0.65 & $1.91 \times 10^{-5}$ & $4.0 \times 10^{28}$ & (1) \\
\hline 01/03-07 & 1.23 & $55 \mathrm{~K}$ & 0.70 & $1.80 \times 10^{-5}$ & $9.0 \times 10^{28}$ & (1) \\
\hline $01 / 24-30$ & 1.37 & $50 \mathrm{~K}$ & 0.70 & $1.75 \times 10^{-5}$ & $6.5 \times 10^{28}$ & (1) \\
\hline 02/00-02 & 1.41 & $45 \mathrm{~K}$ & 0.70 & $1.71 \times 10^{-5}$ & $6.0 \times 10^{28}$ & (1) \\
\hline 02/04-07 & 1.45 & $45 \mathrm{~K}$ & 0.65 & $1.72 \times 10^{-5}$ & $5.5 \times 10^{28}$ & (1) \\
\hline \multicolumn{7}{|c|}{ C/2001 A2 (LINEAR) (2001) } \\
\hline $06 / 06$ & 0.82 & $70 \mathrm{~K}$ & 0.85 & $1.75 \times 10^{-5}$ & $1.0 \times 10^{29}$ & (2) \\
\hline $06 / 11-12$ & 0.86 & $70 \mathrm{~K}$ & 0.85 & $1.80 \times 10^{-5}$ & $1.5 \times 10^{29}$ & $(2,3)$ \\
\hline $06 / 16$ & 0.90 & $65 \mathrm{~K}$ & 0.85 & $2.00 \times 10^{-5}$ & $1.2 \times 10^{29}$ & $(2,3)$ \\
\hline $06 / 17-19$ & 0.92 & $60 \mathrm{~K}$ & 0.80 & $2.00 \times 10^{-5}$ & $0.8 \times 10^{29}$ & (2) \\
\hline $07 / 08-10$ & 1.16 & $50 \mathrm{~K}$ & 0.70 & $1.62 \times 10^{-5}$ & $0.4 \times 10^{29}$ & (2) \\
\hline \multicolumn{7}{|c|}{$\mathrm{C} / 2000 \mathrm{WM}_{1}($ LINEAR) (2001) } \\
\hline $11 / 23-27$ & 1.33 & $50 \mathrm{~K}$ & 0.65 & $1.80 \times 10^{-5}$ & $2.5 \times 10^{28}$ & (4) \\
\hline $12 / 03-04$ & 1.19 & $55 \mathrm{~K}$ & 0.70 & $2.07 \times 10^{-5}$ & $3.7 \times 10^{28}$ & (4) \\
\hline $12 / 05-08$ & 1.14 & $60 \mathrm{~K}$ & 0.70 & $2.05 \times 10^{-5}$ & $4.0 \times 10^{28}$ & (4) \\
\hline \multicolumn{7}{|c|}{ 153P/Ikeya-Zhang (2002) } \\
\hline $03 / 19-20$ & 0.508 & $120 \mathrm{~K}$ & 1.20 & $1.84 \times 10^{-5}$ & $7.0 \times 10^{29}$ & (5) \\
\hline $04 / 24-25$ & 0.96 & $63 \mathrm{~K}$ & 0.88 & $1.75 \times 10^{-5}$ & $2.1 \times 10^{29}$ & (6) \\
\hline $04 / 26-28$ & 1.01 & $60 \mathrm{~K}$ & 0.85 & $1.75 \times 10^{-5}$ & $1.8 \times 10^{29}$ & (6) \\
\hline $04 / 29-30$ & 1.05 & $55 \mathrm{~K}$ & 0.82 & $1.71 \times 10^{-5}$ & $1.6 \times 10^{29}$ & (6) \\
\hline 05/08-09 & 1.19 & $50 \mathrm{~K}$ & 0.75 & $1.87 \times 10^{-5}$ & $1.0 \times 10^{29}$ & (6) \\
\hline $05 / 11-12$ & 1.25 & $48 \mathrm{~K}$ & 0.75 & $1.87 \times 10^{-5}$ & $0.8 \times 10^{29}$ & (6) \\
\hline
\end{tabular}

(1) From power law fit: $17.3 \times 10^{28} r_{\mathrm{h}}^{-3.1}$ based on SWAS $\mathrm{H}_{2} \mathrm{O}$ observations (Bensch et al. 2004).

(2) From a power law fit $6.8 \times 10^{28} r_{\mathrm{h}}^{-2}$ based on Lecacheux et al. (2003) and Hjalmarson et al. (2005).

(3) Outburst from Crovisier et al. (2002).

(4) From Lecacheux et al. (2003) assuming $r_{\mathrm{h}}^{-2}$ dependence: $5.2 \times 10^{28} r_{\mathrm{h}}^{-2}$ molec s${ }^{-1}$.

(5) From Dello Russo et al. (2004).

(6) Power law fit $19.0 \times 10^{28} r_{\mathrm{h}}^{-4}$ based on Lecacheux et al. (2003) (Fig. 14).

Table 8. Comet C/1999 T1 (McNaught-Hartley) production rates.

\begin{tabular}{|c|c|c|c|c|c|c|c|c|c|}
\hline $\begin{array}{c}\text { UT date } \\
{[\mathrm{mm} / \mathrm{dd} . \mathrm{d}]}\end{array}$ & $\begin{array}{c}r_{\mathrm{h}} \\
{[\mathrm{AU}]}\end{array}$ & \multicolumn{8}{|c|}{$\left[10^{25}\right.$ molec s$\left.^{-1}\right]$} \\
\hline $09 / 29.7$ & 1.64 & $4.2 \pm 0.6$ & & & & & & & \\
\hline 01/05.6 & 1.23 & $5.8 \pm 0.7$ & & $2020 \pm 330$ & & $6.8 \pm 2.2$ & & & \\
\hline $01 / 06.6$ & 1.23 & $7.1 \pm 0.7$ & $230 \pm 10$ & & & & & & \\
\hline $01 / 07.6$ & 1.24 & & $370 \pm 190$ & & & $<7.4$ & & & $<1.9$ \\
\hline $01 / 25.5$ & 1.35 & $5.8 \pm 0.4$ & $160 \pm 30$ & & & & & & \\
\hline $01 / 30.6$ & 1.39 & $5.3 \pm 0.4$ & & $<1370$ & & & & & \\
\hline $01 / 31.5$ & 1.41 & $4.9 \pm 0.6$ & $115 \pm 20$ & $610 \pm 70$ & & & $33 \pm 5$ & $<3.1$ & $<0.7$ \\
\hline $02 / 02.1$ & 1.42 & $2.9 \pm 0.2$ & $122 \pm 10$ & & $19 \pm 4$ & $3.1 \pm 0.4$ & & & \\
\hline $02 / 05.7$ & 1.44 & $4.7 \pm 0.4$ & & $700 \pm 170$ & & $7.2 \pm 1.5$ & & & \\
\hline $02 / 06.6$ & 1.45 & $5.1 \pm 0.4$ & & & & & & & $<0.4$ \\
\hline 02/07.6 & 1.46 & $4.7 \pm 1.0$ & & & & & & & \\
\hline
\end{tabular}

order of $10^{-5} \mathrm{~s}^{-1}$, which is also one of the main reasons why SO lines in the near UV (2500-2600 A) have never been detected in comets in contrary to CS. In the case of SO observations in comets $\mathrm{C} / 2001 \mathrm{~A} 2$ and $153 \mathrm{P}$, more than $95 \%$ of the molecules in the beam are in a region (roughly less than $10000 \mathrm{~km}$ from the nucleus) where the collision rate with neutral gas is above $10^{-5} \mathrm{~s}^{-1}$ (assuming a collisional cross-section $\sigma_{c}=2 \times 10^{-14} \mathrm{~cm}^{-2}$ ). Due to relatively large Einstein coefficients of the main lines $\left(1.335 \times 10^{-4} \mathrm{~s}^{-1}\right.$ for the $N_{\mathrm{J}}=5_{6}-4_{5}$ line), radiative decay should also dominate the UV pumping. In summary we have used the same excitation model as for other molecules but without UV radiative pumping. Assuming pure thermal equilibrium would only increase the production rates by $\approx 10 \%$.

\section{Results}

\subsection{Production rates and abundances}

Production rates are given in Tables 8-11. Some are averages of production rates derived from several lines observed the same day (e.g. $\mathrm{HCN} J(3-2)$ and $\mathrm{HCN} J(1-0)$, or $\mathrm{CH}_{3} \mathrm{OH}$ ). We also 
Table 9. Comet C/2001 A2 (LINEAR) production rates.

\begin{tabular}{|c|c|c|c|c|c|c|c|c|c|c|}
\hline $\begin{array}{c}\text { UT date } \\
{[\mathrm{mm} / \mathrm{dd} . \mathrm{d}]}\end{array}$ & $\begin{array}{c}r_{\mathrm{h}} \\
{[\mathrm{AU}]}\end{array}$ & $\mathrm{HCN}$ & $\mathrm{CH}_{3} \mathrm{OH}$ & $\mathrm{CO}$ & $\begin{array}{l}\mathrm{H}_{2} \mathrm{CO} \\
{\left[10^{25}\right.}\end{array}$ & $\begin{array}{c}\text { CS } \\
\text { nolec s }{ }^{-1} \text { ] }\end{array}$ & $\mathrm{H}_{2} \mathrm{~S}$ & $\mathrm{CH}_{3} \mathrm{CN}$ & $\mathrm{HNC}$ & SO \\
\hline $06 / 05.8$ & 0.82 & & & & & $19 \pm 2$ & $77 \pm 12$ & & & \\
\hline $06 / 11.8$ & 0.86 & & $434 \pm 44$ & & & & & & & \\
\hline $06 / 12.8$ & 0.86 & & $393 \pm 68$ & & $97 \pm 18$ & & $119 \pm 14$ & & & \\
\hline $06 / 16.7$ & 0.90 & $13.7 \pm 0.5$ & & & & & & & & \\
\hline $06 / 18.6$ & 0.92 & $8.2 \pm 0.4$ & & & & & & & $0.69 \pm 0.10$ & \\
\hline $06 / 19.6$ & 0.93 & $8.5 \pm 0.6$ & & & & & & & & \\
\hline $07 / 08.3$ & 1.15 & $4.9 \pm 0.2$ & $112 \pm 16$ & $<149$ & & & $46 \pm 2$ & & & \\
\hline $07 / 09.3$ & 1.16 & $6.2 \pm 0.3$ & & & & $1.3 \pm 0.2$ & & $1.1 \pm 0.4$ & $0.17 \pm 0.03$ & $4.7 \pm 1.4$ \\
\hline $07 / 10.3$ & 1.17 & $5.8 \pm 0.6$ & & & $9.5 \pm 2.2$ & & & & & \\
\hline
\end{tabular}

Table 10. Comet $\mathrm{C} / 2000 \mathrm{WM}_{1}$ (LINEAR) production rates.

\begin{tabular}{|c|c|c|c|c|c|c|c|c|c|}
\hline $\begin{array}{c}\text { UT date } \\
\text { [mm/dd.d] }\end{array}$ & $\begin{array}{c}r_{\mathrm{h}} \\
{[\mathrm{AU}]}\end{array}$ & $\mathrm{HCN}$ & $\mathrm{CH}_{3} \mathrm{OH}$ & $\mathrm{CO}$ & $\begin{array}{l}\mathrm{H}_{2} \mathrm{CO} \\
{\left[10^{25}\right.}\end{array}$ & $\begin{array}{c}\mathrm{CS} \\
\text { tolec s }{ }^{-1} \text { ] }\end{array}$ & $\mathrm{H}_{2} \mathrm{~S}$ & $\mathrm{CH}_{3} \mathrm{CN}$ & $\mathrm{HNC}$ \\
\hline $11 / 23.1$ & 1.36 & $1.6 \pm 0.3$ & & & & & & & \\
\hline $11 / 24.1$ & 1.34 & $1.8 \pm 0.1$ & & & $9 \pm 1.6$ & & & & \\
\hline $11 / 24.8$ & 1.33 & $2.0 \pm 0.3$ & & & & & & & \\
\hline $11 / 25.7$ & 1.31 & $2.3 \pm 0.2$ & $30 \pm 3$ & $<38$ & & $0.5 \pm 0.2$ & $3.5 \pm 0.5$ & $0.4 \pm 0.1$ & $<0.09$ \\
\hline $11 / 26.8$ & 1.30 & $2.2 \pm 0.2$ & & & & $1.2 \pm 0.1$ & & & \\
\hline $12 / 03.3$ & 1.19 & $3.1 \pm 0.2$ & $49 \pm 6$ & & & & & & \\
\hline $12 / 04.3$ & 1.18 & $2.8 \pm 0.2$ & & & & & & & $<0.10$ \\
\hline $12 / 05.3$ & 1.16 & $2.9 \pm 0.2$ & $60 \pm 17$ & & & $1.8 \pm 0.2$ & & & \\
\hline $12 / 06.3$ & 1.15 & $3.1 \pm 0.1$ & & & $14 \pm 2$ & & & & \\
\hline $12 / 07.2$ & 1.13 & $3.2 \pm 0.3$ & & $<220$ & & $2.3 \pm 0.3$ & & & \\
\hline $12 / 08.2$ & 1.11 & $3.5 \pm 0.2$ & $60 \pm 3$ & & $17 \pm 5$ & & & & \\
\hline
\end{tabular}

Table 11. Comet 153P/Ikeya-Zhang production rates.

\begin{tabular}{|c|c|c|c|c|c|c|c|c|c|}
\hline \multirow{2}{*}{$\begin{array}{c}\text { UT date } \\
{[\mathrm{mm} / \mathrm{dd} . \mathrm{d}]}\end{array}$} & \multirow{2}{*}{$\begin{array}{c}r_{\mathrm{h}} \\
{[\mathrm{AU}]}\end{array}$} & $\mathrm{HCN}$ & $\mathrm{CH}_{3} \mathrm{OH}$ & $\mathrm{CO}$ & $\mathrm{H}_{2} \mathrm{CO}$ & CS & $\mathrm{H}_{2} \mathrm{~S}$ & $\mathrm{CH}_{3} \mathrm{CN}$ & $\mathrm{HNC}$ \\
\hline & & \multicolumn{8}{|c|}{$\left[10^{26} \mathrm{molec} \mathrm{s}^{-1}\right]$} \\
\hline $03 / 19.7$ & 0.51 & $10.0 \pm 0.4$ & & & & $10.1 \pm 1.1$ & & & \\
\hline $03 / 20.6$ & 0.51 & $10.3 \pm 0.7$ & $104 \pm 27$ & $234 \pm 52$ & & $9.8 \pm 0.9$ & & $1.7 \pm 0.6$ & $2.6 \pm 0.3$ \\
\hline 03/29.9 & 0.57 & $4.5 \pm 0.5$ & & & & & & & \\
\hline $04 / 25.5$ & 0.98 & $2.2 \pm 0.2$ & $49 \pm 8$ & & & & & & $0.10 \pm 0.02$ \\
\hline $04 / 26.5$ & 0.99 & $2.1 \pm 0.1$ & & & & & & & $0.12 \pm 0.03$ \\
\hline $04 / 27.5$ & 1.01 & $2.0 \pm 0.2$ & $38 \pm 13$ & & & & & & $0.09 \pm 0.02$ \\
\hline $04 / 29.3$ & 1.04 & $1.7 \pm 0.0$ & $38 \pm 4$ & & & $0.71 \pm 0.05$ & & $0.21 \pm 0.04$ & $0.07 \pm 0.01$ \\
\hline $04 / 30.3$ & 1.06 & $1.7 \pm 0.1$ & $46 \pm 14$ & & $5.8 \pm 0.3$ & & $12.3 \pm 0.2$ & & $0.09 \pm 0.01$ \\
\hline 05/08.4 & 1.19 & $1.2 \pm 0.1$ & & & & & & & \\
\hline $05 / 11.4$ & 1.24 & $0.8 \pm 0.1$ & $22 \pm 4$ & & & $0.57 \pm 0.09$ & & & HNCO: \\
\hline $05 / 12.1$ & 1.26 & $0.8 \pm 0.1$ & $27 \pm 6$ & $34 \pm 4$ & & & & & $0.31 \pm 0.05$ \\
\hline
\end{tabular}

took into account observational offsets and, when coarse maps were obtained, production rates obtained from the different positions were averaged (see data in Tables 2-5). Figure 14 shows the post-perihelion heliocentric evolution of molecular production rates in comet $153 \mathrm{P}$. Water outgassing rates from other studies have been added for comparison.
Several sources of possible uncertainties on these production rates have been investigated:

- Uncertainty on CS lifetime: the effect of using $\beta_{0}(\mathrm{CS})=2.0 \times 10^{-5} \mathrm{~s}^{-1}$, instead of $1.0 \times 10^{-5} \mathrm{~s}^{-1}$ as in Biver et al. (1999a) is marginal $(\Delta Q / Q \leq 10 \%)$. The most 


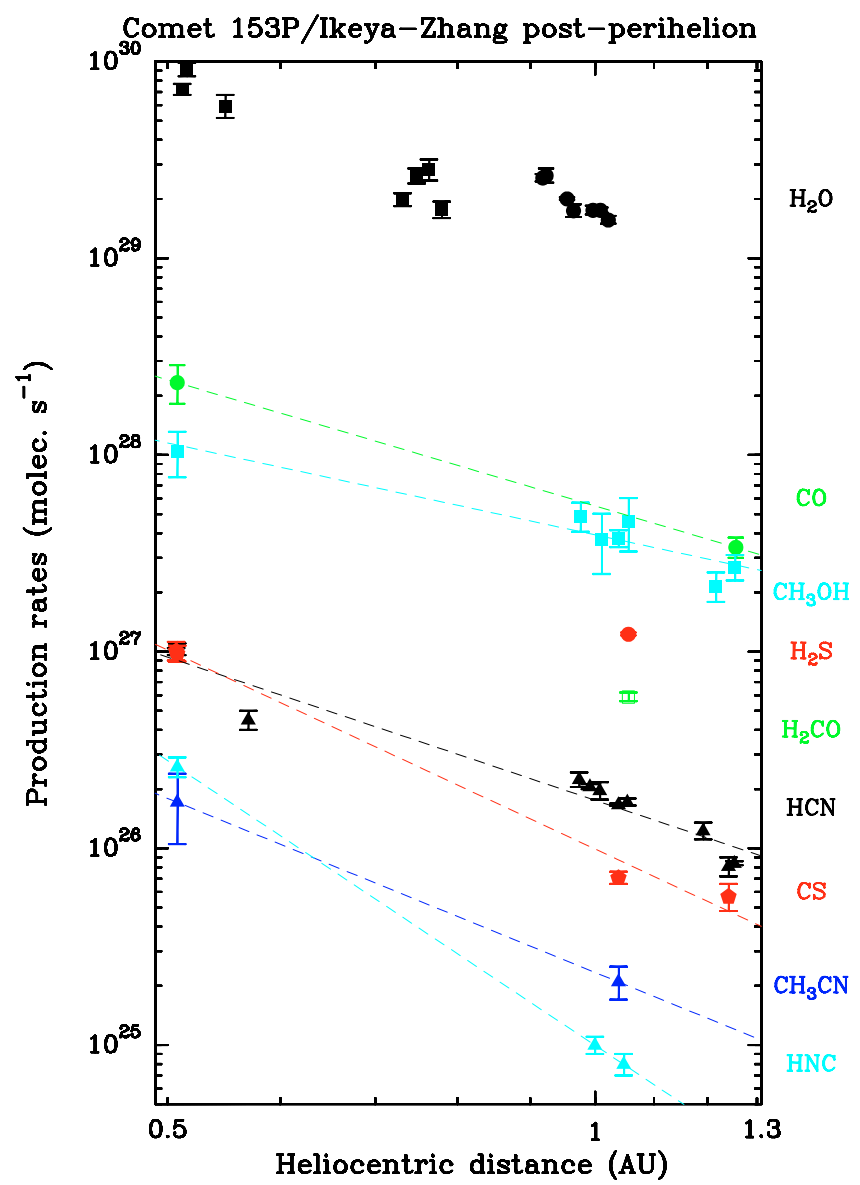

Fig. 14. Evolution of post-perihelion production rates in comet 153P/Ikeya-Zhang. Water production rates are from Odin (black dots, Lecacheux et al. 2003) and from infrared observations (black squares, Dello Russo et al. 2004).

sensitive cases are the observations of C/1999 T1 (for which CS production rates are increased by at most $15 \%$ ) and $153 \mathrm{P}$ around perihelion (20\% increase).

- Uncertainty on gas temperature: the larger uncertainty is for comets observed close to the Sun, i.e. within $0.8 \mathrm{AU}$, where gas temperatures are higher and harder to measure precisely. In fact, the average production rates based on multi-line observations (e.g. $\mathrm{CH}_{3} \mathrm{OH}$ ) are generally not so sensitive to the assumed temperature as they are based on rotational lines from a relatively wide range of energy levels. Otherwise the temperature uncertainty results in a $20 \%$ uncertainty in the production rates in the worst case.

- Uncertainty on collision rates: the electron density scaling factor $x_{\text {ne }}$ is in some way a free parameter to get the best agreement between observations and model. Variations of $x_{\mathrm{ne}}$ in the range $0.2-1.0$ will not change abundance ratios by more than $20 \%$.

Figure 15 plots the result of the abundances relative to water from Table 12. It helps to see clearly where differences between comets are significant. The abundances found in comet C/1995 O1 (Hale-Bopp) (Bockelée-Morvan et al. 2000) are also plotted for comparison. These clearly show that for several molecules $\left(\mathrm{H}_{2} \mathrm{CO}, \mathrm{H}_{2} \mathrm{~S}, \mathrm{CS}, \mathrm{HCN}, \mathrm{HNC}, \mathrm{SO}\right.$ and also

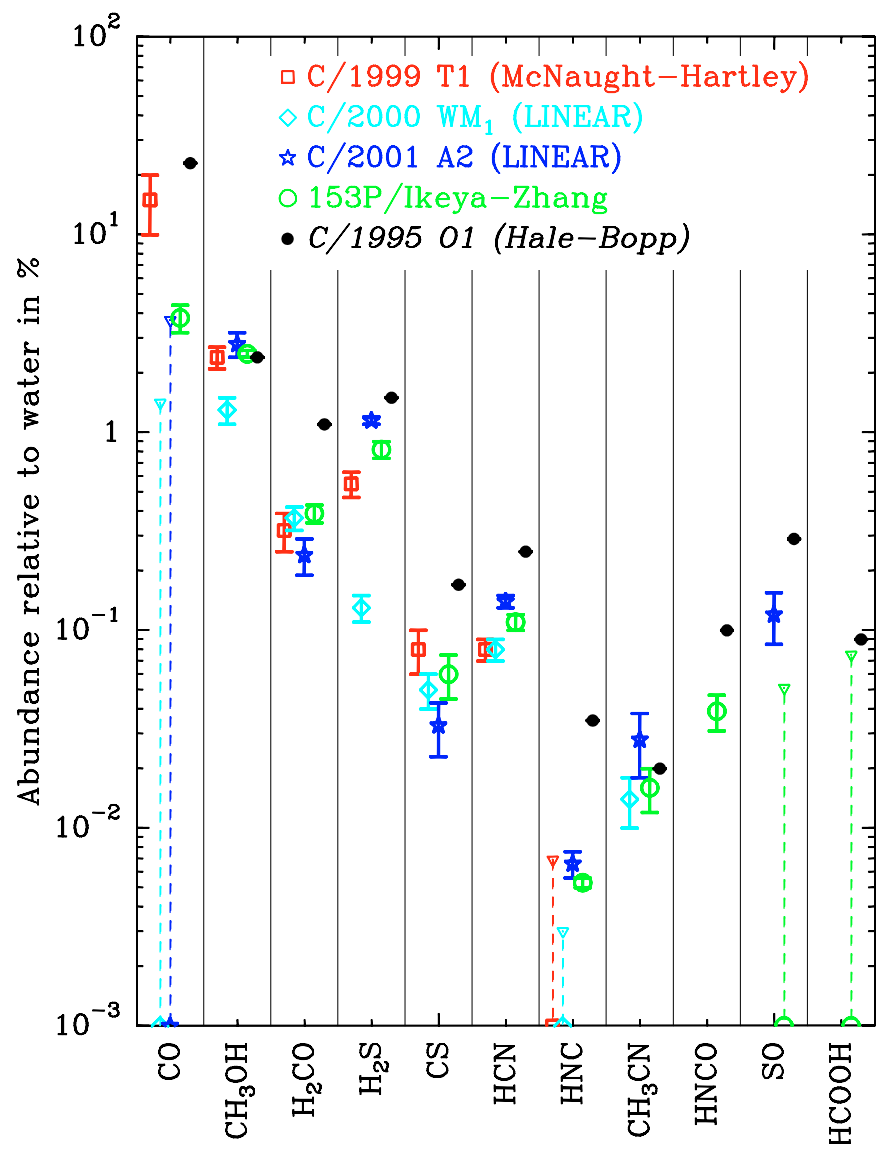

Fig. 15. Plot of the abundances relative to water of 11 molecules observed in the four comets or searched for in at least two of them. Data are from Table 12. For HNC and CS, whose abundances relative to water vary with heliocentric distance, values at $r_{\mathrm{h}} \approx 1 \mathrm{AU}$ are plotted. Abundances measured in Hale-Bopp around perihelion are shown for comparison. Upper limits are drawn with $3-\sigma$ error bars in dashed lines.

for $\mathrm{HC}_{3} \mathrm{~N}$ from Sect. 4.5) the abundances in comet Hale-Bopp were significantly higher than in any of the comets investigated in this paper.

\subsection{Heliocentric variations of the abundances of CS and HNC}

The observations of $\mathrm{HNC}$ and $\mathrm{CS}$ in these four comets strengthen the need to take into account variations with heliocentric distances. For C/2001 A2 and 153P, which were observed on a wider range of heliocentric distances than the others, significant heliocentric variations of the abundances of CS and $\mathrm{HNC}$ are found (Table 12).

The CS/HCN production rate ratio in comet $153 \mathrm{P}$ is proportional to $r_{\mathrm{h}}^{-0.7}$ (Fig. 14, Table 12), which is the same heliocentric dependence as found in comets Hyakutake (Biver et al. 1999a) and Hale-Bopp (Biver et al. 2002). In C/2000 $\mathrm{WM}_{1}$, the $\mathrm{CS} / \mathrm{HCN}$ ratio also increases with decreasing $r_{\mathrm{h}}$, following $\mathrm{CS} / \mathrm{HCN}=0.9 \times r_{\mathrm{h}}^{-2.6 \pm 0.6}$, but since the heliocentric distance changed only by $15 \%$ over the course of the observations, the slope is not very well constrained. The behaviour of C/2001 A2 in April-June 2001 was erratic due to frequent 
Table 12. Compared relative production rates.

\begin{tabular}{|c|c|c|c|c|}
\hline Molecule & C/1999 T1 (McN.-H.) & C/2001 A2 (LINEAR) & $\mathrm{C} / 2000 \mathrm{WM}_{1}$ (LINEAR) & 153P/I.-Z. \\
\hline$\left\langle r_{\mathrm{h}}\right\rangle^{1}$ & 1.3 & 1.1 & 1.2 & 1.0 \\
\hline \multicolumn{5}{|c|}{ Abundance relative to water } \\
\hline $\mathrm{HCN}$ & $0.08 \pm 0.01 \%$ & $0.14 \pm 0.01 \%$ & $0.08 \pm 0.01 \%$ & $0.11 \pm 0.01 \%$ \\
\hline $\mathrm{CH}_{3} \mathrm{OH}$ & $2.4 \pm 0.3 \%$ & $2.8 \pm 0.4 \%$ & $1.3 \pm 0.2 \%$ & $2.5 \pm 0.1 \times r_{\mathrm{h}}^{+0.8} \%$ \\
\hline $\mathrm{CO}$ & $15 \pm 5 \%$ & $<3.7 \%$ & $<1.4 \%$ & $3.8 \pm 0.6 \%$ \\
\hline $\mathrm{H}_{2} \mathrm{CO}$ & $0.32 \pm 0.07 \%$ & $0.24 \pm 0.05 \%$ & $0.37 \pm 0.05 \%$ & $0.39 \pm 0.04 \%$ \\
\hline $\mathrm{H}_{2} \mathrm{CO}(\mathrm{p})$ & $0.16 \pm 0.04 \%$ & $0.05 \pm 0.01 \%$ & $0.09-0.18 \%$ & $0.10 \pm 0.01 \%$ \\
\hline $\mathrm{H}_{2} \mathrm{~S}$ & $0.55 \pm 0.08 \%$ & $1.15 \pm 0.05 \%$ & $0.13 \pm 0.02 \%$ & $0.82 \pm 0.08 \%$ \\
\hline $\mathrm{CS}$ & $0.08 \pm 0.02 \%$ & $0.07 \pm 0.01 \times r_{\mathrm{h}}^{-5} \%$ & $0.05 \pm 0.01 \%$ & $0.067 \pm 0.016 \times r_{\mathrm{h}}^{-1.0} \%$ \\
\hline $\mathrm{HNC}$ & $<0.007 \%$ & $0.0066 \pm 0.0010 \times r_{\mathrm{h}}^{-2.9} \%$ & $<0.003 \%$ & $0.0053 \pm 0.0003 \times r_{\mathrm{h}}^{-2.6 \%}$ \\
\hline $\mathrm{CH}_{3} \mathrm{CN}$ & $<0.052 \%$ & $0.028 \pm 0.010 \%$ & $0.014 \pm 0.004 \%$ & $0.016 \pm 0.004 \%$ \\
\hline \multicolumn{5}{|c|}{ Abundance relative to $\mathrm{HCN}$} \\
\hline $\mathrm{CH}_{3} \mathrm{OH}$ & $31 \pm 5$ & $20 \pm 2$ & $16 \pm 2$ & $22 \pm 6$ \\
\hline $\mathrm{CO}$ & $200 \pm 80$ & $<23$ & $<17$ & $36 \pm 8$ \\
\hline $\mathrm{H}_{2} \mathrm{CO}$ & $4.0 \pm 1.0$ & $1.6 \pm 0.3$ & $4.2 \pm 0.5$ & $3.6 \pm 0.3$ \\
\hline $\mathrm{H}_{2} \mathrm{~S}$ & $6.3 \pm 1.1$ & $6.9 \pm 0.7$ & $1.6 \pm 0.3$ & $7.5 \pm 0.5$ \\
\hline $\mathrm{CS}$ & $1.1 \pm 0.2$ & $0.2 \pm 0.1$ & $0.6 \pm 0.1$ & $0.55 \times r_{\mathrm{h}}^{-0.7}$ \\
\hline $\mathrm{HNC}$ & $<0.08^{2}$ & $0.052 \times r_{\mathrm{h}}^{-3.7}$ & $<0.036^{3}$ & $0.055 \times r_{\mathrm{h}}^{-2.2}$ \\
\hline $\mathrm{CH}_{3} \mathrm{CN}$ & $<0.6$ & $0.19 \pm 0.07$ & $0.18 \pm 0.04$ & $0.14 \pm 0.04$ \\
\hline $\mathrm{HC}_{3} \mathrm{~N}$ & & $<0.05$ & & $<0.09$ \\
\hline OCS & $<125$ & $<1.1$ & & $<2.0$ \\
\hline $\mathrm{HNCO}$ & & $<0.23$ & & $0.39 \pm 0.08$ \\
\hline SO & & $0.8 \pm 0.2$ & & $<0.5$ \\
\hline $\mathrm{HCOOH}$ & & $<1.3$ & & $<0.8$ \\
\hline
\end{tabular}

${ }^{1}$ Mean heliocentric distance (in AU) for the abundances, unless otherwise specified.

${ }^{2}$ at $r_{\mathrm{h}}=1.42 \mathrm{AU}$.

${ }^{3}$ at $r_{\mathrm{h}}=1.18 \mathrm{AU}$.

(p): parent distribution.

outbursts and fragment releases (Jehin et al. 2002). During the first half of June, Nançay $\mathrm{OH}$ observations showed variations of a factor of 3 or more in production rates from day to day. Thus, early June observations at the KPNO 12-m must be cautiously compared to June-July observations. Anyhow, they suggest a steep decrease of the $\mathrm{CS} / \mathrm{H}_{2} \mathrm{O}$ production ratio with heliocentric distance similar to that observed for 153P. The uncertainty on the CS photodissociation rate cannot explain the observed trend: as exposed in Sect. 4.1, the increase in the $\mathrm{CS} / \mathrm{HCN}$ ratio in $153 \mathrm{P}$ between 1 and $0.5 \mathrm{AU}$ can only be reduced from $+65 \%$ down to $+45 \%$ using a photodissociation rate twice lower. Snyder et al. (2001) even suggest a much higher photodissociation rate (5 times the value used here), probably unrealistic according to Biver et al. (2003): that would strongly increase the slope of the $\mathrm{CS} / \mathrm{HCN}$ ratio versus heliocentric distance (to $r_{\mathrm{h}}^{-1.6}$ ). Otherwise, it is worth noting that this trend was also noticed with a different technique, i.e. from UV observations of comet 1P/Halley with IUE (Feldman et al. 1987; Meier \& A'Hearn 1997). So the increase of the CS abundance in cometary comae close to the Sun is very likely and suggests that CS partially behaves as a low-volatility molecule: either its expected main parent $\mathrm{CS}_{2}$ is not easily released from the nucleus or another parent of CS (molecule, polymer or grains) releases additional CS only close to the Sun.

If we compare the $\mathrm{CS} / \mathrm{HCN}$ production rate ratios at the same heliocentric distance $(\approx 1.3 \mathrm{AU})$, then the average values are $1.1,0.2,0.5$ and 0.5 for $\mathrm{C} / 1999 \mathrm{~T} 1$, $\mathrm{C} / 2001 \mathrm{~A} 2, \mathrm{C} / 2000 \mathrm{WM}_{1}$ and 153P, respectively. This shows that $\mathrm{C} / 1999 \mathrm{~T} 1$, only observed at this distance, is significantly richer in $\mathrm{CS}$ than the other comets.

The HNC/HCN production rate ratio exhibited a significant heliocentric dependence in comet Hale-Bopp (Biver et al. 1999b, Irvine et al. 1999). A production of HNC by chemical reactions in the coma was invoked by Rodgers \& Charnley (1998): the presence of HNC in this comet and the increase of its abundance as $r_{\mathrm{h}}$ decreases was explained as due to the increase of outgassing rate and reaction efficiency. We find here again a steep $\left(r_{\mathrm{h}}^{-2.2}\right.$ to $\left.r_{\mathrm{h}}^{-3.7}\right)$ evolution of the $\mathrm{HNC} / \mathrm{HCN}$ ratio in comets $153 \mathrm{P}$ and $\mathrm{C} / 2001 \mathrm{~A} 2$ that were $\approx 50$ times less productive than Hale-Bopp (Table 12). As shown in Fig. 16, the increase of the $\mathrm{HNC} / \mathrm{HCN}$ production rate ratio at shorter heliocentric distances seems to be a common trend to all comets 


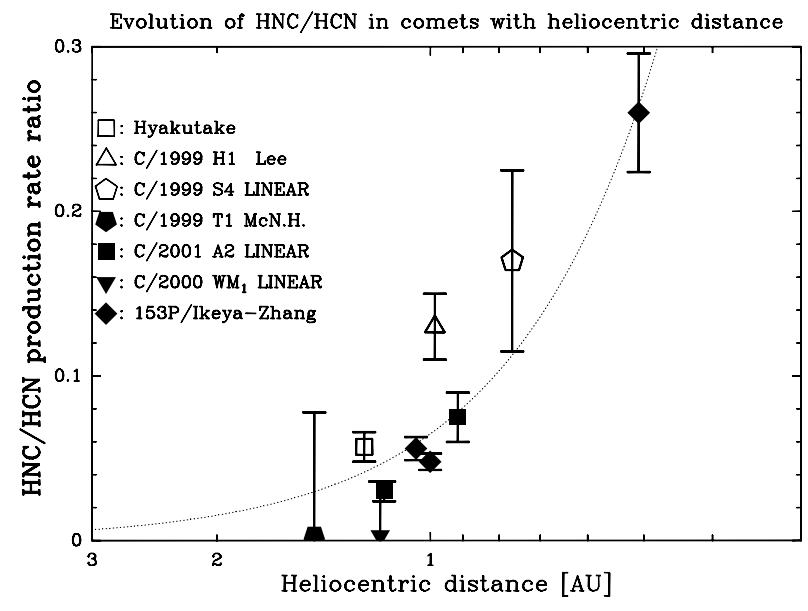

Fig. 16. The HNC/HCN production rate ratio as a function of heliocentric distance observed in 7 comets. The open symbols represent data previously published on comets of similar activity to those studied here: C/1996 B2 (Hyakutake) (Irvine et al. 1996), C/1999 H1 (Lee) (Biver et al. 2000) and C/1999 S4 (LINEAR) (Bockelée-Morvan et al. 2001). The dotted line corresponds to a weighted fit to all data yielding $\mathrm{HNC} / \mathrm{HCN}=0.06 r_{\mathrm{h}}^{-2.1}$.

observed so far. However, according to Rodgers \& Charnley (2001), the HNC/HCN ratio observed in such comets of lesser activity than Hale-Bopp cannot be explained by the same process.

Projecting a similar heliocentric dependence of the $\mathrm{HNC} / \mathrm{HCN}$ ratio to the two other comets $\mathrm{C} / 1999 \mathrm{~T} 1$ and $\mathrm{C} / 2000 \mathrm{WM}_{1}$, all observations are compatible with a ratio of about 0.06 at $1 \mathrm{AU}$ from the Sun (as compared to $\approx 0.2$ in Hale-Bopp), varying roughly as $r_{\mathrm{h}}^{-2}$. The detection of $\mathrm{HNC}$ in $\mathrm{C} / 2000 \mathrm{WM}_{1}$ by Irvine et al. (2003) $(\mathrm{HNC} / \mathrm{HCN}=0.08$ at $\left.r_{\mathrm{h}}=1.08 \mathrm{AU}\right)$, a little closer to the Sun than were our observations, confirms this trend. The origin of HNC in cometary comae remains puzzling. It seems that the process releasing $\mathrm{HNC}$ in the coma is getting really efficient below $r_{\mathrm{h}}=1 \mathrm{AU}$, and it will be worth looking for measurements of the HNC/HCN production rate ratio at small heliocentric distances (Biver et al. 2003). If $\mathrm{HNC}$ is the photodissociation or thermal degradation product of a parent molecule or polymer (as proposed by Rodgers \& Charnley 2001), one may expect the process to reach a maximum efficiency below some heliocentric distance and the $\mathrm{HNC} / \mathrm{HCN}$ ratio will then reach a maximum value.

\subsection{Evolution of the abundances of $\mathrm{CO}$ and $\mathrm{CH}_{3} \mathrm{OH}$ relative to $\mathrm{HCN}$ and $\mathrm{H}_{2} \mathrm{O}$}

In the case of comet $153 \mathrm{P}$ observations at $0.5 \mathrm{AU}$ from the Sun, $\mathrm{CO}$ and $\mathrm{CH}_{3} \mathrm{OH}$ abundances relative to $\mathrm{HCN}$ appear to be twice lower than around $r_{\mathrm{h}}=1.1 \mathrm{AU}$. Given our assumed value of $Q_{\mathrm{H}_{2} \mathrm{O}}$ in Table 7 the abundances of $\mathrm{CO}$ and $\mathrm{CH}_{3} \mathrm{OH}$ relative to $\mathrm{H}_{2} \mathrm{O}$ are also 1.3 and 1.7 times lower than at $1.1 \mathrm{AU}$. But the $\mathrm{H}_{2} \mathrm{O}$ production rates were not measured with the same technique during all 153P observations: Dello Russo et al. (2004) finds $Q_{\mathrm{H}_{2} \mathrm{O}} \propto r_{\mathrm{h}}^{-3.2}$ while combining those data with Odin observation as in Fig. 14 yields $Q_{\mathrm{H}_{2} \mathrm{O}} \propto r_{\mathrm{h}}^{-2.1}$, which is the same slope as found for the $\mathrm{CO}$ production rate evolution with $r_{\mathrm{h}}$.
So the ratios that significantly decrease towards the Sun are: $\mathrm{CH}_{3} \mathrm{OH} / \mathrm{HCN}, \mathrm{CH}_{3} \mathrm{OH} / \mathrm{H}_{2} \mathrm{O}$ and $\mathrm{CO} / \mathrm{HCN}$, while uncertainties on $\mathrm{H}_{2} \mathrm{O}$ production rates are too large to be conclusive about the $\mathrm{CO} / \mathrm{H}_{2} \mathrm{O}$ and $\mathrm{H}_{2} \mathrm{O} / \mathrm{HCN}$ ratios. The decrease of the $\mathrm{CO} / \mathrm{HCN}, \mathrm{CH}_{3} \mathrm{OH} / \mathrm{HCN}$ and $\mathrm{H}_{2} \mathrm{O} / \mathrm{HCN}$ ratios with decreasing heliocentric distance were also observed in comet Hyakutake (Biver et al. 1999a). On the other hand the $\mathrm{CH}_{3} \mathrm{CN} / \mathrm{HCN}$ ratio does not vary with $r_{\mathrm{h}}$. A bias on the $\mathrm{CO}$ and $\mathrm{CH}_{3} \mathrm{OH}$ production rates due to uncertainty on the gas temperature would be less than the observed trend. Possible explanations are not obvious, but if we assume that $\mathrm{CO} / \mathrm{H}_{2} \mathrm{O}$ does not really vary, $\mathrm{HCN} / \mathrm{H}_{2} \mathrm{O}$ would then increase towards the Sun and one hypothesis would be that another source (e.g. HCN polymers) of $\mathrm{CN}$-bearing molecules could become more efficient close to the Sun in releasing $\mathrm{HCN}, \mathrm{HNC}$ and probably $\mathrm{CH}_{3} \mathrm{CN}$. The evolution of methanol abundance with heliocentric distance is still puzzling, but is observed for the third time: it was also noticed in Hale-Bopp (Biver et al. 1999b) that the $\mathrm{CH}_{3} \mathrm{OH} / \mathrm{HCN}$ ratio is higher at $2 \mathrm{AU}$ than at $1 \mathrm{AU}$ from the Sun. So it will be worth investigating in the future the evolution of the methanol abundance in cometary comae on a wide range of heliocentric distance.

\subsection{Differences in composition between comets: is $\mathrm{C} / 2000 \mathrm{WM}_{1}$ depleted in volatile species?}

All four comets are different with respect to the abundances of $\mathrm{HCN}, \mathrm{CO}, \mathrm{CH}_{3} \mathrm{OH}, \mathrm{H}_{2} \mathrm{CO}, \mathrm{H}_{2} \mathrm{~S}$ and $\mathrm{CH}_{3} \mathrm{CN}$ relative to water. Each exhibits at least one abundance ratio that distinguishes it from the others (Table 12, Fig. 15).

A question that is arising is the extent to which variations in coma abundances do reflects differences in nucleus ice composition. The nucleus is expected to be chemically differentiated in layers upon solar heating, with the upper layers depleted in the most volatile species. If this processing significantly altered chemical abundances and if depletion is directly linked to the sublimation temperature of the molecules, then abundances of species with high volatilities should be correlated. Similarly, if the composition of pre-cometary ices was governed by only volatility dependent condensation process, again, volatiles species should be correlated. Gibb et al. (2003) compared the $\mathrm{CH}_{4}$ and $\mathrm{CO}$ abundances relative to water in a sample of 8 Oort cloud comets. These species have comparable volatilities, sublimating at 31 and $24 \mathrm{~K}$, respectively. No apparent correlation is observed between $\mathrm{CO}$ and $\mathrm{CH}_{4}$, with $\mathrm{CO}$ exhibiting much larger abundance variations than $\mathrm{CH}_{4}$. These results suggest that the coma deficiency in hyper-volatiles in Oort cloud comets is not mainly related to chemical aging and also argue against temperature as the main factor controlling the composition of pre-cometary ices (Gibb et al. 2003).

Among the molecules studied in this paper, $\mathrm{H}_{2} \mathrm{~S}$ is the most volatile species after $\mathrm{CO}$ and $\mathrm{CH}_{4}$, with a sublimation temperature $\sim 57 \mathrm{~K}$. As done for $\mathrm{CH}_{4}$, it is interesting to study how $\mathrm{CO}$ and $\mathrm{H}_{2} \mathrm{~S}$ abundances correlate with each other. Figure 17 plots the $\mathrm{H}_{2} \mathrm{~S} / \mathrm{H}_{2} \mathrm{O}$ versus $\mathrm{CO} / \mathrm{H}_{2} \mathrm{O}$ relative abundances for seven comets: the four studied here plus three others in which both $\mathrm{CO}$ and $\mathrm{H}_{2} \mathrm{~S}$ were observed (from 


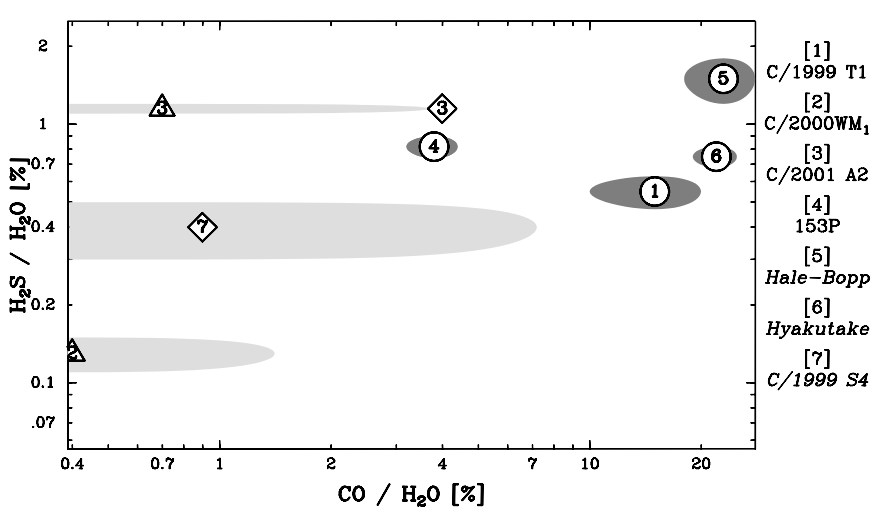

Fig. 17. Abundances of $\mathrm{H}_{2} \mathrm{~S}$ and $\mathrm{CO}$ relative to water in seven comets. Ellipses correspond to uncertainty domains $( \pm 1 \sigma$ on each axis). In the case of $\mathrm{CO}, 3-\sigma$ upper limits obtained in the radio are shown with light shaded ellipses. Circles (with comet number) correspond to the measured radio values, diamonds the infrared ones (Gibb et al. 2003; Mumma et al. 2002) and triangles the UV measurements (Weaver et al. 2003).

Biver et al. 1999a,b, 2000 and Bockelée-Morvan et al. 2001). CO was not detected in the radio in several comets but significant upper limits were obtained and its abundance was also estimated from UV or infrared observations (Weaver et al. 2003; Magee-Sauer et al. 2003; Mumma et al. 2002; Gibb et al. 2003). From Fig. 17, we can notice that:

- C/1999 T1 is CO-rich, with a CO abundance relative to $\mathrm{HCN}$ or water at least 4 times higher than in any of the three others. It has also an average $\mathrm{H}_{2} \mathrm{~S}$ abundance and belongs to the group of the volatile-rich comets like Hyakutake and Hale-Bopp (upper right corner).

- 153P has a lower $\mathrm{CO}$ abundance than the previous ones but is also relatively rich in $\mathrm{H}_{2} \mathrm{~S}$. $153 \mathrm{P}$ is also a $\mathrm{CH}_{4}$-poor comet (Gibb et al. 2003). Yet, even though it may have been originally volatile rich, given its relatively short orbital period, 153P possibly lost part of its $\mathrm{CO}$ and $\mathrm{CH}_{4}$ after many passages close to the Sun.

- $\mathrm{C} / 2001 \mathrm{~A} 2$ is relatively rich in $\mathrm{H}_{2} \mathrm{~S}$, but has less $\mathrm{CO}$ than the previous comets. $\mathrm{CO} / \mathrm{H}_{2} \mathrm{O}$ abundance ratio published in the literature do not agree: $0.7 \%$ from UV observations (Weaver et al. 2003), but measured during an outburst and $\approx 4 \%$ from infrared data (Gibb et al. 2003). In fact both studies infer about the same $\mathrm{CO}$ production rate at close times, but do not have the same reference $\mathrm{H}_{2} \mathrm{O}$ production rate, because of the outburst. This comet may have had a similar history as $153 \mathrm{P}$.

- $\mathrm{C} / 2000 \mathrm{WM}_{1}$ is $\mathrm{H}_{2} \mathrm{~S}$-poor, with the lowest $\mathrm{H}_{2} \mathrm{~S} / \mathrm{HCN}$ or $\mathrm{H}_{2} \mathrm{~S} / \mathrm{H}_{2} \mathrm{O}$ ratio observed in any comet so far. This ratio is at least 3 times lower than any of the other comets. Although this determination relies on the observation of a single $\mathrm{H}_{2} \mathrm{~S}$ line, the detection is secure and was confirmed over several days with simultaneous HCN observations. It is also depleted in CO. Even if we only obtained an upper limit in the radio, it is a low one $\left(\mathrm{CO} / \mathrm{H}_{2} \mathrm{O}<1.4 \%\right.$, Table 12) and UV observations suggest one of the lowest $\mathrm{CO}$ abundance found in any comet $(0.4 \%$, Weaver et al. 2003). To strengthen the case for a volatile-depleted comet, the methanol abundance in $\mathrm{C} / 2000 \mathrm{WM}_{1}$ is also clearly lower in this comet than in the three others (Fig. 15). Finally, Gibb et al. (2003) found that $\mathrm{C} / 2000 \mathrm{WM}_{1}$ is also depleted in methane in comparison to the three other comets, HaleBopp, Hyakutake and C/1999 H1 (Lee). Only C/1999 S4 has a lower $\mathrm{CH}_{4}$ abundance.

In summary, $\mathrm{CO} / \mathrm{H}_{2} \mathrm{O}$ and $\mathrm{H}_{2} \mathrm{~S} / \mathrm{H}_{2} \mathrm{O}$ abundance ratios do not correlate. While no CO-rich $(>10 \%)$ comet has yet been observed with a low $\mathrm{H}_{2} \mathrm{~S}$ content, comets with $\mathrm{CO}$ mixing ratios $\sim 5 \%$ or less exhibit high or low $\mathrm{H}_{2} \mathrm{~S}$ mixing ratios. 153P, despite its numerous passages close to the Sun, is still $\mathrm{H}_{2} \mathrm{~S}$ rich. $\mathrm{C} / 2000 \mathrm{WM}_{1}$ is the first comet ever observed presenting a strong depletion in both $\mathrm{CO}, \mathrm{CH}_{4}$ and $\mathrm{H}_{2} \mathrm{~S}$. The strong depletion in volatiles observed in comet C/1999 S4 led Mumma et al. (2002) to argue that this comet formed close to the Sun, in the Jupiter region: if so, $\mathrm{C} / 2000 \mathrm{WM}_{1}$ might be another good candidate.

\subsection{Abundances or upper limits of other molecules}

The bottom of Table 12 provides results obtained for other molecules previously observed only in comets Hale-Bopp and Hyakutake. OCS, $\mathrm{HC}_{3} \mathrm{~N}$ and $\mathrm{SO}$ production rates were computed with the same model as for the main species, while a purely thermal model is used for $\mathrm{HNCO}$ and $\mathrm{HCOOH}$. Abundances relative to $\mathrm{HCN}$ or upper limits are in most cases in the range of values measured in comets Hyakutake and Hale-Bopp:

- The 3- $\sigma$ upper limits inferred for the $\mathrm{HC}_{3} \mathrm{~N} / \mathrm{HCN}$ ratio in comets $\mathrm{C} / 2001 \mathrm{~A} 2$ and $153 \mathrm{P}$ are comparable to the abundance measured in comet Hale-Bopp (Bockelée-Morvan et al. 2000). But upper limits on the $\mathrm{HC}_{3} \mathrm{~N} / \mathrm{H}_{2} \mathrm{O}$ ratio are three times and twice lower, respectively, than the ratio measured in comet Hale-Bopp. This suggests that the $\mathrm{HC}_{3} \mathrm{~N}$ abundance relative to water was relatively high in comet Hale-Bopp in comparison to other comets. A similar trend is also observed for the $\mathrm{HC}_{3} \mathrm{~N} / \mathrm{CH}_{3} \mathrm{CN}$ abundance ratio which is $<0.3$ in $\mathrm{C} / 2001 \mathrm{~A} 2$ and $<0.6$ in $153 \mathrm{P}$ while slightly above one in Hale-Bopp.

- Significant upper limits on the OCS abundance were also obtained in comets C/2001 A2 and 153P. They are comparable to the values measured in Hyakutake $(\mathrm{OCS} / \mathrm{HCN} \approx 1$ ) and Hale-Bopp (OCS/HCN = 1.6) (Bockelée-Morvan et al. 2000).

- HNCO, detected both in comets Hyakutake (Lis et al. 1997) and Hale-Bopp, was detected for the third time in $153 \mathrm{P}$ (Fig. 9). Its inferred abundance relative to $\mathrm{HCN}$ (Table 12, Lis et al. 1997; Bockelée-Morvan et al. 2000) is 0.4 in all three comets. The $\mathrm{HNCO} / \mathrm{H}_{2} \mathrm{O}$ production rate ratio is however lower than in Hyakutake and HaleBopp (0.04\% versus 0.06 and $0.1 \%$, respectively). The upper limits on the $\mathrm{HNCO}$ abundances in $\mathrm{C} / 2001 \mathrm{~A} 2$ $\left(\mathrm{HNCO} / \mathrm{HCN}<0.23\right.$ and $\left.\mathrm{HNCO} / \mathrm{H}_{2} \mathrm{O}<0.035 \%\right)$ are in the low end range of the values measured in Hyakutake, HaleBopp and 153P.

- SO has been previously detected only in comet Hale-Bopp. It is marginally detected in comet C/2001 A2 (LINEAR) 
(Fig. 3, Table 3). The inferred abundance relative to water is $0.11 \pm 0.03 \%$. The upper limit obtained in comet $153 \mathrm{P} /$ Ikeya-Zhang is even lower $\left(\mathrm{SO} / \mathrm{H}_{2} \mathrm{O}<0.05 \%\right)$, suggesting that Hale-Bopp was rather rich in $\mathrm{SO}_{\text {or }} \mathrm{SO}_{2}(0.2-$ $0.3 \%$, Bockelée-Morvan et al. 2000).

- HCOOH was searched for in comets C/2001 A2 and 153P through its $J_{\mathrm{Ka}, \mathrm{Kc}}\left(10_{0,10}-9_{0,9}\right)$ line at $220.038 \mathrm{GHz}$ (same tuning as for SO and HNCO: around $220 \mathrm{GHz}$, Tables 1, 3 and 5). The upper limits obtained for the $\mathrm{HCOOH} / \mathrm{H}_{2} \mathrm{O}$ production rate ratio $(0.2 \%$ and $0.08 \%$ respectively) are comparable to the abundance in Hale-Bopp. When comparing to methanol, we get $\mathrm{HCOOH} / \mathrm{CH}_{3} \mathrm{OH}<7 \%(\mathrm{C} / 2001 \mathrm{~A} 2)$, $<3 \%(153 \mathrm{P})$ and $4 \%$ in Hale-Bopp, suggesting that these comets are not significantly richer in $\mathrm{HCOOH}$ than comet Hale-Bopp.

- NS was only detected in comet Hale-Bopp (Irvine et al. 2000). We attempted a deep search in 153P/Ikeya-Zhang of the $N=11 / 2-9 / 2 e$ and $N=11 / 2-9 / 2 f$ lines at 253.569 GHz and 253.971 GHz, respectively. Summing the two lines (Table 5), we obtain an upper limit on the column density $N_{\text {col }}<3.6 \times 10^{11} \mathrm{~cm}^{-2}$. The origin and lifetime of NS are unknown and we assume a photodissociation rate in the range $0.1-2 \times 10^{-4} \mathrm{~s}^{-1}$ as in Irvine et al. (2000). Assuming a Haser parent density distribution, the corresponding upper limits in production rate are in the range $1.3-1.8 \times 10^{25}$ molec s$^{-1}$. This corresponds to an upper limit on the abundance of NS relative to water in $153 \mathrm{P}$ of $0.02 \%$. In comet Hale-Bopp, Irvine et al. (2000) found $\mathrm{NS} / \mathrm{H}_{2} \mathrm{O}=0.02 \%$ while Crovisier et al. (2004) found $\mathrm{NS} / \mathrm{H}_{2} \mathrm{O}<0.01 \%$ from the same $254 \mathrm{GHz}$ lines as observed here. So our upper limit in $153 \mathrm{P}$ is comparable to the values obtained in comet Hale-Bopp, but comparison may be hazardous since the origin of this radical in cometary atmosphere is unknown. If we now assume that NS is produced in the coma with a parent scale-length of $10^{4} \mathrm{~km}$ or more, our upper limit becomes more than twice higher than the corresponding abundance in Hale-Bopp due to the proximity and small beam with which we observed $153 \mathrm{P}$.

\subsection{HDO in $153 P / / k e y a-Z h a n g$}

The deuterium abundance in water is an important parameter for investigating the origin of cometary material (see e.g., Altwegg \& Bockelée-Morvan 2003). Variations among comets may be expected if they did not formed in the same regions of the Solar Nebula (Hersant et al. 2001). We searched for the HDO $\left(1_{10}-1_{01}\right)$ line at $509.292 \mathrm{GHz}$ in comet $153 \mathrm{P} /$ IkeyaZhang using the CSO. Due to unexpected losses in telescope efficiency at this frequency, the search was not as efficient as anticipated and the line was not detected. Meanwhile, the 3- $\sigma$ upper limit derived for the HDO production rate is $Q_{\mathrm{HDO}}<$ $1.0 \times 10^{26}$ molec s$^{-1}$. On the same date (26 Apr. 2002), the observations of $\mathrm{H}_{2} \mathrm{O}$ and $\mathrm{H}_{2}^{18} \mathrm{O}$ with the Odin satellite yield a confident value of $Q_{\mathrm{H}_{2} \mathrm{O}}=(1.8 \pm 0.2) \times 10^{29}$ molec s$^{-1}$ (Lecacheux et al. 2003). Thus $\mathrm{HDO} / \mathrm{H}_{2} \mathrm{O}<(5.6 \pm 0.6) \times 10^{-4}$ or $(\mathrm{D} / \mathrm{H})_{\mathrm{H}_{2} \mathrm{O}}<(2.8 \pm 0.3) \times 10^{-4}$ in $153 \mathrm{P} /$ Ikeya-Zhang. Our measurement does not confirm the high $(\mathrm{D} / \mathrm{H})_{\mathrm{H}_{2} \mathrm{O}}$ value of $\approx 1.5 \times 10^{-3}$ determined by Gibb et al. (2002) in the same comet from a tentative detection of a HDO infrared line. Our upper limit is significant as the $(\mathrm{D} / \mathrm{H})_{\mathrm{H}_{2} \mathrm{O}}$ ratio measured in other comets are, 2.6-3.4 $\times 10^{-4}$ in 1P/Halley (Eberhardt et al. 1995, Balsiger et al. 1995), $2.9 \pm 1.0 \times 10^{-4}$ in Hyakutake (Bockelée-Morvan et al. 1998) and $(3.3 \pm 0.8) \times 10^{-4}$ in HaleBopp (Meier et al. 1998). It does not exclude the $(D / H)_{\mathrm{H}_{2} \mathrm{O}}$ to be lower in comet 153P than in other comets. Since comet 153P is CO-depleted compared to comets $1 \mathrm{P} / \mathrm{Halley}$, Hyakutake and Hale-Bopp, a low deuterium abundance could have suggested that comet 153P formed closer to the Sun than did the other three.

\section{Conclusion}

In the present study we reported the detection of 6 to 9 molecules in comets C/1999 T1 (McNaught-Hartley), $\mathrm{C} / 2001 \mathrm{~A} 2$ (LINEAR), $\mathrm{C} / 2000 \quad \mathrm{WM}_{1} \quad$ (LINEAR) and 153P/Ikeya-Zhang. In total, significant results on the relative abundances of up to 13 different molecules were obtained. This is one of the most extensive chemical survey of comets since Hyakutake and Hale-Bopp investigations. All comets discussed in the paper (including C/1999 S4 (LINEAR) and C/1999 H1 (Lee)) share a similar dynamical origin. They are long-period comets originating from the Oort cloud and are not at their first perihelion passage. 153P/Ikeya-Zhang may have experienced more alteration by solar heating, given its three recent recorded perihelion passages.

This study confirms previous evidences for chemical diversity among the Oort cloud population (Biver et al. 2002; Mumma et al. 2002). The variation of the $\mathrm{H}_{2} \mathrm{~S}$ and $\mathrm{CO}$ content between comets suggests that the deficiency is these hypervolatiles is not only related to comet aging upon solar heating. This is emphasized by the composition of $\mathrm{C} / 2000 \mathrm{WM}_{1}$, which shows a much more severe depletion in both $\mathrm{H}_{2} \mathrm{~S}$ and $\mathrm{CO}$ than does $153 \mathrm{P}$. Interestingly, $\mathrm{C} / 2000 \mathrm{WM}_{1}$ is also less abundant in $\mathrm{CH}_{4}$ than 153P (Gibb et al. 2003). Comparison between the $\mathrm{H}_{2} \mathrm{~S}$ and $\mathrm{CO}$ contents among comets shows that a deficiency in $\mathrm{CO}$ is not necessarily correlated with a deficiency in $\mathrm{H}_{2} \mathrm{~S}$. Possibly $\mathrm{C} / 2000 \mathrm{WM}_{1}$ formed in a relatively warm region of the solar nebula which partly prevented the condensation or trapping of $\mathrm{H}_{2} \mathrm{~S}$ and $\mathrm{CO}$. But the absence of a clear correlation between volatility and abundance variations among comets (all parent molecules included) suggests that temperature and condensation were not the only factors that controlled the composition of cometary ices. Alternative explanations are debated as clathrate hydrates formation (Iro et al. 2003) or chemical processing in the Solar Nebula (Gail 2002).

Observations of $\mathrm{HDO}$ in comet $153 \mathrm{P}$ yield $(\mathrm{D} / \mathrm{H})_{\mathrm{H}_{2} \mathrm{O}}<$ $(2.8 \pm 0.3) \times 10^{-4}$, an upper limit equal to the $\mathrm{D} / \mathrm{H}$ value measured in comets $1 \mathrm{P} /$ Halley, Hyakutake and Hale-Bopp. A low $\mathrm{D} / \mathrm{H}$ ratio in $153 \mathrm{P}$ is thus not excluded. In addition, marginal detections or upper limits obtained on some of these comets suggest that $\mathrm{CH}_{3} \mathrm{CN}, \mathrm{HC}_{3} \mathrm{~N}$, OCS, $\mathrm{HNCO}, \mathrm{SO}$ and $\mathrm{HCOOH}$ may have been particularly abundant in comet Hale-Bopp.

The four comets studied in this paper were observed at several times to investigate the heliocentric evolution of 
molecular production rates. A few interesting results need to be emphasized:

- We confirm the heliocentric variation of the CS/HCN abundance ratio in $r_{\mathrm{h}}^{-0.7}$ observed in Hyakutake and Hale-Bopp from observations of $153 \mathrm{P}$ in the range $r_{\mathrm{h}}=0.5-1.2 \mathrm{AU}$.

- The monitoring of $\mathrm{HNC} / \mathrm{HCN}$ in $153 \mathrm{P}$ and $\mathrm{C} / 2001 \mathrm{~A} 2$ shows that this ratio is strongly $r_{\mathrm{h}}$-dependent $\left(\approx r_{\mathrm{h}}^{-2.5}\right.$ on average). All measurements obtained so far are consistent with $\mathrm{HNC} / \mathrm{HCN} \approx 6 \%$ at $1 \mathrm{AU}$, the exception being comet Hale-Bopp $(\approx 15 \%$ at $1 \mathrm{AU})$. Chemical processing in the coma was proposed to explain the same heliocentric trend observed in comet Hale-Bopp, but is inefficient in these less active comets (Rodgers \& Charnley 1998). The HNC/HCN abundance in the coma seems related both to the heliocentric distance and (to a lesser extent) to the gas or dust production rate of the comet.

- We measure a factor of $\approx 2$ decrease of the $\mathrm{CH}_{3} \mathrm{OH}$ and $\mathrm{CO}$ abundances relative to $\mathrm{HCN}$ in $153 \mathrm{P}$ from 1.0 to $0.5 \mathrm{AU}$ from the Sun. This was observed in comet Hyakutake and in C/2002 X5 (Kudo-Fujikawa) (Biver et al. 2003). However, at least part of this trend may be due to enhanced production of $\mathrm{HCN}$ at small heliocentric distances due to an extra source of $\mathrm{CN}$-bearing species (since the $\mathrm{HCN} / \mathrm{CH}_{3} \mathrm{CN}$ does not vary).

The improvement of telescope sensitivity should further help in making extensive chemical investigations of comets. This will provide a more comprehensive view of the chemical composition and diversity of Solar System comets.

Acknowledgements. We are grateful to the IRAM, CSO, Kitt-Peak and SEST staff and to other observers for their assistance during the observations. IRAM is an international institute co-funded by the Centre National de la recherche scientifique (CNRS), the Max Planck Gesellschaft and the Instituto Geográfico Nacional, Spain. The CSO is supported by National Science Foundation grant AST 99-80846. The SEST was operated jointly by the Swedish National Facility for Radio Astronomy and by the European Southern Observatory. The Kitt Peak $12 \mathrm{~m}$ telescope is operated by the Arizona Radio Observatory (ARO), Steward Observatory, the University of Arizona and with partial funding from the Research Corporation. This research has been supported by the CNRS and the Programme national de planétologie de l'Institut des sciences de l'univers et de l'environnement (INSUE). N. Biver was also supported by a contract from the European Space Agency during part of the program. M. Womack acknowledges support from the NSF CAREER program and NASA Planetary Astronomy program.

\section{References}

Altwegg, K., \& Bockelée-Morvan, D. 2003, SSRv, 106, 139

Balsiger, H., Altwegg, K., \& Geiss, J. 1995, JGR, 100, 5827

Bensch, F., Bergin, E. A., Bockelée-Morvan, D., Melnick, G. J., \& Biver, N. 2004, ApJ, 609, 1164

Bergin, E. A., Neufeld, D. A., Kleiner, S. C., et al. 2000, IAU Circ., 7596

Biver, N. 1997, Ph.D. Thesis, Paris-7 University

Biver, N., Bockelée-Morvan, D., Crovisier, J., et al. 1999a, AJ, 118, 1850

Biver, N., Bockelée-Morvan, D., Colom, P., et al. 1999b, Earth, Moon, and Planets, 78, 5
Biver, N., Bockelée-Morvan, D., Crovisier, J., et al. 2000, AJ, 120, 1554

Biver, N., Bockelée-Morvan, D., Croviser, J., et al. 2002, Earth Moon and Planets, 90, 323

Biver, N., Bockelée-Morvan, D., Crovisier, J., et al. 2003, BAAS, 35, 968

Biver, N., Bockelée-Morvan, D., Crovisier, J., et al. 2006, Planet. Space Sci., submitted

Bockelée-Morvan, D., Gautier, D., Lis, D. C., et al. 1998, Icarus, 133, 147

Bockelée-Morvan, D., Lis, D. C., Wink, J. E., et al. 2000, A\&A, 353, 1101

Bockelée-Morvan, D., Biver, N., Moreno, R., et al. 2001, Science, 292, 1339

Bockelée-Morvan, D., Crovisier, J., Mumma, M. J., \& Weaver H. A. 2004, in Comets II, ed. M. C. Festou, H. U. Keller, \& H. A. Weaver (Univ. of Arizona Press), 391

Colom, P., Biver, N., Crovisier, J., et al. 2004, in SF2A, Scientific Highlights 2004, ed. F. Combes, et al. (EDP Sciences), 69

Combi, M. R., Harris, W. M., \& Smyth, W. H. 2004, in Comets II, ed. M. C. Festou, H. U. Keller, \& H. A. Weaver (Univ. of Arizona Press), 523

Crovisier, J. 1989, A\&A, 213, 459

Crovisier, J. 1994, J. Geophys. Res., 99-E2, 3777

Crovisier, J., Colom, P., Gérard, E., et al. 2002, Asteroids, Comets, Meteors, ESA SP-500, 685

Crovisier, J., Bockelée-Morvan, D., Colom, P., et al. 2005, A\&A, 418, 1141

Dello Russo, N., DiSanti, M. A., Magee-Sauer, K., et al. 2004, Icarus, 168,186

Dello Russo, N., Bonev, B. P., DiSanti, M. A., et al. 2005, ApJ, 621, 537

DiSanti, M. A., Dello Russo, N., Magee-Sauer, K., et al. 2002, Asteroids, Comets, Meteors, ESA SP-500, 571

Duncan, M., Levison, H., \& Dones, L. 2004, in Comets II, ed. M. C. Festou, H. U. Keller, \& H. A. Weaver (Univ. of Arizona Press), 193

Eberhardt, P., Reber, M., Krankowsky, D., \& Hodges, R. R. 1995, A\&A, 302, 301

Feldman, P. D., Festou, M. C., A'Hearn, M. F., et al. 1987, A\&A, 187, 325

Feldman, P. D., Weaver, H. A., \& Burgh, E. B. 2002, ApJ, 576, 91

Gail, H.-P. 2002, A\&A, 390, 253

Gibb, E. L., Mumma, M. J., Disanti, M. A., Dello Russo, N., \& Magee-Sauer, K. 2002, in Asteroids, Comets, Meteors, ESA SP-500, 705

Gibb, E. L., Mumma, M. J., Dello Russo, N., DiSanti, M. A., \& Magee-Sauer, K. 2003, Icarus, 165, 391

Green, D. W. E. 2000, IAU Circ., 7546

Hasegawa, I., \& Nakano, S. 2003, MNRAS, 345, 883

Hersant, F., Gautier, D., \& Huré, J. 2001, ApJ, 554, 391

Hjalmarson, Å., Bergman, P., Biver, N., et al. 2005, Adv. Space Res., 36,1031

Iro, N., Gautier, D., Hersant, F., Bockelée-Morvan, D., \& Lunine, J. I. 2003, Icarus, 161, 511

Irvine, W. M., Bockelée-Morvan, D., Lis, D. C., et al. 1996, Nature, 383,418

Irvine, W. M., Dickens, J. E., Lovell, A. J., et al. 1999, Earth Moon and Planets, 78, 29

Irvine, W. M., Senay, M., Lovell, A. J., et al. 2000, Icarus, 143, 412

Irvine, W. M., Bergman, P., Lowe, T. B., et al. 2003, Origins of Life and Evolution of the Biosphere, 33, 609

Jehin, E., Boehnhardt, H., Sekanina, Z., et al. 2002, Earth, Moon and Planets, 90, 147 
Kim, S. J., Bockelée-Morvan, D., Crovisier, J., \& Biver, N. 1999, Earth, Moon, and Planets, 78, 65

Lecacheux, A., Biver, N., Crovisier, J., et al. 2003, A\&A, 402, L55

Lis, D. C., Keene, J., Young, K., et al. 1997, Icarus, 130, 355

Magee-Sauer, K., Mumma, M. J., Dello Russo, N., et al. 2003, BAAS, 35, 987

Marsden, B. G., \& Nakano, S. 2002, IAU Circ., 7843

McNaught, R. H., \& Hartley, M. 1999, IAU Circ., 7273

Meier, R., \& A'Hearn, M. F. 1997, Icarus, 125, 164

Meier, R., Owen, T. C., Matthews, H. E., et al. 1998, Science, 279, 842

Müller, H. S. P., Schlöder, F., Stutzki, J., \& Winnewisser, G. 2005, J. Mol. Struct., 742, 215
Mumma, M. J., DiSanti, M. A., Dello Russo, N., et al. 2002, in Asteroids, Comets, and Meteors, ESA SP-500, 753

Nakano, S., \& Zhu, J. 2002, IAU Circ., 7812

Pickett, H. M., Poynter, R. L., Cohen, E. A., et al. 1998, J. Quant. Spectrosc. Rad. Transfer, 60, 883

Rodgers, S. D., \& Charnley, S. B. 1998, ApJ, 501, L227

Rodgers, S. D., \& Charnley, S. B. 2001, MNRAS, 323, 84

Sekanina, Z., Jehin, E., Boehnhardt, H., et al. 2002, ApJ, 572, 679

Snyder, L. E., Veal, J. M., Woodney, L. M., et al. 2001, AJ, 121, 1147

Weaver, H. A., Feldman, P. D., A'Hearn, M. F., et al. 2003, BAAS, 35, 968 
N. Biver et al.: Comets C/1999 T1, C/2001 A2, C/2000 $\mathrm{WM}_{1}$ and 153P, Online Material p 1

\section{Online Material}


N. Biver et al.: Comets C/1999 T1, C/2001 A2, C/2000 $\mathrm{WM}_{1}$ and 153P, Online Material p 2

Table 1. Line frequencies and average beam sizes (HPBW).

\begin{tabular}{|c|c|c|c|c|c|}
\hline \multirow[t]{2}{*}{ Line } & \multirow[t]{2}{*}{ Transition } & \multirow{2}{*}{$\begin{array}{c}\text { Freq. } \\
{[\mathrm{GHz}]}\end{array}$} & \multicolumn{3}{|c|}{ IRAM CSO KPNO } \\
\hline & & & {$\left[{ }^{\prime \prime}\right]$} & {$\left[{ }^{\prime \prime}\right]$} & {$\left[{ }^{\prime \prime}\right]$} \\
\hline $\mathrm{HCN}^{*}$ & $1-0$ & 88.632 & 26.6 & - & \\
\hline $\mathrm{CH}_{3} \mathrm{OH}$ & $3_{0}-2_{0} E$ & 145.094 & 17.0 & - & 41 \\
\hline $\mathrm{CH}_{3} \mathrm{OH}$ & $3_{-1}-2_{-1} E$ & 145.097 & 17.0 & - & 41 \\
\hline $\mathrm{CH}_{3} \mathrm{OH}$ & $3_{0}-2{ }_{0} A^{+}$ & 145.103 & 17.0 & - & 41 \\
\hline $\mathrm{CH}_{3} \mathrm{OH}$ & $3_{2}-2{ }_{2} E$ & 145.126 & 17.0 & - & 41 \\
\hline $\mathrm{HC}_{3} \mathrm{~N}$ & $16-15$ & 145.561 & 16.8 & - & \\
\hline OCS & $12-11$ & 145.947 & 16.8 & - & \\
\hline CS & $3-2$ & 146.969 & 16.6 & - & 40 \\
\hline $\mathrm{CH}_{3} \mathrm{CN}$ & $8_{3}-7_{3}$ & 147.149 & 16.6 & - & 40 \\
\hline $\mathrm{CH}_{3} \mathrm{CN}$ & $8_{2}-7_{2}$ & 147.163 & 16.6 & - & 40 \\
\hline $\mathrm{CH}_{3} \mathrm{CN}$ & $8_{1}-7_{1}$ & 147.172 & 16.6 & - & 40 \\
\hline $\mathrm{CH}_{3} \mathrm{CN}$ & $8_{0}-7_{0}$ & 147.175 & 16.6 & - & 40 \\
\hline $\mathrm{H}_{2} \mathrm{CO}$ & $2_{11}-1_{10}$ & 150.498 & & - & 39 \\
\hline $\mathrm{CH}_{3} \mathrm{OH}$ & $7_{0}-7_{-1} E$ & 156.828 & 15.4 & - & 38 \\
\hline $\mathrm{CH}_{3} \mathrm{OH}$ & $6_{0}-6_{-1} E$ & 157.049 & 15.4 & - & 38 \\
\hline $\mathrm{CH}_{3} \mathrm{OH}$ & $5_{0}-5_{-1} E$ & 157.179 & 15.4 & - & 38 \\
\hline $\mathrm{CH}_{3} \mathrm{OH}$ & $4_{0}-4_{-1} E$ & 157.246 & 15.4 & - & 38 \\
\hline $\mathrm{CH}_{3} \mathrm{OH}$ & $3_{0}-3_{-1} E$ & 157.270 & 15.4 & - & 38 \\
\hline $\mathrm{CH}_{3} \mathrm{OH}$ & $1_{0}-1_{-1} E$ & 157.272 & 15.4 & - & 38 \\
\hline $\mathrm{CH}_{3} \mathrm{OH}$ & $2_{0}-2_{-1} E$ & 157.276 & 15.4 & - & 38 \\
\hline $\mathrm{H}_{2} \mathrm{~S}$ & $1_{10}-1_{01}$ & 168.763 & 14.4 & - & 35 \\
\hline $\mathrm{HNCO}$ & $10_{0,10}-9_{0,9}$ & 219.798 & 11.0 & & \\
\hline $\mathrm{SO}$ & $N_{J}=6_{5}-5_{4}$ & 219.949 & 11.0 & & \\
\hline $\mathrm{HCOOH}$ & $10_{0,10}-9_{0,9}$ & 220.038 & 11.0 & & \\
\hline $\mathrm{CH}_{3} \mathrm{OH}$ & $8_{0}-7_{1} E$ & 220.078 & 11.0 & & \\
\hline $\mathrm{H}_{2} \mathrm{CO}$ & $3_{12}-2_{11}$ & 225.697 & 10.9 & 31 & \\
\hline $\mathrm{CO}$ & $2-1$ & 230.538 & 10.7 & 30.5 & \\
\hline $\mathrm{CH}_{3} \mathrm{OH}$ & $5_{0}-4_{0} E$ & 241.700 & 10.2 & 29 & \\
\hline $\mathrm{CH}_{3} \mathrm{OH}$ & $5_{-1}-4_{-1} E$ & 241.767 & 10.2 & 29 & \\
\hline $\mathrm{CH}_{3} \mathrm{OH}$ & $5_{0}-4_{0} A^{+}$ & 241.791 & 10.2 & 29 & \\
\hline $\mathrm{CH}_{3} \mathrm{OH}$ & $5_{1}-4_{1} E$ & 241.879 & 10.2 & 29 & \\
\hline $\mathrm{CH}_{3} \mathrm{OH}$ & $5_{2}-4_{2} A^{+}$ & 241.888 & 10.2 & 29 & \\
\hline $\mathrm{CH}_{3} \mathrm{OH}$ & $5_{2}-4_{E}$ & 241.905 & 10.2 & 29 & \\
\hline $\mathrm{CS}$ & $5-4$ & 244.936 & 10.0 & 28.5 & \\
\hline $\mathrm{CH}_{3} \mathrm{OH}$ & $9_{3}-9_{2} A^{-+}$ & 251.360 & 9.8 & 28 & \\
\hline $\mathrm{CH}_{3} \mathrm{OH}$ & $8_{3}-8_{2} A^{-+}$ & 251.517 & 9.8 & 28 & \\
\hline $\mathrm{CH}_{3} \mathrm{OH}$ & $7_{3}-7_{2} A^{-+}$ & 251.642 & 9.8 & 28 & \\
\hline $\mathrm{CH}_{3} \mathrm{OH}$ & $6_{3}-6_{2} A^{-+}$ & 251.738 & 9.8 & 28 & \\
\hline $\mathrm{CH}_{3} \mathrm{OH}$ & $5_{3}-5_{2} A^{-+}$ & 251.812 & 9.8 & 28 & \\
\hline $\mathrm{SO}$ & $N_{J}=5_{6}-4_{5}$ & 251.826 & 9.8 & 28 & \\
\hline $\mathrm{CH}_{3} \mathrm{OH}$ & $4_{3}-4_{2} A^{-+}$ & 251.867 & 9.8 & 28 & \\
\hline $\mathrm{CH}_{3} \mathrm{OH}$ & $5_{3}-5_{2} A^{+-}$ & 251.891 & 9.8 & 28 & \\
\hline $\mathrm{CH}_{3} \mathrm{OH}$ & $6_{3}-6_{2} A^{+-}$ & 251.896 & 9.8 & 28 & \\
\hline $\mathrm{CH}_{3} \mathrm{OH}$ & $4_{3}-4_{2} A^{+-}$ & 251.900 & 9.8 & 28 & \\
\hline $\mathrm{CH}_{3} \mathrm{OH}$ & $3_{3}-3_{2} A^{-+}$ & 251.906 & 9.8 & 28 & \\
\hline $\mathrm{CH}_{3} \mathrm{OH}$ & $3_{3}-3_{2} A^{+-}$ & 251.917 & 9.8 & 28 & \\
\hline $\mathrm{CH}_{3} \mathrm{OH}$ & $7_{3}-7_{2} A^{+-}$ & 251.924 & 9.8 & 28 & \\
\hline $\mathrm{CH}_{3} \mathrm{OH}$ & $8_{3}-8_{2} A^{+-}$ & 251.985 & 9.8 & 28 & \\
\hline $\mathrm{CH}_{3} \mathrm{OH}$ & $9_{3}-9_{2} A^{+-}$ & 252.090 & 9.8 & 28 & \\
\hline $\mathrm{CH}_{3} \mathrm{OH}$ & $10_{3}-10_{2} A^{+-}$ & 252.253 & 9.8 & 28 & \\
\hline NS & $11 / 2-9 / 2 e$ & 253.571 & 9.7 & & \\
\hline NS & $11 / 2-9 / 2 f$ & 253.969 & 9.7 & & \\
\hline $\mathrm{CH}_{3} \mathrm{OH}$ & $2_{0}-1_{-1} E$ & 254.015 & 9.7 & & \\
\hline $\mathrm{HC}_{3} \mathrm{~N}$ & $28-27$ & 254.700 & & 27.5 & \\
\hline $\mathrm{HCN}^{*}$ & $3-2$ & 265.886 & 9.4 & 26.5 & 22.5 \\
\hline HNC & $3-2$ & 271.981 & 9.3 & 25.9 & - \\
\hline
\end{tabular}

Table 1. continued.

\begin{tabular}{llrccc}
\hline \hline Line & Transition & \multicolumn{3}{c}{ Freq. } & \multicolumn{3}{c}{ IRAM CSO KPNO } \\
& & {$[\mathrm{GHz}]$} & {$\left[{ }^{\prime \prime}\right]$} & {$\left[{ }^{\prime \prime}\right]$} & {$\left[{ }^{\prime}\right]$} \\
\hline $\mathrm{CH}_{3} \mathrm{OH}$ & $21_{1}-2_{0} A^{-+}$ & 304.208 & - & 23.0 & - \\
$\mathrm{CH}_{3} \mathrm{OH}$ & $4_{1}-4_{0} A^{-+}$ & 307.166 & - & 22.8 & - \\
$\mathrm{CS}$ & $7-6$ & 342.883 & - & 20.6 & - \\
$\mathrm{CO}$ & $3-2$ & 345.796 & - & 20.4 & - \\
$\mathrm{H}_{2} \mathrm{CO}$ & $5_{15}-4_{14}$ & 351.769 & - & 20.0 & - \\
$\mathrm{HCN}$ & $4-3$ & 354.505 & - & 19.8 & - \\
$\mathrm{HDO}$ & $1_{10}-1_{01}$ & 509.292 & - & 14.0 & - \\
\hline
\end{tabular}

Notes: frequencies are from Müller et al. (2005) or Pickett et al. (1998) (see text).

"-_" Means that this telescope is not equiped to observe this line.

* The SEST beam sizes at 89 and $266 \mathrm{GHz}$ are 54" and 18.5" respectively. 
Table 2. Molecular observations in comet C/1999 T1 (McNaught-Hartley).

\begin{tabular}{|c|c|c|c|c|c|c|c|}
\hline $\begin{array}{c}\text { UT date } \\
{[\mathrm{mm} / \mathrm{dd} . \mathrm{dd}-\text { dd.dd }]}\end{array}$ & $\begin{array}{l}\left\langle r_{\mathrm{h}}\right\rangle \\
{[\mathrm{AU}]}\end{array}$ & $\begin{array}{c}\langle\Delta\rangle \\
{[\mathrm{AU}]}\end{array}$ & $\begin{array}{r}\text { Int. time } \\
\text { [min] }\end{array}$ & Species (transition) & $\begin{array}{c}\int T_{b} \mathrm{~d} v \\
{\left[\mathrm{~K} \mathrm{~km} \mathrm{~s}^{-1}\right]}\end{array}$ & $\begin{array}{c}\text { Velocity offset } \\
{\left[\mathrm{km} \mathrm{s}^{-1}\right]}\end{array}$ & Offset \\
\hline SEST $15 \mathrm{~m}:$ & \multicolumn{7}{|c|}{ September 2000: } \\
\hline $09 / 28.64-30.74$ & 1.641 & 2.056 & 280 & $\mathrm{HCN}(3-2)$ & $0.136 \pm 0.018$ & $-0.27 \pm 0.10$ & $4^{\prime \prime}$ \\
\hline $09 / 28.64-30.74$ & 1.641 & 2.056 & 280 & $\mathrm{HCN}(1-0)$ & $<0.021$ & & $4^{\prime \prime}$ \\
\hline IRAM $30 \mathrm{m:}$ & \multicolumn{7}{|c|}{ January-February 2001: } \\
\hline $01 / 24.46-24.53$ & 1.345 & 1.303 & 60 & $\mathrm{HCN}(3-2)$ & $0.575 \pm 0.085$ & $-0.01 \pm 0.08$ & $4.7^{\prime \prime}$ \\
\hline $01 / 24.46-33.50$ & 1.398 & 1.288 & 720 & $\mathrm{HCN}(1-0)$ & $0.063 \pm 0.006$ & $-0.08 \pm 0.06$ & $5.1^{\prime \prime}$ \\
\hline $01 / 24.46-33.50$ & 1.395 & 1.291 & 500 & $\mathrm{CO}(2-1)$ & $0.058 \pm 0.007$ & $+0.07 \pm 0.06$ & $5.1^{\prime \prime}$ \\
\hline \multirow[t]{7}{*}{$01 / 24.46-33.50$} & 1.400 & 1.287 & 500 & $\mathrm{CH}_{3} \mathrm{OH}(1,0-1,-1) \mathrm{E}$ & $0.033 \pm 0.008$ & $-0.41 \pm 0.17$ & $5.1^{\prime \prime}$ \\
\hline & & & & $\mathrm{CH}_{3} \mathrm{OH}(2,0-2,-1) \mathrm{E}$ & $0.029 \pm 0.008$ & $-0.35 \pm 0.18$ & \\
\hline & & & & $\mathrm{CH}_{3} \mathrm{OH}(3,0-3,-1) \mathrm{E}$ & $0.058 \pm 0.008$ & $-0.13 \pm 0.08$ & \\
\hline & & & & $\mathrm{CH}_{3} \mathrm{OH}(4,0-4,-1) \mathrm{E}$ & $0.045 \pm 0.007$ & $-0.04 \pm 0.10$ & \\
\hline & & & & $\mathrm{CH}_{3} \mathrm{OH}(5,0-5,-1) \mathrm{E}$ & $0.040 \pm 0.006$ & $-0.34 \pm 0.11$ & \\
\hline & & & & $\mathrm{CH}_{3} \mathrm{OH}(6,0-6,-1) \mathrm{E}$ & $0.033 \pm 0.007$ & $-0.07 \pm 0.12$ & \\
\hline & & & & $\mathrm{CH}_{3} \mathrm{OH}(7,0-7,-1) \mathrm{E}$ & $0.028 \pm 0.006$ & $+0.06 \pm 0.11$ & \\
\hline $01 / 25.48-25.51$ & 1.352 & 1.300 & 35 & $\mathrm{HCN}(3-2)$ & $0.380 \pm 0.148$ & & $5.0^{\prime \prime 1}$ \\
\hline $01 / 26.31-26.50$ & 1.359 & 1.297 & 160 & $\mathrm{HCN}(3-2)$ & $0.425 \pm 0.083$ & $-0.11 \pm 0.11$ & $5.5^{\prime \prime 1}$ \\
\hline $01 / 31.16-31.28$ & 1.398 & 1.288 & 95 & $\mathrm{HCN}(3-2)$ & $0.433 \pm 0.026$ & $+0.09 \pm 0.04$ & $5.0^{\prime \prime}$ \\
\hline $01 / 31.16-32.48$ & 1.405 & 1.287 & 330 & $\mathrm{HNC}(3-2)$ & $<0.076$ & & $5.1^{\prime \prime}$ \\
\hline $01 / 31.16-32.48$ & 1.403 & 1.287 & 330 & $\mathrm{H}_{2} \mathrm{~S}\left(1_{10}-1_{01}\right)$ & $0.081 \pm 0.012$ & $-0.13 \pm 0.08$ & $5.0^{\prime \prime}$ \\
\hline $02 / 01.20-01.29$ & 1.406 & 1.287 & 80 & $\mathrm{CS}(3-2)$ & $<0.047$ & & $5.1^{\prime \prime}$ \\
\hline $02 / 01.20-02.50$ & 1.412 & 1.287 & 205 & $\mathrm{CS}(5-4)$ & $0.083 \pm 0.010$ & $+0.10 \pm 0.07$ & $5.2^{\prime \prime}$ \\
\hline $02 / 01.20-01.29$ & 1.406 & 1.287 & 80 & $\mathrm{H}_{2} \mathrm{CO}\left(3_{12}-2_{11}\right)$ & $0.053 \pm 0.010$ & $+0.06 \pm 0.13$ & $5.1^{\prime \prime}$ \\
\hline $02 / 01.20-01.29$ & 1.406 & 1.287 & 80 & $\mathrm{CH}_{3} \mathrm{CN}(8,0+8,1+8,2)$ & $<0.076$ & & $5.1^{\prime \prime}$ \\
\hline $02 / 02.20-02.34$ & 1.415 & 1.287 & 120 & $\mathrm{HCN}(3-2)$ & $0.266 \pm 0.020$ & $+0.15 \pm 0.05$ & $4.7^{\prime \prime}$ \\
\hline CSO $10 \mathrm{~m}:$ & \multicolumn{7}{|c|}{ January-February 2001: } \\
\hline $01 / 05.60-05.65$ & 1.227 & 1.419 & 42.7 & $\mathrm{HCN}(3-2)$ & $0.186 \pm 0.023$ & $-0.06 \pm 0.11$ & $6.7^{\prime \prime}$ \\
\hline $01 / 05.66-05.72$ & 1.228 & 1.417 & 58.7 & $\mathrm{CO}(3-2)$ & $0.154 \pm 0.024$ & $+0.06 \pm 0.11$ & $6.0^{\prime \prime}$ \\
\hline $01 / 05.66-05.72$ & 1.228 & 1.417 & 58.7 & $\operatorname{CS}(7-6)$ & $0.079 \pm 0.025$ & $-0.24 \pm 0.23$ & $6.0^{\prime \prime}$ \\
\hline 01/06.59-06.62 & 1.232 & 1.410 & 32.0 & $\mathrm{HCN}(3-2)$ & $0.240 \pm 0.025$ & $-0.02 \pm 0.07$ & $5.5^{\prime \prime}$ \\
\hline \multirow[t]{2}{*}{$01 / 06.63-06.71$} & 1.233 & 1.410 & 72.0 & $\mathrm{CH}_{3} \mathrm{OH}(2,1-2,0) \mathrm{A}-+$ & $0.165 \pm 0.018$ & $-0.04 \pm 0.05$ & $5.5^{\prime \prime}$ \\
\hline & & & & $\mathrm{CH}_{3} \mathrm{OH}(4,1-4,0) \mathrm{A}-+$ & $0.220 \pm 0.018$ & $-0.14 \pm 0.08$ & $5.5^{\prime \prime}$ \\
\hline 01/07.61-07.68 & 1.238 & 1.402 & 64.0 & $\mathrm{HNC}(3-2)$ & $<0.075$ & & $5.7^{\prime \prime}$ \\
\hline \multirow[t]{4}{*}{ 01/07.69-07.71 } & 1.238 & 1.401 & 16.0 & $\mathrm{CH}_{3} \mathrm{OH}(5,0-4,0) \mathrm{A}+$ & $0.175 \pm 0.026$ & $-0.16 \pm 0.10$ & $5.7^{\prime \prime}$ \\
\hline & & & & $\mathrm{CH}_{3} \mathrm{OH}(5,-1-4,-1) \mathrm{E}$ & $0.080 \pm 0.026$ & $-0.32 \pm 0.24$ & $5.7^{\prime \prime}$ \\
\hline & & & & $\mathrm{CH}_{3} \mathrm{OH}(5,0-4,0) \mathrm{E}$ & $0.139 \pm 0.032$ & & $5.7^{\prime \prime}$ \\
\hline & & & & $\mathrm{CH}_{3} \mathrm{OH}(5,2-4,2) \mathrm{E}$ & $<0.096$ & & $5.7^{\prime \prime}$ \\
\hline 01/07.69-07.71 & 1.238 & 1.401 & 16.0 & $\operatorname{CS}(5-4)$ & $<0.078$ & & $5.7^{\prime \prime}$ \\
\hline $01 / 30.60-30.65$ & 1.393 & 1.289 & 52.0 & $\mathrm{HCN}(3-2)$ & $0.206 \pm 0.017$ & $+0.37 \pm 0.06$ & $5.0^{\prime \prime}$ \\
\hline $01 / 30.66-30.71$ & 1.393 & 1.288 & 48.0 & $\mathrm{CO}(2-1)$ & $<0.049$ & & $5.0^{\prime \prime}$ \\
\hline $02 / 04.56-08.62$ & 1.440 & 1.288 & 154. & $\mathrm{CO}(3-2)$ & $0.070 \pm 0.017$ & $+0.48 \pm 0.20$ & $5.8^{\prime \prime}$ \\
\hline $02 / 04.56-08.62$ & 1.440 & 1.288 & 154. & $\operatorname{CS}(7-6)$ & $0.087 \pm 0.018$ & $-0.16 \pm 0.13$ & $5.8^{\prime \prime}$ \\
\hline $02 / 05.58-05.64$ & 1.444 & 1.288 & 50.7 & $\mathrm{HCN}(3-2)$ & $0.180 \pm 0.020$ & $-0.08 \pm 0.07$ & $6.0^{\prime \prime}$ \\
\hline $02 / 05.65-05.70$ & 1.444 & 1.288 & 53.3 & $\mathrm{HCN}(4-3)$ & $0.226 \pm 0.032$ & $-0.06 \pm 0.09$ & $6.0^{\prime \prime}$ \\
\hline $02 / 06.58-06.61$ & 1.452 & 1.289 & 37.3 & $\mathrm{HCN}(3-2)$ & $0.205 \pm 0.018$ & $+0.00 \pm 0.06$ & $5.8^{\prime \prime}$ \\
\hline $02 / 06.62-07.70$ & 1.457 & 1.290 & 150. & $\mathrm{HNC}(3-2)$ & $<0.018$ & & $5.9^{\prime \prime}$ \\
\hline $02 / 07.56-07.57$ & 1.461 & 1.291 & 8.0 & $\mathrm{HCN}(3-2)$ & $0.188 \pm 0.038$ & $+0.11 \pm 0.13$ & $6.0^{\prime \prime}$ \\
\hline
\end{tabular}

${ }^{1}$ Loss in efficiency due to frost on the antenna (beam degraded to $14^{\prime \prime}$ ). 
N. Biver et al.: Comets C/1999 T1, C/2001 A2, C/2000 $\mathrm{WM}_{1}$ and 153P, Online Material p 4

Table 3. Molecular observations in comet $\mathrm{C} / 2001 \mathrm{~A} 2$ (LINEAR).

\begin{tabular}{|c|c|c|c|c|c|c|c|}
\hline $\begin{array}{c}\text { UT date (2001) } \\
\text { [mm/dd.dd-dd.dd] }\end{array}$ & $\begin{array}{l}\left\langle r_{\mathrm{h}}\right\rangle \\
{[\mathrm{AU}]}\end{array}$ & $\begin{array}{l}\langle\Delta\rangle \\
{[\mathrm{AU}]}\end{array}$ & $\begin{array}{r}\text { Int. time } \\
\text { [min] }\end{array}$ & Species (transition) & $\begin{array}{c}\int T_{b} \mathrm{~d} v \\
{\left[\mathrm{~K} \mathrm{~km} \mathrm{~s}^{-1}\right]}\end{array}$ & $\begin{array}{c}\text { Velocity offset } \\
{\left[\mathrm{km} \mathrm{s}^{-1}\right]}\end{array}$ & Offset \\
\hline Kitt Peak 12 m: & \multicolumn{7}{|c|}{ June 2001: } \\
\hline $06 / 05.71-05.77$ & 0.815 & 0.419 & 60 & $\mathrm{H}_{2} \mathrm{~S}\left(1_{10}-1_{01}\right)$ & $0.114 \pm 0.018$ & $-0.04 \pm 0.10$ & $3^{\prime \prime}$ \\
\hline 06/05.79-05.87 & 0.816 & 0.418 & 84 & $\mathrm{CS}(3-2)$ & $0.167 \pm 0.015$ & $+0.50 \pm 0.11$ & $6^{\prime \prime}$ \\
\hline \multirow[t]{4}{*}{$06 / 11.71-11.87$} & 0.855 & 0.355 & 174 & $\mathrm{CH}_{3} \mathrm{OH}(1,0-1,-1) \mathrm{E}$ & $0.059 \pm 0.022$ & $0.0 \pm 0.0$ & $11^{\prime \prime}$ \\
\hline & & & & $\mathrm{CH}_{3} \mathrm{OH}(2,0-2,-1) \mathrm{E}$ & $0.094 \pm 0.024$ & $0.0 \pm 0.0$ & \\
\hline & & & & $\mathrm{CH}_{3} \mathrm{OH}(3,0-3,-1) \mathrm{E}$ & $0.114 \pm 0.020$ & $0.0 \pm 0.0$ & \\
\hline & & & & $\mathrm{CH}_{3} \mathrm{OH}(4,0-4,-1) \mathrm{E}$ & $0.158 \pm 0.027$ & $0.0 \pm 0.0$ & \\
\hline $06 / 12.71-12.75$ & 0.863 & 0.346 & 30 & $\mathrm{H}_{2} \mathrm{~S}\left(1_{10}-1_{01}\right)$ & $0.251 \pm 0.030$ & $0.06 \pm 0.08$ & $<5^{\prime \prime}$ \\
\hline $06 / 12.78-12.87$ & 0.863 & 0.345 & 66 & $\mathrm{H}_{2} \mathrm{CO}\left(2_{11}-1_{10}\right)$ & $0.074 \pm 0.014$ & $0.20 \pm 0.14$ & $5^{\prime \prime}$ \\
\hline \multirow[t]{4}{*}{$06 / 12.78-12.87$} & 0.863 & 0.345 & 66 & $\mathrm{CH}_{3} \mathrm{OH}(3,0-2,0) \mathrm{A}+$ & $0.100 \pm 0.023$ & $0.0 \pm 0.0$ & $5^{\prime \prime}$ \\
\hline & & & & $\mathrm{CH}_{3} \mathrm{OH}(3,-1-2,-1) \mathrm{E}$ & $0.094 \pm 0.023$ & $0.0 \pm 0.0$ & \\
\hline & & & & $\mathrm{CH}_{3} \mathrm{OH}(3,0-2,0) \mathrm{E}$ & $0.084 \pm 0.021$ & $0.0 \pm 0.0$ & \\
\hline & & & & $\mathrm{CH}_{3} \mathrm{OH}(3,2-2,2) \mathrm{E}$ & $0.055 \pm 0.024$ & $0.0 \pm 0.0$ & \\
\hline CSO $10 \mathrm{m:}$ & \multicolumn{7}{|c|}{ June 2001: } \\
\hline $06 / 16.66-16.67$ & 0.897 & 0.310 & 18.7 & $\mathrm{HCN}(3-2)$ & $2.095 \pm 0.070$ & $+0.10 \pm 0.03$ & $2.5^{\prime \prime}$ \\
\hline 06/17.64-19.68 & 0.916 & 0.294 & 104. & $\mathrm{HNC}(3-2)$ & $0.138 \pm 0.020$ & $+0.12 \pm 0.12$ & $2.5^{\prime \prime}$ \\
\hline 06/18.63-18.64 & 0.916 & 0.294 & 16.0 & $\mathrm{HCN}(3-2)$ & $1.430 \pm 0.060$ & $+0.08 \pm 0.03$ & $2.5^{\prime \prime}$ \\
\hline 06/19.63-19.64 & 0.926 & 0.286 & 9.3 & $\operatorname{HCN}(3-2)$ & $1.520 \pm 0.110$ & $+0.06 \pm 0.06$ & $2.5^{\prime \prime}$ \\
\hline IRAM 30 m: & \multicolumn{7}{|c|}{ July 2001: } \\
\hline $07 / 08.19-08.20$ & 1.143 & 0.267 & 10 & $\mathrm{HCN}(3-2)$ & $2.530 \pm 0.105$ & $+0.01 \pm 0.02$ & $4.2^{\prime \prime}$ \\
\hline 07/08.19-08.34 & 1.144 & 0.267 & 100 & $\operatorname{HCN}(1-0)$ & $0.209 \pm 0.013$ & $-0.07 \pm 0.03$ & $4.2^{\prime \prime}$ \\
\hline 07/08.19-08.34 & 1.144 & 0.267 & 100 & $\mathrm{CO}(2-1)$ & $<0.076$ & & $4.2^{\prime \prime}$ \\
\hline \multirow[t]{7}{*}{ 07/08.19-08.27 } & 1.144 & 0.267 & 60 & $\mathrm{CH}_{3} \mathrm{OH}(1,0-1,-1) \mathrm{E}$ & $0.060 \pm 0.013$ & $-0.36 \pm 0.12$ & $4.2^{\prime \prime}$ \\
\hline & & & & $\mathrm{CH}_{3} \mathrm{OH}(2,0-2,-1) \mathrm{E}$ & $0.194 \pm 0.013$ & $-0.01 \pm 0.04$ & \\
\hline & & & & $\mathrm{CH}_{3} \mathrm{OH}(3,0-3,-1) \mathrm{E}$ & $0.202 \pm 0.013$ & $-0.10 \pm 0.03$ & \\
\hline & & & & $\mathrm{CH}_{3} \mathrm{OH}(4,0-4,-1) \mathrm{E}$ & $0.207 \pm 0.014$ & $-0.09 \pm 0.03$ & \\
\hline & & & & $\mathrm{CH}_{3} \mathrm{OH}(5,0-5,-1) \mathrm{E}$ & $0.194 \pm 0.014$ & $-0.09 \pm 0.03$ & \\
\hline & & & & $\mathrm{CH}_{3} \mathrm{OH}(6,0-6,-1) \mathrm{E}$ & $0.195 \pm 0.013$ & $-0.11 \pm 0.03$ & \\
\hline & & & & $\mathrm{CH}_{3} \mathrm{OH}(7,0-7,-1) \mathrm{E}$ & $0.158 \pm 0.013$ & $-0.05 \pm 0.04$ & \\
\hline 07/08.21-10.35 & 1.157 & 0.274 & 355 & $\mathrm{HNC}(3-2)$ & $0.098 \pm 0.017$ & $+0.29 \pm 0.10$ & $4.3^{\prime \prime}$ \\
\hline 07/08.30-08.34 & 1.145 & 0.268 & 40 & $\mathrm{H}_{2} \mathrm{~S}\left(1_{10}-1_{01}\right)$ & $0.926 \pm 0.036$ & $-0.06 \pm 0.02$ & $4.2^{\prime \prime}$ \\
\hline 07/09.17-09.33 & 1.157 & 0.274 & 140 & $\operatorname{HCN}(1-0)$ & $0.270 \pm 0.011$ & $-0.04 \pm 0.02$ & $4.3^{\prime \prime}$ \\
\hline \multirow[t]{3}{*}{ 07/09.17-09.33 } & 1.157 & 0.274 & 140 & $\mathrm{CH}_{3} \mathrm{CN}(8,0-7,0)$ & $0.041 \pm 0.008$ & $+0.07 \pm 0.09$ & $4.3^{\prime \prime}$ \\
\hline & & & & $\mathrm{CH}_{3} \mathrm{CN}(8,1-7,1)$ & $0.040 \pm 0.008$ & $+0.11 \pm 0.10$ & \\
\hline & & & & $\mathrm{CH}_{3} \mathrm{CN}(8,2-7,2)$ & $0.043 \pm 0.008$ & $-0.02 \pm 0.11$ & \\
\hline 07/09.17-09.33 & 1.157 & 0.274 & 140 & $\operatorname{CS}(3-2)$ & $0.063 \pm 0.007$ & $+0.16 \pm 0.06$ & $4.3^{\prime \prime}$ \\
\hline 07/09.17-10.30 & 1.163 & 0.277 & 220 & $\mathrm{SO}\left(6_{5}-5_{4}\right)$ & $0.029 \pm 0.009$ & $+0.20 \pm 0.19$ & $4.3^{\prime \prime}$ \\
\hline 07/09.17-10.30 & 1.163 & 0.277 & 220 & $\operatorname{HNCO}\left(10_{0,10}-9_{0,9}\right)$ & $<0.029$ & & $4.3^{\prime \prime}$ \\
\hline 07/10.16-10.18 & 1.169 & 0.280 & 30 & $\mathrm{HCN}(3-2)$ & $3.015 \pm 0.050$ & $-0.05 \pm 0.04$ & $4.3^{\prime \prime}$ \\
\hline $07 / 10.16-10.35$ & 1.170 & 0.280 & 155 & $\mathrm{HCN}(1-0)$ & $0.220 \pm 0.010$ & $-0.12 \pm 0.02$ & $4.3^{\prime \prime}$ \\
\hline $07 / 10.16-10.35$ & 1.170 & 0.280 & 75 & $\mathrm{H}_{2} \mathrm{CO}\left(3_{12}-2_{11}\right)$ & $0.079 \pm 0.018$ & $+0.35 \pm 0.14$ & $4.3^{\prime \prime}$ \\
\hline 07/10.16-10.35 & 1.170 & 0.280 & 155 & OCS $(12-11)$ & $<0.018$ & & $4.3^{\prime \prime}$ \\
\hline 07/10.16-10.35 & 1.170 & 0.280 & 155 & $\mathrm{HC}_{3} \mathrm{~N}(16-15)$ & $<0.020$ & & $4.3^{\prime \prime}$ \\
\hline 07/10.21-10.30 & 1.170 & 0.280 & 80 & $\operatorname{HCOOH}\left(10_{0,10}-9_{0,9}\right)$ & $<0.036$ & & $4.3^{\prime \prime}$ \\
\hline
\end{tabular}


Table 4. Molecular observations in comet $\mathrm{C} / 2000 \mathrm{WM}_{1}$ (LINEAR).

\begin{tabular}{|c|c|c|c|c|c|c|c|}
\hline $\begin{array}{c}\text { UT date (2001) } \\
\text { [mm/dd.dd-dd.dd] }\end{array}$ & $\begin{array}{l}\left\langle r_{\mathrm{h}}\right\rangle \\
{[\mathrm{AU}]}\end{array}$ & $\begin{array}{l}\langle\Delta\rangle \\
{[\mathrm{AU}]}\end{array}$ & $\begin{array}{r}\text { Int. time } \\
\text { [min] }\end{array}$ & Species (transition) & $\begin{array}{c}\int T_{b} \mathrm{~d} v \\
{\left[\mathrm{~K} \mathrm{~km} \mathrm{~s}^{-1}\right]}\end{array}$ & $\begin{array}{c}\text { Velocity offset } \\
{\left[\mathrm{km} \mathrm{s}^{-1}\right]}\end{array}$ & $\overline{\text { Offset }}$ \\
\hline IRAM $30 \mathrm{m:}$ & \multicolumn{7}{|c|}{ November 2001: } \\
\hline $11 / 23.03-23.06$ & 1.359 & 0.387 & 35 & $\mathrm{HCN}(3-2)$ & $0.580 \pm 0.092$ & $-0.10 \pm 0.08$ & $5^{\prime \prime}$ \\
\hline $11 / 23.03-24.21$ & 1.345 & 0.376 & 320 & $\mathrm{HCN}(1-0)$ & $0.082 \pm 0.007$ & $-0.34 \pm 0.05$ & $4.5^{\prime \prime}$ \\
\hline $11 / 23.03-24.21$ & 1.344 & 0.374 & 320 & $\mathrm{H}_{2} \mathrm{CO}\left(3_{12}-2_{11}\right)$ & $0.069 \pm 0.012$ & $-0.30 \pm 0.11$ & $4.5^{\prime \prime}$ \\
\hline $11 / 23.03-27.14$ & 1.317 & 0.356 & 615 & $\mathrm{CS}(3-2)$ & $0.020 \pm 0.007$ & $-0.19 \pm 0.21$ & $5.0^{\prime \prime}$ \\
\hline \multirow[t]{7}{*}{$11 / 23.03-27.14$} & 1.317 & 0.356 & 615 & $\mathrm{CH}_{3} \mathrm{OH}(1,0-1,-1) \mathrm{E}$ & $0.029 \pm 0.004$ & $-0.37 \pm 0.09$ & $5.0^{\prime \prime}$ \\
\hline & & & & $\mathrm{CH}_{3} \mathrm{OH}(2,0-2,-1) \mathrm{E}$ & $0.032 \pm 0.004$ & $-0.49 \pm 0.09$ & \\
\hline & & & & $\mathrm{CH}_{3} \mathrm{OH}(3,0-3,-1) \mathrm{E}$ & $0.039 \pm 0.004$ & $-0.25 \pm 0.06$ & \\
\hline & & & & $\mathrm{CH}_{3} \mathrm{OH}(4,0-4,-1) \mathrm{E}$ & $0.050 \pm 0.004$ & $-0.28 \pm 0.05$ & \\
\hline & & & & $\mathrm{CH}_{3} \mathrm{OH}(5,0-5,-1) \mathrm{E}$ & $0.049 \pm 0.005$ & $-0.25 \pm 0.06$ & \\
\hline & & & & $\mathrm{CH}_{3} \mathrm{OH}(6,0-6,-1) \mathrm{E}$ & $0.037 \pm 0.004$ & $-0.23 \pm 0.07$ & \\
\hline & & & & $\mathrm{CH}_{3} \mathrm{OH}(7,0-7,-1) \mathrm{E}$ & $0.035 \pm 0.005$ & $-0.15 \pm 0.09$ & \\
\hline $11 / 23.82-24.21$ & 1.343 & 0.374 & 285 & $\mathrm{HCN}(3-2)$ & $0.689 \pm 0.014$ & $-0.16 \pm 0.01$ & $4.5^{\prime \prime}$ \\
\hline $11 / 23.98-27.14$ & 1.321 & 0.358 & 555 & $\mathrm{H}_{2} \mathrm{~S}\left(1_{10}-1_{01}\right)$ & $0.059 \pm 0.008$ & $-0.24 \pm 0.08$ & $4.7^{\prime \prime}$ \\
\hline $11 / 24.78-24.80$ & 1.330 & 0.364 & 20 & $\mathrm{HCN}(3-2)$ & $0.981 \pm 0.052$ & $-0.16 \pm 0.03$ & $4.6^{\prime \prime}$ \\
\hline $11 / 24.78-25.18$ & 1.327 & 0.362 & 275 & $\mathrm{HCN}(1-0)$ & $0.069 \pm 0.006$ & $-0.34 \pm 0.06$ & $4.9^{\prime \prime}$ \\
\hline $11 / 24.78-26.13$ & 1.330 & 0.356 & 520 & $\mathrm{CO}(2-1)$ & $<0.022$ & & 4.6" \\
\hline $11 / 24.84-26.13$ & 1.320 & 0.356 & 480 & $\mathrm{HNC}(3-2)$ & $<0.044$ & & $5.0^{\prime \prime}$ \\
\hline \multirow[t]{3}{*}{$11 / 25.75-25.79$} & 1.314 & 0.353 & 20 & $\operatorname{HCN}(3-2)$ & $0.813 \pm 0.068$ & $-0.05 \pm 0.05$ & $5.0^{\prime \prime}$ \\
\hline & & & 5 & $\operatorname{HCN}(3-2)$ & $0.777 \pm 0.136$ & $-0.39 \pm 0.11$ & $5.5^{\prime \prime}$ \\
\hline & & & 10 & $\mathrm{HCN}(3-2)$ & $0.489 \pm 0.095$ & $-0.05 \pm 0.10$ & $11.0^{\prime \prime}$ \\
\hline \multirow[t]{3}{*}{$11 / 25.75-26.02$} & 1.313 & 0.352 & 180 & $\mathrm{CH}_{3} \mathrm{CN}(8,0-7,0)$ & $0.016 \pm 0.007$ & & \\
\hline & & & & $\mathrm{CH}_{3} \mathrm{CN}(8,1-7,1)$ & $0.009 \pm 0.007$ & $-0.60 \pm 0.22$ & $5.0^{\prime \prime}$ \\
\hline & & & & $\mathrm{CH}_{3} \mathrm{CN}(8,2-7,2)$ & $0.015 \pm 0.007$ & & \\
\hline $11 / 25.75-26.13$ & 1.312 & 0.351 & 245 & $\mathrm{HCN}(1-0)$ & $0.101 \pm 0.007$ & $-0.26 \pm 0.04$ & $5.0^{\prime \prime}$ \\
\hline $11 / 26.75-26.78$ & 1.298 & 0.343 & 25 & $\operatorname{HCN}(3-2)$ & $0.957 \pm 0.066$ & $-0.27 \pm 0.05$ & $5.0^{\prime \prime}$ \\
\hline $11 / 26.75-27.14$ & 1.295 & 0.341 & 485 & $\mathrm{CS}(5-4)$ & $0.118 \pm 0.011$ & $-0.01 \pm 0.05$ & $4.7^{\prime \prime}$ \\
\hline CSO $10 \mathrm{m:}$ & \multicolumn{7}{|c|}{ December 2001: } \\
\hline $12 / 03.18-03.25$ & 1.193 & 0.317 & 48.0 & $\mathrm{HCN}(3-2)$ & $0.490 \pm 0.015$ & $-0.14 \pm 0.12$ & $9^{\prime \prime}$ \\
\hline \multirow[t]{2}{*}{$12 / 03.21-03.23$} & 1.194 & 0.317 & 10.6 & $\operatorname{HCN}(3-2)$ & $0.580 \pm 0.035$ & $-0.06 \pm 0.03$ & $9.5^{\prime \prime}$ \\
\hline & & & 10.6 & $\mathrm{HCN}(3-2)$ & $0.308 \pm 0.034$ & $-0.05 \pm 0.07$ & $21^{\prime \prime}$ \\
\hline \multirow[t]{2}{*}{$12 / 03.28-03.40$} & 1.191 & 0.317 & 104. & $\mathrm{CH}_{3} \mathrm{OH}(2,1-2,0) \mathrm{A}-+$ & $0.170 \pm 0.013$ & $-0.18 \pm 0.04$ & $6^{\prime \prime}$ \\
\hline & & & & $\mathrm{CH}_{3} \mathrm{OH}(4,1-4,0) \mathrm{A}-+$ & $0.196 \pm 0.013$ & $-0.18 \pm 0.04$ & \\
\hline $12 / 03.41-05.40$ & 1.176 & 0.319 & 192 & $\mathrm{HNC}(3-2)$ & $<0.021$ & & $5^{\prime \prime}$ \\
\hline $12 / 04.17-04.21$ & 1.178 & 0.319 & 32.0 & $\mathrm{HCN}(3-2)$ & $0.492 \pm 0.021$ & $-0.11 \pm 0.03$ & $5^{\prime \prime}$ \\
\hline $12 / 04.21-04.22$ & 1.178 & 0.319 & 8.0 & $\mathrm{HCN}(3-2)$ & $0.531 \pm 0.041$ & $+0.07 \pm 0.05$ & $4^{\prime \prime}$ \\
\hline $12 / 04.38-04.39$ & 1.175 & 0.319 & 8.0 & $\mathrm{HCN}(3-2)$ & $0.588 \pm 0.035$ & $-0.08 \pm 0.04$ & $5^{\prime \prime}$ \\
\hline \multirow[t]{6}{*}{$12 / 04.40-05.35$} & 1.165 & 0.322 & 133. & $\mathrm{CH}_{3} \mathrm{OH}(5,0-4,0) \mathrm{A}+$ & $0.079 \pm 0.012$ & $-0.21 \pm 0.10$ & $5^{\prime \prime}$ \\
\hline & & & & $\mathrm{CH}_{3} \mathrm{OH}(5,-1-4,-1) \mathrm{E}$ & $0.074 \pm 0.012$ & $-0.16 \pm 0.10$ & \\
\hline & & & & $\mathrm{CH}_{3} \mathrm{OH}(5,0-4,0) \mathrm{E}$ & $0.043 \pm 0.013$ & & \\
\hline & & & & $\mathrm{CH}_{3} \mathrm{OH}(5,1-4,1) \mathrm{E}$ & $0.044 \pm 0.014$ & & \\
\hline & & & & $\mathrm{CH}_{3} \mathrm{OH}(5,2-4,2) \mathrm{A}+$ & $0.049 \pm 0.012$ & & \\
\hline & & & & $\mathrm{CH}_{3} \mathrm{OH}(5,2-4,2) \mathrm{E}$ & $0.084 \pm 0.014$ & & \\
\hline $12 / 04.40-05.35$ & 1.165 & 0.322 & 133. & $\mathrm{CS}(5-4)$ & $0.083 \pm 0.011$ & $-0.02 \pm 0.08$ & $5^{\prime \prime}$ \\
\hline \multirow[t]{2}{*}{$12 / 05.16-05.21$} & 1.162 & 0.322 & 21.3 & $\mathrm{HCN}(3-2)$ & $0.620 \pm 0.028$ & $-0.06 \pm 0.03$ & $3.5^{\prime \prime}$ \\
\hline & & & 21.3 & $\mathrm{HCN}(3-2)$ & $0.382 \pm 0.028$ & $-0.08 \pm 0.05$ & $14.5^{\prime \prime}$ \\
\hline $12 / 05.35-05.37$ & 1.158 & 0.323 & 16.0 & $\mathrm{HCN}(3-2)$ & $0.487 \pm 0.033$ & $-0.07 \pm 0.04$ & $5^{\prime \prime}$ \\
\hline $12 / 06.18-06.35$ & 1.145 & 0.327 & 24.0 & $\mathrm{HCN}(3-2)$ & $0.582 \pm 0.024$ & $-0.04 \pm 0.03$ & $4.5^{\prime \prime}$ \\
\hline $12 / 06.23-06.34$ & 1.144 & 0.328 & 104. & $\mathrm{H}_{2} \mathrm{CO}\left(3_{12}-2_{11}\right)$ & $0.061 \pm 0.010$ & $+0.04 \pm 0.10$ & $4.5^{\prime \prime}$ \\
\hline $12 / 06.36-08.29$ & 1.125 & 0.336 & 152. & $\operatorname{CS}(7-6)$ & $0.149 \pm 0.022$ & $-0.26 \pm 0.10$ & $4^{\prime \prime}$ \\
\hline $12 / 06.36-08.29$ & 1.125 & 0.336 & 216. & $\mathrm{CO}(3-2)$ & $0.104 \pm 0.020$ & $-0.20 \pm 0.12$ & $4^{\prime \prime}$ \\
\hline \multirow[t]{2}{*}{$12 / 07.17-07.20$} & 1.129 & 0.334 & 13.3 & $\mathrm{HCN}(3-2)$ & $0.526 \pm 0.033$ & $+0.02 \pm 0.04$ & $4^{\prime \prime}$ \\
\hline & & & 10.7 & $\mathrm{HCN}(3-2)$ & $0.462 \pm 0.036$ & $+0.05 \pm 0.05$ & $14.5^{\prime \prime}$ \\
\hline \multirow[t]{2}{*}{$12 / 07.35-08.37$} & 1.116 & 0.340 & 80.0 & $\mathrm{CH}_{3} \mathrm{OH}(2,1-2,0) \mathrm{A}-+$ & $0.173 \pm 0.014$ & $-0.39 \pm 0.06$ & $4.8^{\prime \prime}$ \\
\hline & & & & $\mathrm{CH}_{3} \mathrm{OH}(4,1-4,0) \mathrm{A}-+$ & $0.224 \pm 0.013$ & $-0.19 \pm 0.04$ & \\
\hline $12 / 08.17-08.21$ & 1.113 & 0.341 & 34.7 & $\mathrm{HCN}(4-3)$ & $0.861 \pm 0.038$ & $-0.02 \pm 0.03$ & $4.8^{\prime \prime}$ \\
\hline $12 / 08.17-08.21$ & 1.113 & 0.341 & 34.7 & $\mathrm{H}_{2} \mathrm{CO}\left(5_{15}-4_{14}\right)$ & $0.140 \pm 0.039$ & $+0.17 \pm 0.17$ & $4.8^{\prime \prime}$ \\
\hline
\end{tabular}


N. Biver et al.: Comets C/1999 T1, C/2001 A2, C/2000 $\mathrm{WM}_{1}$ and 153P, Online Material p 6

Table 5. Molecular observations in comet 153P/Ikeya-Zhang.

\begin{tabular}{|c|c|c|c|c|c|c|c|}
\hline $\begin{array}{c}\text { UT date (2002) } \\
\text { [mm/dd.dd-dd.dd] }\end{array}$ & $\begin{array}{l}\left\langle r_{\mathrm{h}}\right\rangle \\
{[\mathrm{AU}]}\end{array}$ & $\begin{array}{c}\langle\Delta\rangle \\
{[\mathrm{AU}]}\end{array}$ & $\begin{array}{l}\text { Integration } \\
\text { time [min] }\end{array}$ & Species (transition) & $\begin{array}{c}\int T_{b} \mathrm{~d} v \\
{\left[\mathrm{~K} \mathrm{~km} \mathrm{~s}^{-1}\right]}\end{array}$ & $\begin{array}{c}\text { Velocity offset } \\
{\left[\mathrm{km} \mathrm{s}^{-1}\right]} \\
\end{array}$ & Offset \\
\hline IRAM $30 \mathrm{m:}$ & \multicolumn{7}{|c|}{ March 2002: } \\
\hline $03 / 19.74-19.78$ & 0.507 & 0.802 & 35 & $\mathrm{HCN}(3-2)$ & $4.193 \pm 0.167$ & $-0.04 \pm 0.09$ & $6.5^{\prime \prime}$ \\
\hline 03/19.74-19.78 & 0.507 & 0.802 & 35 & $\mathrm{HNC}(3-2)$ & $0.398 \pm 0.161$ & $-0.19 \pm 0.47$ & $8.8^{\prime \prime}$ \\
\hline 03/19.74-19.78 & 0.507 & 0.802 & 35 & $\mathrm{CS}(3-2)$ & $0.306 \pm 0.033$ & $+0.18 \pm 0.13$ & $6^{\prime \prime}$ \\
\hline \multirow[t]{3}{*}{ 03/19.74-20.61 } & 0.507 & 0.795 & 90 & $\mathrm{CH}_{3} \mathrm{OH}(3,0-3,-1) \mathrm{E}$ & $0.086 \pm 0.024$ & $-0.02 \pm 0.29$ & $10^{\prime \prime}$ \\
\hline & & & & $\mathrm{CH}_{3} \mathrm{OH}(5,0-5,-1) \mathrm{E}$ & $0.122 \pm 0.025$ & $-0.26 \pm 0.22$ & \\
\hline & & & & $\mathrm{CH}_{3} \mathrm{OH}(7,0-7,-1) \mathrm{E}$ & $0.104 \pm 0.025$ & $-0.54 \pm 0.29$ & \\
\hline \multirow[t]{4}{*}{ 03/20.46-20.57 } & 0.508 & 0.789 & 55 & $\mathrm{CS}(3-2)$ & $0.342 \pm 0.019$ & $+0.06 \pm 0.07$ & $3.1^{\prime \prime}$ \\
\hline & & & 10 & $\mathrm{CS}(3-2)$ & $0.308 \pm 0.044$ & $+0.20 \pm 0.17$ & $7.0^{\prime \prime}$ \\
\hline & & & 25 & $\mathrm{CS}(3-2)$ & $0.266 \pm 0.032$ & $+0.48 \pm 0.15$ & $10.2^{\prime \prime}$ \\
\hline & & & 10 & $\mathrm{CS}(3-2)$ & $0.169 \pm 0.045$ & $+0.42 \pm 0.33$ & $13.2^{\prime \prime}$ \\
\hline \multirow[t]{4}{*}{$03 / 20.46-20.57$} & 0.508 & 0.789 & 55 & $\mathrm{CH}_{3} \mathrm{CN}(8,0-7,0)$ & $0.063 \pm 0.018$ & & $3.3^{\prime \prime}$ \\
\hline & & & & $\mathrm{CH}_{3} \mathrm{CN}(8,1-7,1)$ & $0.037 \pm 0.018$ & & \\
\hline & & & & $\mathrm{CH}_{3} \mathrm{CN}(8,2-7,2)$ & $0.069 \pm 0.018$ & & \\
\hline & & & & $\mathrm{CH}_{3} \mathrm{CN}(8,3-7,3)$ & $0.045 \pm 0.022$ & & \\
\hline \multirow[t]{7}{*}{$03 / 20.46-20.57$} & 0.508 & 0.789 & 55 & $\mathrm{CH}_{3} \mathrm{OH}(1,0-1,-1) \mathrm{E}$ & $0.053 \pm 0.030$ & & $3^{\prime \prime}$ \\
\hline & & & & $\mathrm{CH}_{3} \mathrm{OH}(2,0-2,-1) \mathrm{E}$ & $0.100 \pm 0.030$ & & \\
\hline & & & & $\mathrm{CH}_{3} \mathrm{OH}(3,0-3,-1) \mathrm{E}$ & $0.108 \pm 0.033$ & $+0.11 \pm 0.30$ & \\
\hline & & & & $\mathrm{CH}_{3} \mathrm{OH}(4,0-4,-1) \mathrm{E}$ & $0.188 \pm 0.032$ & $+0.40 \pm 0.20$ & \\
\hline & & & & $\mathrm{CH}_{3} \mathrm{OH}(5,0-5,-1) \mathrm{E}$ & $0.104 \pm 0.031$ & $+0.02 \pm 0.23$ & \\
\hline & & & & $\mathrm{CH}_{3} \mathrm{OH}(6,0-6,-1) \mathrm{E}$ & $0.121 \pm 0.032$ & $+0.27 \pm 0.21$ & \\
\hline & & & & $\mathrm{CH}_{3} \mathrm{OH}(7,0-7,-1) \mathrm{E}$ & $0.159 \pm 0.028$ & $-0.09 \pm 0.16$ & \\
\hline \multirow[t]{5}{*}{$03 / 20.46-20.61$} & 0.508 & 0.788 & 55 & $\mathrm{HCN}(3-2)$ & $6.801 \pm 0.060$ & $+0.05 \pm 0.02$ & $2.6^{\prime \prime}$ \\
\hline & & & 10 & $\operatorname{HCN}(3-2)$ & $4.209 \pm 0.139$ & $+0.01 \pm 0.08$ & $7.7^{\prime \prime}$ \\
\hline & & & 15 & $\mathrm{HCN}(3-2)$ & $2.822 \pm 0.127$ & $+0.15 \pm 0.11$ & $9.7^{\prime \prime}$ \\
\hline & & & 10 & $\mathrm{HCN}(3-2)$ & $2.240 \pm 0.135$ & $+0.10 \pm 0.15$ & $10.9^{\prime \prime}$ \\
\hline & & & 10 & $\mathrm{HCN}(3-2)$ & $1.734 \pm 0.128$ & $+0.54 \pm 0.18$ & $12.5^{\prime \prime}$ \\
\hline \multirow[t]{4}{*}{$03 / 20.46-20.61$} & 0.508 & 0.788 & 55 & $\mathrm{HNC}(3-2)$ & $1.666 \pm 0.075$ & $+0.15 \pm 0.05$ & $4.6^{\prime \prime}$ \\
\hline & & & 10 & $\mathrm{HNC}(3-2)$ & $1.266 \pm 0.158$ & $+0.15 \pm 0.14$ & $5.7^{\prime \prime}$ \\
\hline & & & 25 & $\mathrm{HNC}(3-2)$ & $0.672 \pm 0.107$ & $-0.13 \pm 0.18$ & $11.0^{\prime \prime}$ \\
\hline & & & 10 & $\operatorname{HNC}(3-2)$ & $<0.507$ & & $14.5^{\prime \prime}$ \\
\hline 03/20.64-20.68 & 0.509 & 0.786 & 40 & $\mathrm{HCN}(1-0)$ & $0.306 \pm 0.019$ & $-0.02 \pm 0.07$ & $2.5^{\prime \prime}$ \\
\hline 03/20.64-20.68 & 0.509 & 0.786 & 40 & $\mathrm{HNC}(1-0)$ & $0.063 \pm 0.026$ & & $4^{\prime \prime}$ \\
\hline 03/20.64-20.68 & 0.509 & 0.786 & 80 & $\mathrm{CO}(2-1)$ & $0.129 \pm 0.030$ & $+0.33 \pm 0.24$ & $3^{\prime \prime}$ \\
\hline IRAM 30 m: & \multicolumn{7}{|c|}{ April 2002: } \\
\hline $04 / 29.24-29.37$ & 1.039 & 0.405 & 100 & $\mathrm{HCN}(3-2)$ & $5.225 \pm 0.046$ & $-0.06 \pm 0.02$ & $2.5^{\prime \prime}$ \\
\hline $04 / 29.24-29.37$ & 1.039 & 0.405 & 100 & $\mathrm{HNC}(3-2)$ & $0.271 \pm 0.048$ & $+0.20 \pm 0.14$ & $2.5^{\prime \prime}$ \\
\hline \multirow[t]{4}{*}{$04 / 29.24-29.37$} & 1.039 & 0.405 & 100 & $\mathrm{CH}_{3} \mathrm{CN}(8,0-7,0)$ & $0.051 \pm 0.012$ & & $2.5^{\prime \prime}$ \\
\hline & & & & $\mathrm{CH}_{3} \mathrm{CN}(8,1-7,1)$ & $0.039 \pm 0.012$ & & \\
\hline & & & & $\mathrm{CH}_{3} \mathrm{CN}(8,2-7,2)$ & $0.037 \pm 0.012$ & & \\
\hline & & & & $\mathrm{CH}_{3} \mathrm{CN}(8,3-7,3)$ & $0.035 \pm 0.011$ & & \\
\hline \multirow[t]{7}{*}{$04 / 29.24-29.37$} & 1.039 & 0.405 & 100 & $\mathrm{CH}_{3} \mathrm{OH}(1,0-1,-1) \mathrm{E}$ & $0.183 \pm 0.017$ & $-0.06 \pm 0.07$ & $2.5^{\prime \prime}$ \\
\hline & & & & $\mathrm{CH}_{3} \mathrm{OH}(2,0-2,-1) \mathrm{E}$ & $0.276 \pm 0.017$ & $-0.06 \pm 0.05$ & \\
\hline & & & & $\mathrm{CH}_{3} \mathrm{OH}(3,0-3,-1) \mathrm{E}$ & $0.308 \pm 0.017$ & $-0.11 \pm 0.04$ & \\
\hline & & & & $\mathrm{CH}_{3} \mathrm{OH}(4,0-4,-1) \mathrm{E}$ & $0.410 \pm 0.018$ & $-0.13 \pm 0.03$ & \\
\hline & & & & $\mathrm{CH}_{3} \mathrm{OH}(5,0-5,-1) \mathrm{E}$ & $0.364 \pm 0.017$ & $-0.08 \pm 0.04$ & \\
\hline & & & & $\mathrm{CH}_{3} \mathrm{OH}(6,0-6,-1) \mathrm{E}$ & $0.279 \pm 0.018$ & $-0.02 \pm 0.05$ & \\
\hline & & & & $\mathrm{CH}_{3} \mathrm{OH}(7,0-7,-1) \mathrm{E}$ & $0.300 \pm 0.018$ & $-0.04 \pm 0.05$ & \\
\hline $04 / 29.24-29.37$ & 1.039 & 0.405 & 100 & $\mathrm{CS}(3-2)$ & $0.178 \pm 0.013$ & $+0.01 \pm 0.05$ & $2.5^{\prime \prime}$ \\
\hline $04 / 30.18-30.19$ & 1.054 & 0.405 & 13 & $\mathrm{HCN}(3-2)$ & $5.779 \pm 0.111$ & $+0.00 \pm 0.04$ & $2^{\prime \prime}$ \\
\hline $04 / 30.18-30.35$ & 1.056 & 0.405 & 128 & $\mathrm{H}_{2} \mathrm{CO}\left(3_{12}-2_{11}\right)$ & $0.361 \pm 0.019$ & $+0.06 \pm 0.04$ & $2.5^{\prime \prime}$ \\
\hline $04 / 30.18-30.35$ & 1.056 & 0.405 & 128 & $\mathrm{H}_{2} \mathrm{~S}\left(1_{10}-1_{01}\right)$ & $1.106 \pm 0.017$ & $+0.01 \pm 0.01$ & $2.5^{\prime \prime}$ \\
\hline $04 / 30.18-30.35$ & 1.056 & 0.405 & 138 & $\mathrm{HCN}(1-0)$ & $0.372 \pm 0.013$ & $-0.01 \pm 0.03$ & $2.5^{\prime \prime}$ \\
\hline $04 / 30.18-30.35$ & 1.056 & 0.405 & 128 & $\mathrm{CH}_{3} \mathrm{OH}(4,1-3,2) \mathrm{E}$ & $0.071 \pm 0.021$ & & $2.5^{\prime \prime}$ \\
\hline $04 / 30.20-30.35$ & 1.056 & 0.405 & 115 & $\mathrm{HNC}(3-2)$ & $0.323 \pm 0.031$ & $+0.14 \pm 0.07$ & $2.5^{\prime \prime}$ \\
\hline
\end{tabular}


Table 5. continued.

\begin{tabular}{|c|c|c|c|c|c|c|c|}
\hline $\begin{array}{c}\text { UT date (2002) } \\
\text { [mm/dd.dd-dd.dd] }\end{array}$ & $\begin{array}{l}\left\langle r_{\mathrm{h}}\right\rangle \\
{[\mathrm{AU}]}\end{array}$ & $\begin{array}{l}\langle\Delta\rangle \\
{[\mathrm{AU}]}\end{array}$ & $\begin{array}{l}\text { Integration } \\
\text { time [min] }\end{array}$ & Species (transition) & $\begin{array}{c}\int T_{b} \mathrm{~d} v \\
{\left[\mathrm{~K} \mathrm{~km} \mathrm{~s}^{-1}\right]}\end{array}$ & $\begin{array}{l}\text { Velocity offset } \\
{\left[\mathrm{km} \mathrm{s}^{-1}\right]}\end{array}$ & Offset \\
\hline IRAM $30 \mathrm{~m}:$ & \multicolumn{7}{|c|}{ continued - May 2002: } \\
\hline $05 / 08.33-08.37$ & 1.192 & 0.425 & 20 & $\mathrm{HCN}(3-2)$ & $2.324 \pm 0.222$ & $+0.08 \pm 0.18$ & $8^{\prime \prime}$ \\
\hline \multirow[t]{7}{*}{$05 / 08.33-11.37$} & 1.217 & 0.434 & 66 & $\mathrm{CH}_{3} \mathrm{OH}(1,0-1,-1) \mathrm{E}$ & $0.140 \pm 0.035$ & $-0.08 \pm 0.12$ & $6^{\prime \prime}$ \\
\hline & & & & $\mathrm{CH}_{3} \mathrm{OH}(2,0-2,-1) \mathrm{E}$ & $0.151 \pm 0.035$ & $-0.06 \pm 0.14$ & \\
\hline & & & & $\mathrm{CH}_{3} \mathrm{OH}(3,0-3,-1) \mathrm{E}$ & $0.236 \pm 0.035$ & $-0.36 \pm 0.10$ & \\
\hline & & & & $\mathrm{CH}_{3} \mathrm{OH}(4,0-4,-1) \mathrm{E}$ & $0.202 \pm 0.035$ & $-0.25 \pm 0.13$ & \\
\hline & & & & $\mathrm{CH}_{3} \mathrm{OH}(5,0-5,-1) \mathrm{E}$ & $0.171 \pm 0.035$ & $-0.25 \pm 0.15$ & \\
\hline & & & & $\mathrm{CH}_{3} \mathrm{OH}(6,0-6,-1) \mathrm{E}$ & $0.143 \pm 0.035$ & $+0.14 \pm 0.14$ & \\
\hline & & & & $\mathrm{CH}_{3} \mathrm{OH}(7,0-7,-1) \mathrm{E}$ & $0.130 \pm 0.035$ & $-0.12 \pm 0.13$ & \\
\hline \multirow[t]{3}{*}{$05 / 11.33-11.37$} & 1.242 & 0.443 & 21 & $\mathrm{HCN}(3-2)$ & $2.014 \pm 0.078$ & $-0.07 \pm 0.03$ & $5.5^{\prime \prime}$ \\
\hline & & & 8 & $\mathrm{HCN}(3-2)$ & $1.791 \pm 0.107$ & $-0.10 \pm 0.05$ & $7.3^{\prime \prime}$ \\
\hline & & & 11 & $\mathrm{HCN}(3-2)$ & $0.833 \pm 0.093$ & $+0.04 \pm 0.08$ & $14.5^{\prime \prime}$ \\
\hline $05 / 11.33-11.37$ & 1.242 & 0.443 & 21 & $\mathrm{HCN}(1-0)$ & $0.178 \pm 0.024$ & $-0.18 \pm 0.11$ & $5.5^{\prime \prime}$ \\
\hline \multirow[t]{2}{*}{$05 / 11.33-11.37$} & 1.242 & 0.443 & 21 & $\mathrm{CS}(5-4)$ & $0.336 \pm 0.044$ & $+0.06 \pm 0.09$ & $5^{\prime \prime}$ \\
\hline & & & 19 & $\mathrm{CS}(5-4)$ & $0.254 \pm 0.049$ & $-0.00 \pm 0.13$ & $11^{\prime \prime}$ \\
\hline \multirow[t]{2}{*}{ 05/11.97-11.98 } & 1.253 & 0.447 & 5 & $\mathrm{HCN}(3-2)$ & $2.910 \pm 0.097$ & $-0.09 \pm 0.03$ & $2^{\prime \prime}$ \\
\hline & & & 3 & $\mathrm{HCN}(3-2)$ & $2.338 \pm 0.128$ & $-0.11 \pm 0.04$ & $5^{\prime \prime}$ \\
\hline $05 / 11.97-12.35$ & 1.257 & 0.449 & 308 & $\mathrm{HCN}(1-0)$ & $0.232 \pm 0.006$ & $-0.18 \pm 0.02$ & $2^{\prime \prime}$ \\
\hline $05 / 11.97-12.35$ & 1.255 & 0.448 & 270 & $\mathrm{CH}_{3} \mathrm{OH}(8,0-7,1) \mathrm{E}$ & $0.138 \pm 0.007$ & $-0.11 \pm 0.04$ & $2^{\prime \prime}$ \\
\hline $05 / 11.97-12.35$ & 1.255 & 0.448 & 273 & $\operatorname{HNCO}(10,0,10-9,0,9)$ & $0.043 \pm 0.007$ & $+0.14 \pm 0.11$ & $2^{\prime \prime}$ \\
\hline $05 / 11.97-12.35$ & 1.255 & 0.448 & 273 & $\mathrm{SO}\left(6_{5}-5_{4}\right)$ & $<0.018$ & & $2^{\prime \prime}$ \\
\hline $05 / 11.97-12.35$ & 1.255 & 0.448 & 308 & OCS $(12-11)$ & $<0.026$ & & $2^{\prime \prime}$ \\
\hline $05 / 11.97-12.35$ & 1.255 & 0.448 & 308 & $\mathrm{HC}_{3} \mathrm{~N}(16-15)$ & $<0.030$ & & $2^{\prime \prime}$ \\
\hline $05 / 11.97-12.35$ & 1.255 & 0.448 & 273 & $\operatorname{HCOOH}(10,0,10-9,0,9)$ & $<0.019$ & & $2^{\prime \prime}$ \\
\hline \multirow[t]{2}{*}{$05 / 11.99-12.18$} & 1.254 & 0.447 & 165 & $\mathrm{NS}(11 / 2-9 / 2) \mathrm{e}$ & $<0.054$ & & $2^{\prime \prime}$ \\
\hline & & & & $\operatorname{NS}(11 / 2-9 / 2) f$ & $<0.067$ & & $2^{\prime \prime}$ \\
\hline 05/11.99-12.18 & 1.254 & 0.447 & 165 & $\mathrm{CH}_{3} \mathrm{OH}(2,0-1,-1) \mathrm{E}$ & $0.099 \pm 0.021$ & $-0.05 \pm 0.21$ & $2^{\prime \prime}$ \\
\hline $05 / 12.19-12.35$ & 1.257 & 0.449 & 170 & $\mathrm{CO}(2-1)$ & $0.114 \pm 0.014$ & $-0.04 \pm 0.09$ & $2^{\prime \prime}$ \\
\hline Kitt Peak $12 \mathrm{~m}$ : & \multicolumn{7}{|c|}{ March 2002: } \\
\hline $03 / 29.94-29.95$ & 0.570 & 0.629 & 12.0 & $\mathrm{HCN}(3-2)$ & $1.560 \pm 0.173$ & & $10^{\prime \prime}$ \\
\hline CSO $10 \mathrm{m:}$ & \multicolumn{7}{|c|}{ April 2002: } \\
\hline \multirow[t]{3}{*}{$04 / 25.44-25.48$} & 0.975 & 0.409 & 18.6 & $\mathrm{HCN}(3-2)$ & $2.541 \pm 0.091$ & $-0.02 \pm 0.04$ & $5^{\prime \prime}$ \\
\hline & & & 5.4 & $\mathrm{HCN}(3-2)$ & $2.582 \pm 0.110$ & $-0.08 \pm 0.04$ & $6.5^{\prime \prime}$ \\
\hline & & & 5.4 & $\mathrm{HCN}(3-2)$ & $1.520 \pm 0.145$ & $+0.03 \pm 0.09$ & $14.8^{\prime \prime}$ \\
\hline \multirow[t]{14}{*}{$04 / 25.50-25.68$} & 0.977 & 0.409 & 114 & $\mathrm{CH}_{3} \mathrm{OH}(3,3-3,2) \mathrm{A}-+$ & $0.083 \pm 0.016$ & $-0.47 \pm 0.17$ & $4^{\prime \prime}$ \\
\hline & & & & $\mathrm{CH}_{3} \mathrm{OH}(3,3-3,2) \mathrm{A}+-$ & $0.087 \pm 0.018$ & $-0.11 \pm 0.14$ & \\
\hline & & & & $\mathrm{CH}_{3} \mathrm{OH}(4,3-4,2) \mathrm{A}-+$ & $0.107 \pm 0.019$ & & \\
\hline & & & & $\mathrm{CH}_{3} \mathrm{OH}(4,3-4,2) \mathrm{A}+-$ & $0.126 \pm 0.018$ & $-0.18 \pm 0.11$ & \\
\hline & & & & $\mathrm{CH}_{3} \mathrm{OH}(5,3-5,2) \mathrm{A}-+$ & $0.139 \pm 0.020$ & $-0.07 \pm 0.11$ & \\
\hline & & & & $\mathrm{CH}_{3} \mathrm{OH}(5,3-5,2) \mathrm{A}+-$ & $0.155 \pm 0.018$ & $-0.07 \pm 0.09$ & \\
\hline & & & & $\mathrm{CH}_{3} \mathrm{OH}(6,3-6,2) \mathrm{A}-+$ & $0.170 \pm 0.019$ & & \\
\hline & & & & $\mathrm{CH}_{3} \mathrm{OH}(6,3-6,2) \mathrm{A}+-$ & $0.155 \pm 0.018$ & $-0.18 \pm 0.07$ & \\
\hline & & & & $\mathrm{CH}_{3} \mathrm{OH}(7,3-7,2) \mathrm{A}-+$ & $0.184 \pm 0.019$ & & \\
\hline & & & & $\mathrm{CH}_{3} \mathrm{OH}(7,3-7,2) \mathrm{A}+-$ & $0.131 \pm 0.018$ & $-0.18 \pm 0.08$ & \\
\hline & & & & $\mathrm{CH}_{3} \mathrm{OH}(8,3-8,2) \mathrm{A}-+$ & $0.097 \pm 0.015$ & & \\
\hline & & & & $\mathrm{CH}_{3} \mathrm{OH}(8,3-8,2) \mathrm{A}+-$ & $0.122 \pm 0.019$ & & \\
\hline & & & & $\mathrm{CH}_{3} \mathrm{OH}(9,3-9,2) \mathrm{A}-+$ & $0.092 \pm 0.019$ & & \\
\hline & & & & $\mathrm{CH}_{3} \mathrm{OH}(9,3-9,2) \mathrm{A}+-$ & $0.072 \pm 0.019$ & & \\
\hline $04 / 26.47-26.49$ & 0.992 & 0.407 & 8.0 & $\mathrm{HCN}(3-2)$ & $2.444 \pm 0.069$ & $-0.01 \pm 0.03$ & $4^{\prime \prime}$ \\
\hline $04 / 26.49-26.54$ & 0.992 & 0.407 & 49.3 & $\mathrm{HNC}(3-2)$ & $0.131 \pm 0.022$ & $-0.10 \pm 0.18$ & $4.5^{\prime \prime}$ \\
\hline $04 / 26.55-26.69$ & 0.994 & 0.407 & 128 & $\operatorname{HDO}\left(1_{10}-1_{01}\right)$ & $<0.855$ & & $4^{\prime \prime}$ \\
\hline \multirow[t]{4}{*}{$04 / 27.40-27.47$} & 1.009 & 0.406 & 12.0 & $\mathrm{HCN}(3-2)$ & $2.490 \pm 0.052$ & $-0.03 \pm 0.02$ & $3.4^{\prime \prime}$ \\
\hline & & & 2.7 & $\mathrm{HCN}(3-2)$ & $2.265 \pm 0.117$ & $-0.04 \pm 0.05$ & $5.5^{\prime \prime}$ \\
\hline & & & 6.7 & $\mathrm{HCN}(3-2)$ & $1.879 \pm 0.072$ & $-0.06 \pm 0.04$ & $9.3^{\prime \prime}$ \\
\hline & & & 10.7 & $\mathrm{HCN}(3-2)$ & $1.411 \pm 0.074$ & $-0.03 \pm 0.05$ & $11.8^{\prime \prime}$ \\
\hline \multirow[t]{3}{*}{$04 / 27.47-27.55$} & 1.010 & 0.406 & 2.7 & $\mathrm{HCN}(3-2)$ & $2.649 \pm 0.084$ & $-0.01 \pm 0.03$ & $3.3^{\prime \prime}$ \\
\hline & & & 5.3 & $\mathrm{HCN}(3-2)$ & $2.190 \pm 0.055$ & $-0.02 \pm 0.02$ & $8.3^{\prime \prime}$ \\
\hline & & & 4.0 & $\mathrm{HCN}(3-2)$ & $1.579 \pm 0.063$ & $-0.03 \pm 0.04$ & $15.3^{\prime \prime}$ \\
\hline $04 / 27.47-27.51$ & 1.009 & 0.406 & 34.7 & $\mathrm{HNC}(3-2)$ & $0.174 \pm 0.037$ & $-0.15 \pm 0.22$ & $3.0^{\prime \prime}$ \\
\hline $04 / 27.55-27.60$ & 1.010 & 0.405 & 42.6 & $\mathrm{HNC}(3-2)$ & $0.119 \pm 0.030$ & $-0.40 \pm 0.28$ & $5.0^{\prime \prime}$ \\
\hline
\end{tabular}


Table 5. continued.

\begin{tabular}{|c|c|c|c|c|c|c|c|}
\hline $\begin{array}{c}\text { UT date (2002) } \\
\text { [mm/dd.dd-dd.dd] }\end{array}$ & $\begin{array}{l}\left\langle r_{\mathrm{h}}\right\rangle \\
{[\mathrm{AU}]}\end{array}$ & $\begin{array}{c}\langle\Delta\rangle \\
{[\mathrm{AU}]}\end{array}$ & $\begin{array}{l}\text { Integration } \\
\text { time [min] }\end{array}$ & Species (transition) & $\begin{array}{c}\int T_{b} \mathrm{~d} v \\
{\left[\mathrm{~K} \mathrm{~km} \mathrm{~s}^{-1}\right]}\end{array}$ & $\begin{array}{c}\text { Velocity offset } \\
{\left[\mathrm{km} \mathrm{s}^{-1}\right]}\end{array}$ & Offset \\
\hline CSO $10 \mathrm{m:}$ & \multicolumn{7}{|c|}{ April 2002 - continued: } \\
\hline $04 / 27.60-27.68$ & 1.011 & 0.405 & 84.3 & $\begin{array}{l}\mathrm{CH}_{3} \mathrm{OH}(3,3-3,2) \mathrm{A}-+ \\
\mathrm{CH}_{3} \mathrm{OH}(3,3-3,2) \mathrm{A}+- \\
\mathrm{CH}_{3} \mathrm{OH}(4,3-4,2) \mathrm{A}-+ \\
\mathrm{CH}_{3} \mathrm{OH}(4,3-4,2) \mathrm{A}+- \\
\mathrm{CH}_{3} \mathrm{OH}(5,3-5,2) \mathrm{A}-+ \\
\mathrm{CH}_{3} \mathrm{OH}(5,3-5,2) \mathrm{A}+- \\
\mathrm{CH}_{3} \mathrm{OH}(6,3-6,2) \mathrm{A}-+ \\
\mathrm{CH}_{3} \mathrm{OH}(6,3-6,2) \mathrm{A}+- \\
\mathrm{CH}_{3} \mathrm{OH}(7,3-7,2) \mathrm{A}-+ \\
\mathrm{CH}_{3} \mathrm{OH}(7,3-7,2) \mathrm{A}+- \\
\mathrm{CH}_{3} \mathrm{OH}(8,3-8,2) \mathrm{A}-+ \\
\mathrm{CH}_{3} \mathrm{OH}(8,3-8,2) \mathrm{A}+- \\
\mathrm{CH}_{3} \mathrm{OH}(9,3-9,2) \mathrm{A}-+ \\
\mathrm{CH}_{3} \mathrm{OH}(9,3-9,2) \mathrm{A}+- \\
\mathrm{CH}_{3} \mathrm{OH}(10,3-10,2) \mathrm{A}+-\end{array}$ & $\begin{array}{l}0.017 \pm 0.017 \\
0.069 \pm 0.017 \\
0.113 \pm 0.021 \\
0.076 \pm 0.017 \\
0.103 \pm 0.016 \\
0.104 \pm 0.021 \\
0.127 \pm 0.021 \\
0.108 \pm 0.021 \\
0.085 \pm 0.017 \\
0.138 \pm 0.024 \\
0.087 \pm 0.017 \\
0.133 \pm 0.024 \\
0.081 \pm 0.021 \\
0.107 \pm 0.021 \\
0.102 \pm 0.025\end{array}$ & $-0.15 \pm 0.10$ & $6^{\prime \prime}$ \\
\hline $04 / 27.60-27.68$ & 1.011 & 0.405 & 84.3 & $\mathrm{SO}\left(5_{6}-4_{5}\right)$ & $<0.036$ & & $6^{\prime \prime}$ \\
\hline $04 / 27.60-27.68$ & 1.011 & 0.405 & 84.3 & $\mathrm{HC}_{3} \mathrm{~N}(28-27)$ & $<0.036$ & & $6^{\prime \prime}$ \\
\hline
\end{tabular}

